Universidade de Brasília - UnB

Instituto de Ciências Biológicas

Departamento de Botânica

PADRÕES DE DISTRIBUIÇÃO DE ASTERACEAE EM ÁREAS PROTEGIDAS NO PLANALTO DE DIAMANTINA, MINAS GERAIS, BRASIL

Daniel Augusto Chaves 
PADRÕES DE DISTRIBUIÇÃO DE ASTERACEAE EM ÁREAS PROTEGIDAS NO PLANALTO DE DIAMANTINA, MINAS GERAIS, BRASIL

Aluno: Daniel Augusto Chaves Orientadora: Carolyn Elinore Barnes Proença

Dissertação apresentada ao Programa de Pós-Graduação em Botânica como parte dos requisitos para a obtenção do título de mestre em Botânica da Universidade de Brasília (UnB). 


\section{PADRÕES DE DISTRIBUIÇÃO DE ASTERACEAE EM ÁREAS PROTEGIDAS NO PLANALTO DE DIAMANTINA, MINAS GERAIS, BRASIL}

\section{DANIEL AUGUSTO CHAVES}

Dissertação apresentada ao Departamento de Botânica da Universidade de Brasília - UnB, como parte das exigências do curso de Pós-graduação em Botânica, para obtenção do título de Mestre.

Banca examinadora:

Prof. Dr ${ }^{\mathrm{a}}$. Carolyn Elinore Barnes Proença

Universidade de Brasília - UnB Departamento de Botânica (Orientadora)

Dr. José Roberto Rodrigues Pinto

Universidade de Brasília - UnB Departamento de Botânica (Membro titular)

Dr. Evandro Luiz Mendonça Machado

Universidade Federal dos Vales do Jequitinhonha e Mucuri- UFVJM (Membro titular)

Dr. Marcelo Brilhante de Medeiros

Embrapa Recursos Genéticos e Biotecnologia (Membro suplente) 
Quem um dia ensinar os homens a voar, Deslocará todos os marcos de limite; Os marcos mesmo voarão pelos ares, e esse alguém batizará de novo a Terra - de a "Leve".

Assim falou Zaratustra... 


\section{AGRADECIMENTOS}

Agradeço primeiramente aos principais atores dessa conquista, meus pais, Helena e Chico, a base de todo meu incentivo e inspiração. Aos quais devo muitas orações feitas nos meus momentos de ausência. Às minhas irmãs Cecília e Natália, à minha vó Maria e meu querido sobrinho Vinícius.

Agradeço às pessoas que tiveram papel fundamental no meu crescimento intelectual durante toda tese, me proporcionando entendimento claro dos passos a seguir. Carol Proença, pela orientação objetiva. Marcelo Brilhante e Suelma Ribeiro pela dedicação e disposição na coorientação, e que confiaram no meu trabalho entoado pelos seus incentivos de coragem.

Aos amigos fraternos da República BotEco, os quais dedico grande parte do meu saudosismo por Brasília. Gustavo Mariano, Caqui (Leonardo Borges), Marinheiro (Jéverson Giroldo), Maxstill (Maxmiller Ferreira), Marco Túlio, Bené (Ebenézer Rodrigues), Raphael Matias, Artur de Paula. E aos agregados que sempre levaram alegrias cineras de importância sem igual, Gustavo Paiva, Helena Lara, Rodrigo Rosa, Pamela Moser, Natalia Perigolo, Aelton Giroldo, Raíssa Ribeiro, Monique Alves, Tamilis Rocha, Keiko Fueta, Laura Orioli, Lívia Moura e vários outros que de coração estão em minhas reticências...

Aos amigos já de outros "carnavais" da República SENZALA, que me receberam de volta para reviver novos tempos de Diamantina. Frango (Matheus Gonsalves), Caixa II (Marcos Felipe), Nelinho e Pistico (Tiago Galves).

Amigos também de outras épocas, que reencontramos na República MST (Mexido Sem Tempero). Feroz do Mato (Vinícius Mendonça), Lulu (Luiza Alves), Jaqueline, Bruninho, Wanessa, e as duas criaturinhas ainda no voo da cegonha Pétala e Heitor.

Agradeço em especial a Pamela Moser, que sempre teve disposição em ler e corrigir o trabalho escrito e que me aconselhou de forma muito objetiva em vários momentos da tese. Ao João Bringel pela ajuda nas identificações. Ao Maxstill e ao Formiga Silvestre (Luiz Felipe), pelas filosofias em cima de nossos trabalhos que de muitas formas enriqueceram nossas discussões, tal 
qual foi o aprendizado com o programa R. Ao Shitão (Washington Oliveira), que também me ajudou com dúvidas no programa $\mathrm{R}$.

Aos amigos e parceiros de campo, que proporcionaram as melhores experiências de trabalho e muita empolgação nas incansáveis campanhas embelezadas pelas mais fascinantes paisagens. Suelma Ribeiro, Marcelo Brilhante, Valdeci Ferreira, Tamilis Rocha, Caixa II, Broca (Juan Galves), Mané Galinha (Paulo Duarte), Guilherme Braga, Fernando Hiago, Marcel Pinheiro, Koé (Marco Aurélio) e Poulet (Paulo Henrique).

À Biotrópicos pelo apoio e financiamento em parte do projeto.

Aos recursos financeiros concedidos e materiais de campo fornecidos pela Embrapa e ICMBio.

À Coordenação de Aperfeiçoamento de Pessoal de Nível Superior (CAPES), pela concessão da bolsa de estudo.

Aos membros da banca que aceitaram o convite.

E por fim ao Deus Criador da Natureza. 
SUMÁRIO

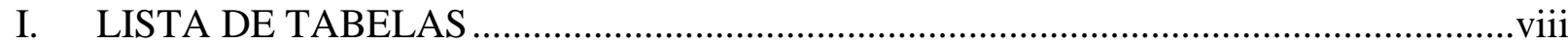

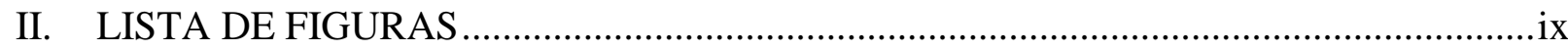

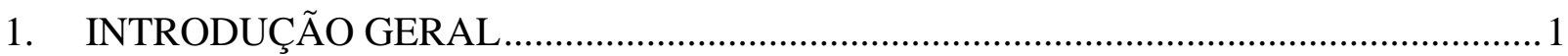

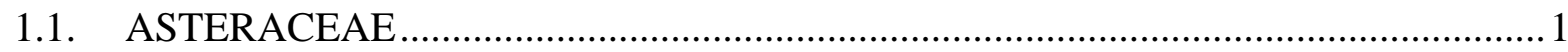

1.2. SERRA DO ESPINHAÇO ................................................................................

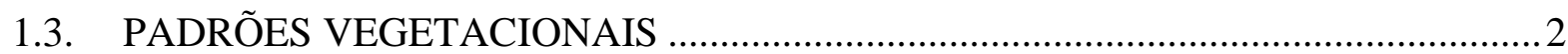

2. ASTERACEAE BERCHT. \& J. PRESL.: COMPOSIÇÃO FLORÍSTICA, ABUNDÂNCIA E FORMAS DE VIDA NO PLANALTO DE DIAMANTINA, BRASIL .................................5

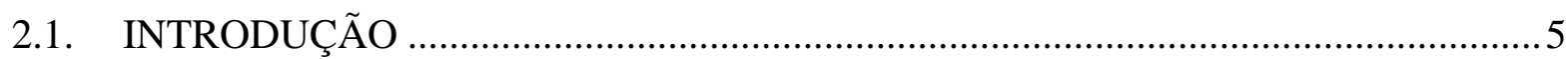

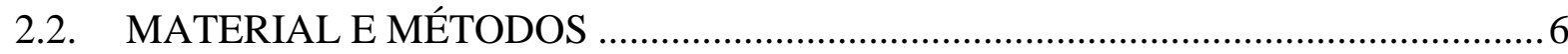

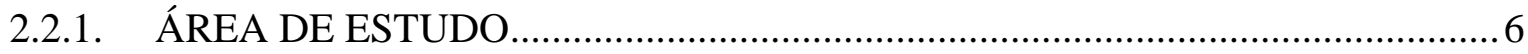

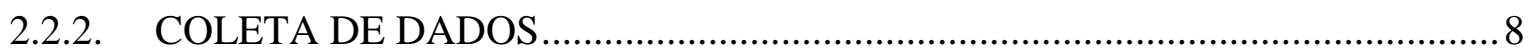

2.2.3. DESCRIÇÃO DAS UNIDADES AMOSTRAIS ..............................................

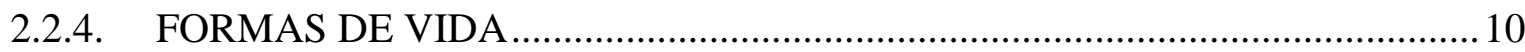

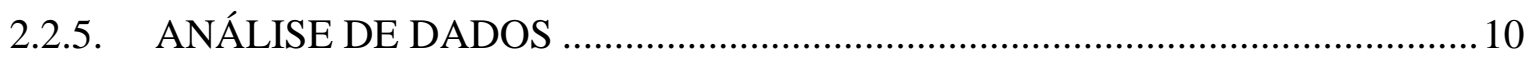

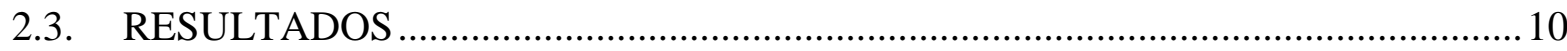

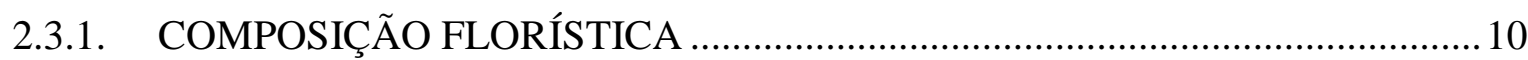

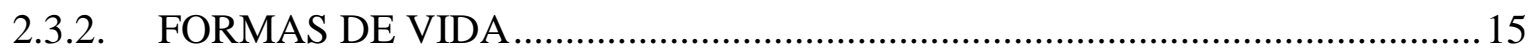

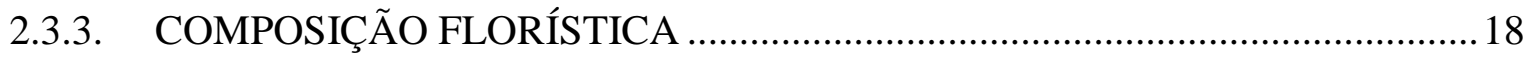

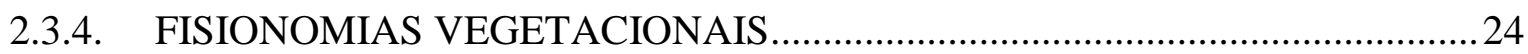

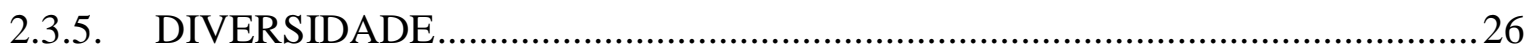

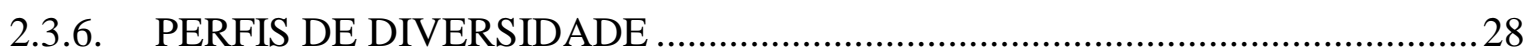

2.3.7. COMPOSIÇÃO DAS FORMAS DE VIDA..................................................... 28

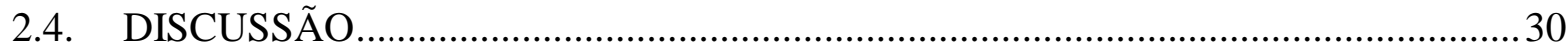

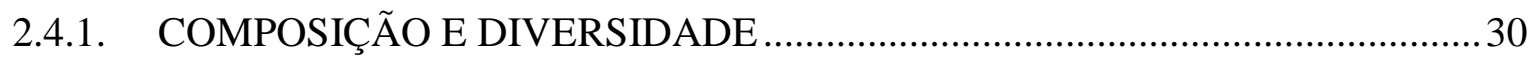


3. DISTRIBUIÇÃO DE ESPÉCIES DE ASTERACEAE AO LONGO DE UM GRADIENTE AMBIENTAL RUPESTRE EM DUAS ÁREAS PROTEGIDAS NO PLANALTO DE

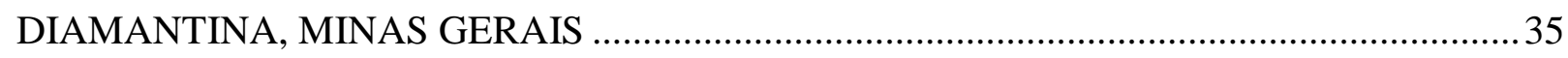

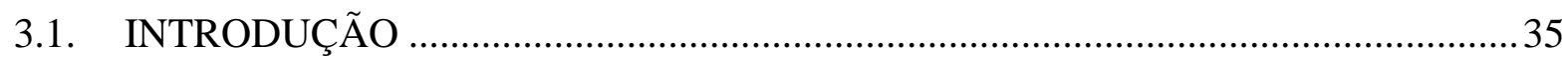

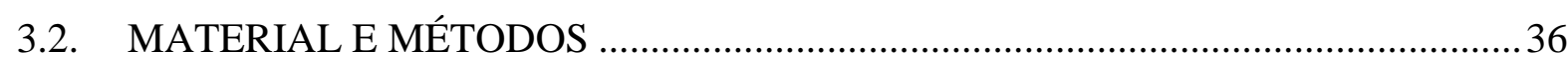

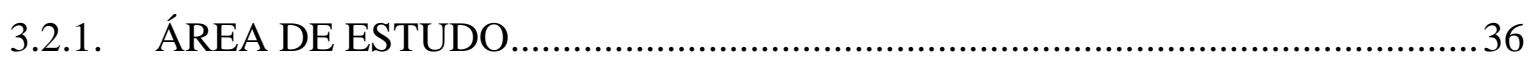

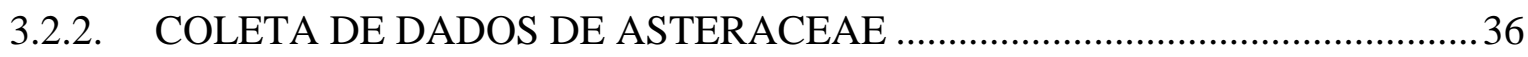

3.2.3. COLETA DE DADOS DOS FATORES AMBIENTAIS ..................................... 36

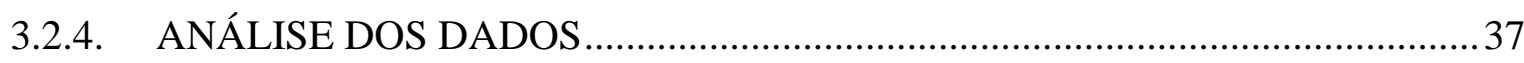

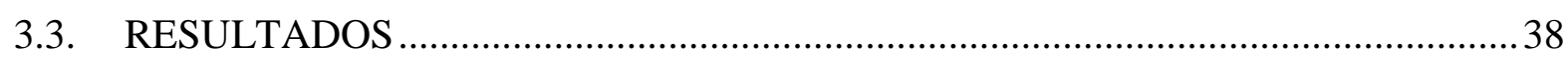

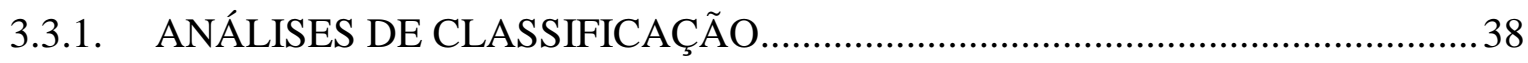

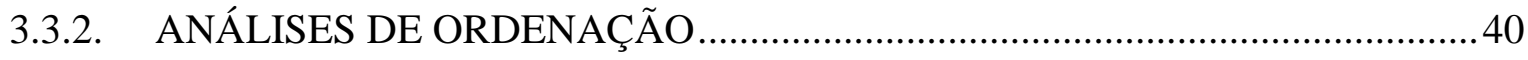

3.4. DISCUSSÃO

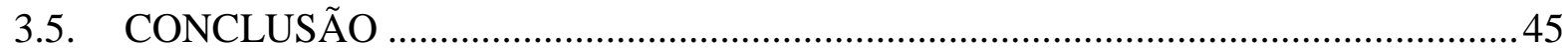

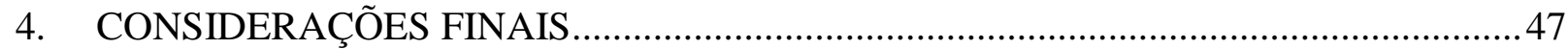

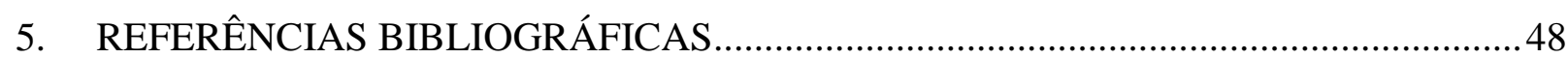




\section{LISTA DE TABELAS}

Tabela 1. Lista de espécies de asteraceae BerCht. \& J. PRESL. coletadas dentro do Parque Estadual do Rio Preto (PERP), Parque nacional das Sempre-Vivas (PNSV) E fora das áreas protegidas no Planalto de Diamantina, Minas Gerais. (+) indica QUe a eSPÉcie fol coletada, (-) INDICA QUE A ESPÉCIE NÃO FOI ENCONTRADA DENTRO DE ÁREAS PROTEGIDAS. "No DE COLETAS" É REFERENTE AO NÚMERO DE VEZES QUE DETERMINADA ESPÉCIE FOI COLETADA. "№ DE EXSICATAS" É O NÚMERO DE EXSICATAS QUE FORAM PRODUZIDAS COM AS COLETAS. (UB) HERBÁRIO DA UNIVERSIDADE DE BRASílIA, NO Distrito Federal; E (HDJF) HERBÁRIo DENDROLÓGICO JEANINE FELFILI, NA UNIVERSIDADE FEDERAL DOS VALES Do JeQuitinhonha E MuCURI EM Diamantina, Minas GERAIS.

TABELA 2. LISTA DE ESPÉCIES DE ASTERACEAE BERCHT. \& J. PRESL. AMOSTRADAS NOS MÓDULOS RAPELD dentro do Parque Estadual do Rio Preto (PERP) e Parque Nacional das Sempre-Vivas (PNSV) no Planalto de Diamantina, MinAs GeRAIS. (+) InDICA AS ESPÉCIES QUE FORAM AMOSTRADAS, (-) INDICA AS eSPÉCIES QUE NÃo FORAM AMOSTRADAS DENTRO DA ÁREA PROTEGIDA. "HÁbito 1" FOI UMA PRIMEIRA SEPARAÇÃO DAS ESPÉCIES QUANTO A FORMA DE VIDA E "HÁbITO 2" É UMA SEGUNDA SEPARAÇãO, MAIS ESPECÍFICA, DAS FORMAS DE VIDA (FIgURA 4). "FAIXA DE AMOSTRA" CORRESPONDE A ÁREA DE AMOSTRAGEM ESTABELECIDA PARA A ESPÉCIE DENTRO DAS UNIDADES AMOSTRAIS

TABELA 3. VALORES MÍNIMOS E MÁXIMOS PARA AS VARIÁVEIS AMBIENTAIS COLETADAS NAS ÁREAS PROTEGIDAS EM ambiente rupestre no Planalto de Diamantina, Parque Estadual do Rio Preto (PERP) e Parque NACIONAL DAS SEMPRE-VIVAS (PNSV).

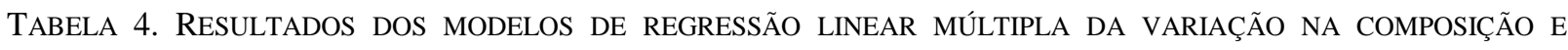
ABUNDÂNCIA DAS ESPÉCIES DE ASTERACEAE SEPARADO EM HÁBITOS HERBÁCEOS, ARBUSTIVOS, ARVORETÓIDES, ARBÓREAS E TODOS OS HÁBITOS JUNTOS EM AMBIENTES RUPESTRES LOCALIZADOS NO PARQUE Estadual do Rio Preto (PERP) e Parque Nacional das SEMPRE-VIVAS (PNSV), SITUADOS No Planalto de Diamantina, Serra do Espinhaço, Minas Gerais. Beta: coeficiente padronizado; SE: erroPADRÃO; B: COEFICIENTE NÃO-PADRONIZADO. SIGNIFICÂNCIA (P $\leq 0,05)$ INDICADA EM NEGRITO. 


\section{LISTA DE FIGURAS}

FIGURA 1: LOCALIZAÇÃO DOS MÓDULOS RAPELD USADOS PARA ESTUDO DE COMUNIDADES VEGETAIS DA FAMÍLIA

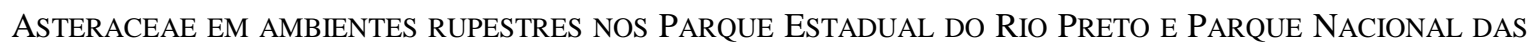
SEMPRE-VIVAS, Ambos localizados no Planalto de Diamantina EM MinAs GERAIS, BRASIL...

FIGURA 2. DESENHO AMOSTRAL DO MÓDULO RAPELD PNSV I LOCALIZADO NO PARQUE NACIONAL DAS SEMPREVIVAS EM AMBIENTES RUPESTRES. NA FIGURA SUPERIOR ESQUERDA A POSIÇÃO DO MÓDULO DENTRO DO PARQUE NACIONAL DAS SEMPRE-VIVAS E A LOCALIZAÇÃO DAS UNIDADES AMOSTRAIS, DESTACADA POR UM CÍRCULO. FIGURA DA DIREITA MOSTRA A UNIDADE AMOSTRAL SV1P1 E COMO AS SUAS 25 SUBUNIDADES DE 40 X 10 M FORAM ALOCADAS. FIGURA INFERIOR ESQUERDA MOSTRA COMO A AMOSTRAGEM PARA AS ÁREAS DE 0,05 HECTARES (FAIXA DE 2 METROS), 0,2 HECTARES (FAIXA DE 4 METROS PARA OS DOIS LADOS DA TRILHA), E 1 HECTARE (TODA EXTENSÃO DA SUBUNIDADE).

Figura 3. Diagrama de VEnN MOSTRA A DistribuiÇÃo do NÚMERO DE ESPÉCIES ENTRE AS DUAS ÁREAS

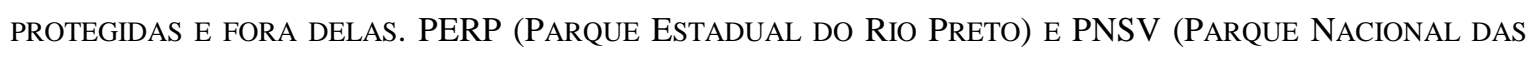
SEMPRE-VIVAS) Situados no Planalto de Diamantina, SERRA do EsPinhaÇO, Minas Gerais. 11

FIGURA 4. DESENHO ESQUEMÁTICO DAS FORMAS DE VIDA OU HÁBITOS QUE FORAM OBSERVADOS ENTRE AS ESPÉCIES coletadas dentro das Áreas Protegidas, PARque Estadual do Rio Preto e Parque Nacional das Sempre-Vivas, em ambientes Rupestres no Planalto de Diamantina, Minas Gerais. Hábito das ESPÉCIES. (4.1) LESSINGIANTHUS CF. SANTOSII (H.ROB.) H.ROB., (4.2) LESSINGIANTHUS PSILOPHYLLUS (DC.) H.Rob., (4.3) Chromolaena barRosoae R.M.King \& H.Rob., (4.4) ChrySOLAENa CF SimpleX (LeSS.) DeMATT., (4.5) ChRYSOLAENA OBOVATA (LESS.) DEMATT., (4.6) BIDENS FLAGELLARIS BAKER, (4.7) BACCHARIS aphylla (Vell.) DC., (4.8) Viguiera bracteata Gardner., (4.9) Proteopsis ARGENTEA Mart. \& ZuCC. EX

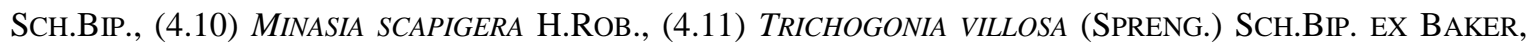
(4.12) LEPIDAPLOA RUFOGRISEA (A. ST.-HIL.) H.Rob.), (4.13) MIKANIA SP., (4.14) LYCHNOPHORA TOMENTOSA (MART. EX DC.) SCH.BIP, E (4.15) EREMANTHUS INCANUS (LESS.) LESS. .17

FIGURA 5. DIAGRAMA DE VENN MOSTRANDO A DISTRIBUIÇÃO DO NÚMERO DE ESPÉCIES ENTRE OS TRÊS MÓDULOS. OS MÓdulos PERP I E PERP II localizados no PARQue ESTADUAL do Rio PRETO E O MÓdulo PNSV I localizado no Parque Nacional das Sempre-ViVAs, ambos no Planalto de Diamantina, SERRA do ESPINHAÇO, MINAS GERAIS. 18

FIGURA 6. REPRESENTAÇÃO dOS DEZ GÊNEROS MAIS ABUNDANTES DENTRO DE CADA MÓDULO. PERP I E PERP II Localizados no Parque Estadual do Rio Preto e PNSV I localizado no PARQue Nacional Das SEMPRE-Vivas, Ambos Situados no Planalto de Diamantina, SERRA do EsPinhaço, Minas Gerais.. 22

FIGURA 7. REPRESENTAÇÃO DAS DEZ ESPÉCIES MAIS ABUNDANTES DENTRO DE CADA MÓDULO. PERP I E PERP II Localizados no Parque Estadual do Rio Preto e PNSV I localizado no Parque Nacional das Sempre-VIVAS, Ambos Situados no Planalto de Diamantina, SERRA Do EsPinhaÇO, Minas Gerais.. 23 
FIGURA 8: COMPARAÇÃO DA RIQUEZA ENTRE OS TRÊS MÓDULOS POR MEIO DA CURVA DE RAREFAÇÃO BASEADO NO NÚMERO DE INDIVÍDUOS. A BARRA VERTICAL REPRESENTA O INTERVALO DE CONFIANÇA 95\%. PERP I E PERP II LOCALIZAdos no PARQUe ESTADUAL DO Rio PRETO E PNSV I LOCALIZADO NO PARQUE NACIONAL DAS Sempre-ViVAs, ambos Situados no Planalto de Diamantina, SerRa do Espinhaço, Minas Gerais.. 26

FIGURA 9. COMPARAÇÃO DA RIQUEZA ENTRE AS UNIDADES AMOSTRAIS DENTRO DE CADA MÓDULO POR MEIO DA CURVA DE RAREFAÇÃO BASEADO NA FREQUÊNCIA DAS ESPÉCIES DENTRO DE CADA SUBUNIDADE DENTRO DE CADA UNIDADE AMOSTRAL. PERP I E PERP II LOCALIZADOS NO PARQUE ESTADUAL DO RIO PRETO E PNSV I Localizado no Parque Nacional das SEMPRE-VIVAS, Ambos Situados no Planalto de Diamantina, SERra do ESPINHAÇO, Minas GERAIS. A LEGENDA PARA AS UNIDADES AMOSTRAIS DEVE SER ENTENDIDA COMO NOS EXEMPLOS A SEGUIR. RP1P2 - RP1: MóDUlo I DO PARQUE ESTADUAL DO RIO PRETO (PERP I); E P2: PARCELA 2. RP2P1 - RP2: MódULO II DO PARQUE ESTADUAL DO RIO PRETO (PERP II); E P1: PARCELA 1. SV1P1 - SV1: MÓDULO I DO PARQUE NACIONAL DAS SEMPRE-VIVAS; P1: PARCELA 1.

FIGURA 10. REPRESENTAÇÃO DOS PERFIS DE DIVERSIDADE PARA CADA MÓDULO. PERP 1 E PERP 2 LOCALIZADOS NO PARQUE ESTADUAL DO Rio PRETO E PNSV 1 LOCALIZAdO NO PARQUE NACIONAL DAS SEMPRE-VIVAS, AMBOS Situados no Planalto de Diamantina, SERra do Espinhaço, Minas Gerais. 28

FIGURA 11. GRÁFICO DE BARRAS REPRESENTANDO A ABUNDÂNCIA DAS FORMAS DE VIDA ENTRE OS MÓDULOS EM ÁREAS PROTEGIDAS. PERP I E PERP II lOCALIZADOS NO PARQUE ESTADUAL DO Rio PRETO E PNSV I localizado no Parque Nacional das SEMPRE-VIVAS, Ambos Situados no Planalto de Diamantina, SERRA DO ESPINHAÇO, MinAS GERAIS 30

FIGURA 12. CLASSIFICAÇÃO DAS UNIDADES AMOSTRAIS BASEADAS NA COMPOSIÇÃO E ABUNDÂNCIA DAS ESPÉCIES EM

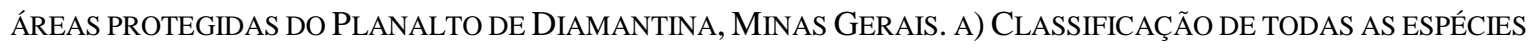
JUNTAS; B) ClaSSIFICAÇÃO DAS ESPÉCIES HERBÁCEAS; C) CLASSIFICAÇÃO DAS ESPÉCIES ARBUSTIVAS; D) ClassifiCAÇÃO DAS ESPÉCIES ARVORETÓIDES; E) CLASSIFICAÇÃO DAS ESPÉCIES ARBÓREAS. RP1P2 - RP1: Módulo I do Parque Estadual do Rio PRETo (PERP I); E P2: PARCEla 2. RP2P1 - RP2: MódULO II DO Parque Estadual do Rio Preto (PERP II); E P1: PARCEla 1. SV1P1 - SV1: Módulo I do Parque NACIONAL DAS SEMPRE-VIVAS; P1: PARCELA 1. 39

FIGURA 13. ORDENAÇÃO DAS UNIDADES AMOSTRAIS BASEADAS NA COMPOSIÇÃO E ABUNDÂNCIA DAS ESPÉCIES EM Áreas protegidas do Planalto de Diamantina, Minas Gerais. ClassificaÇão de: a) todas as ESPÉCIES; B) ESPÉCIES HERBÁCEAS; C) ESPÉCIES ARBUSTIVAS; D) ESPÉCIES ARVORETÓIDES; E) ESPÉCIES ARbÓREAS. (ALT) ALTITUdE; (ALU) ALUMíNIO NO SOlO; (ARG) QUANTIDADE DE ARGILA NO SOLO; (DEC) DECLIVIDADE; (FOS) FÓSFORO; (ROC) ROCHOSIDADE; E (SBA) SOMA DAS BASES. 


\section{ABSTRACT}

In this paper we investigate the mesoscale distribution patters of the Familiy Asteraceae related to environmental factors. The study was conducted in the Parque Estadual do Rio Preto (PERP) and Parque Nacional das Sempre-Vivas (PNSV). In both parks samplings were made in an environment called "Complexo Rupestre de Quartzito". The vegetation sampling followed the Method RAPELD. Three modules were allocated, two in the PERP and one in the PNSV and for each module, seven sampling units were inventoried. The environmental variables related to the distribution patters of Asteraceae were: altitude, aluminum and phosphorous in the soil, clay proportion in the soil, slope, rockiness and sum of exchangeable bases. Before sampling, the floristic survey was carried out in the whole study area of influence and, subsequently the inventory was done for all life forms of Asteraceae species. In the floristic survey 195 species, belonging to 45 genders, in which 134 were collected in the PERP, 77 in the PNSV and 87 were collected outside both parks. For the ones that were collected outside the protected areas, 22 were not found in either one. In the module survey, 12.755 individuals of Asteraceae were inventoried, belonging to 130 species and 42 genders. Among the environmental factors related to species distribution patters, the altitude and the sum of bases had more importance were the elevated concentration for the sum of bases was associated to places with higher altitude. Phosphorous content was also important in the differentiation of the composition associated to places with more quantity of rock outcrops. Knowing the flora distribution patterns is one of the most fundamental tools for the development of management plans in protected areas. In this case, we address the importance of environmental conditionings as necessary to the local biodiversity maintenance of Asteraceae.

Key - words: Compositae, Floristic Patterns, Environmental Patterns and Life Forms. 


\section{RESUMO}

Neste trabalho investigamos os padrões de distribuição em mesoescala da família Asteraceae relacionada com fatores ambientais. O estudo foi realizado no Parque Estadual do Rio Preto (PERP) e Parque Nacional das Sempre-vivas (PNSV). Em ambos os parques as amostragens foram feitas em ambiente denominado "Complexo Rupestre de Quartzito". A amostragem da vegetação seguiu a metodologia do RAPELD (RAP - Protocolo de Amostragem Rápida; PELD - Projeto Ecológico de Longa Duração). Três módulos foram alocados, dois no PERP e um no PNSV, e para cada módulo sete unidades amostrais foram inventariadas. As variáveis ambientais relacionadas com os padrões de distribuição de Asteraceae foram: altitude, alumínio no solo, proporção de argila no solo, declividade, fósforo no solo, rochosidade e soma de bases trocáveis. Antes da amostragem foi realizado o levantamento florístico em toda área de influência do estudo, e posteriormente realizado o inventário para todas as formas de vida das espécies de Asteraceae. No levantamento florístico foram encontradas 195 espécies perten centes a 45 gêneros, onde 134 foram coletadas dentro do PERP, 77 dentro do PNSV e 87 foram coletadas fora dos parques. Das que foram coletadas fora das áreas protegidas, 22 não foram encontradas em nenhuma das duas Unidades de Conservação. No levantamento dos módulos foram inventariados 12.755 indivíduos de Asteraceae pertencentes a 130 espécies e 42 gêneros. Dentre os fatores ambientais relacionados com os padrões de distribuição das espécies, a altitude e a soma das bases tiveram maior importância, onde as elevadas concentrações para a soma das bases estavam associadas aos locais de maior altitude. $\mathrm{O}$ teor de fósforo também foi importante na diferenciação da composição associado aos locais com maior quantidade de afloramentos rochosos. Conhecer os padrões de distribuição da flora é uma das ferramentas fundamentais à elaboração dos planos e manejos para Unidades de Conservação. Neste caso abordamos a importância dos condicionantes ambientais necessários à manutenção da biodiversidade local de Asteraceae.

Palavras-chaves: Compositae, Padrão Florístico, Padrão Ambiental, Formas de Vida. 


\section{INTRODUÇÃO GERAL}

\subsection{ASTERACEAE}

Asteraceae Bercht. \& J. Presl. é uma das famílias mais numerosas dentre as Angiospermas, com cerca de 23.000 espécies distribuídas em 1.600 gêneros (Anderberg et al., 2007). No Brasil é representada por cerca de 1.900 espécies distribuídas em 180 gêneros que colonizam as mais variadas formações vegetacionais (Roque \& Bautista, 2008; Barroso, 1991; Nakajima \& Semir, 2001). A família recebe grande atenção pela representatividade entre as Fanerógamas por representar cerca de $10 \%$ do total da flora de Angiospermas (Roque \& Bautista, 2008; Wilson, 1986).

Os primeiros registros e caminhos evolutivos para a família na América do Sul apontam para os períodos entre o Paleoceno e Eoceno (65 a 35 milhões de anos antes do presente), onde movimentos tectônicos e mudanças climáticas favoreceram o processo evolutivo da família, como também a dispersão geográfica no período do Mioceno (23 a 5 milhões de anos antes do presente) relacionada ao desenvolvimento de regiões semiáridas (Anderberg et al., 2007). O armazenamento de compostos secundários foi outro determinante no processo de dispersão e ocupação, pois além de defesa contra herbivoria também permitiram às plantas desta familía capacidade de ajustar rapidamente o potencial osmótico de suas células, possibilitando avançar mesmo em condições de baixa disponibilidade de água, em clima sazonal (Anderberg et al., 2007; Hendry 1996). Tais mecanismos evolutivos permitiram a família se estabelecer de forma generalizada, principalmente em fisionomias arborizadas e de campo durante o final do Mioceno e desenvolvendo adaptação para as condições mais frias e secas subsequentes, no Plioceno (5 a 1,6 milhões de anos antes do presente) (Anderberg et al., 2007).

As espécies de Asteraceae tem distribuição cosmopolita, exceto em Antartica, e são frequentemente encontradas em ambientes abertos como campos graminosos e campos com baixa densidade de árvores (Anderberg et al., 2007; Funk et al., 2005), com enorme representatividade em regiões montanhosas (Anderberg et al., 2007; Conceição \& Pirani, 2005). As espécies variam muito em termos de formas de vida, frequentemente são subarbustos, arbustos e herbáceas anuais, bianuais ou perenes; árvores e lianas são menos frequentes, e raramente são epífitas ou aquáticas (Anderberg et al., 2007). As herbáceas perenes e os tipos arbustivos são comumente dotados de órgãos subterrâneos de reserva (Anderberg et al., 2007).

O sucesso evolutivo da família é atribuído à produção de compostos secundários derivados dos poliacetilenos e lactonas sesquiterpênicas que atuam como sistema químico de 
defesa (Cronquist, 1988). Tais compostos representam a grande importância econômica da família na medicina tradicional; as espécies também são incluídas entre os produto alimentício, cosméticos ou plantas ornamentais (Roque \& Bautista, 2008).

\subsection{SERRA DO ESPINHAÇO}

A Serra do Espinhaço está localizada a leste do Brasil e representa uma cadeia de montanhas formada por dois blocos principais disjuntos, a Chapada Diamantina no estado da Bahia e a Cadeia do Espinhaço em Minas Gerais (Giulietti \& Pirani, 1988; Harley, 1995). A Serra do Espinhaço se estende numa orientação norte-sul por mais de $1000 \mathrm{~km}$ de comprimento e variações na largura entre 50 e 100 km, com limite na Serra de Jacobina na Bahia ao norte, e ao sul a Serra de Ouro Branco em Minas Gerais (Giulietti \& Pirani, 1988; Giulietti, 1990; Harley, 1995).

A formação da Serra do Espinhaço teve início no período Pré-cambriano, primeiramente submetido a longos processos erosivos e mais recentemente movimentos tectônicos no Terciário que resultaram numa superfície arqueada de dobramentos paralelos e perpendiculares que são responsáveis pela complexidade das características estruturais do relevo (Abreu, 1984; Mauro et. al., 1982). Os solos arenosos e rasos são caracterizados pela extrema erosão proveniente da decomposição de quartzito e arenito sobre a rocha mãe (Eiten, 1978; Semir, 1991). Os solos também são muito pedregosos, ácidos e com baixa capacidade de retenção de água (Giulietti et al., 1987).

A denominação do tipo de vegetação encontrado na Serra do Espinhaço é muito discutida por se tratar de ambiente extremamente heterogêneo que entre vales e montanhas se diferencia em campos, Cerrado sentido amplo, matas e afloramentos em espaço muitas vezes pequeno. $\mathrm{O}$ ambiente é caracterizado por um padrão fitofisionomico acima de 900 metros ao nível do mar com elevado grau de afloramentos rochosos e consequente redução da profundidade do solo, assim como é encontrado no alto das montanhas da Serra do Espinhaço e serras que se encontram disjuntas e isoladas.

\subsection{PADRÕES VEGETACIONAIS}

Os padrões de especiação florística na América ocorreram em função de três importantes eventos, a conexão fitogeográfica entre as Américas Central e do Sul pelo soerguimento de ilhas em local de atividade vulcânica; o soerguimento Andino pelo encontro das placas tectonicas e as flutuações climáticas durante os períodos de glaciação (Gentry, 1982). A flora rica e variada na 
América do Sul também tem fortes ligações com o período Terciário 65 a 1,5 milhões de anos antes do presente) e Cretáceo (145 a 65 milhões de anos do presente) marcado pelo isolamento florístico após a separação com o continente Africano (McKenna, 1981).

Do ponto de vista florístico a América do Sul se tornou uma ilha, e tais características ecológicas foram importantes para que algumas famílias se desenvolvessem e conquistassem território (Gentry, 1982). Mais adiante acidentes orogênicos que geraram conexões entre a região sul da América Central e América do Sul pelo soerguimento de ilhas, que posteriormente se conectou substancialmente através do Istimus do Panamá, também foram importantes no processo de especiação e dispersão da flora na América do Sul (Keigwin, 1978; Marshall et al., 1982).

Os primeiros estudos com padrões florísticos apontaram a existência de correlação entre variações bióticas e abióticas com a diversidade de espécies nos tipos vegetacionais Neotropicais (Ashton 1969; Gentry, 1981; Tuomisto et al. 1995; Fine et al., 2005; Antonelli \& Sanmatín 2011). Embora os autores anteriormente citados estivessem mais concentrados em florestas tropicais, estas observações também foram feitas para as regiões montanhosas no Brasil, como a Serra do Espinhaço e suas disjunções isoladas (Giulietti \& Pirani, 1988; Giulietti et al., 1988; Benites et al., 2003; Rapini et al., 2008).

Os fatores que determinam a distribuição da vegetação no Cerrado são citados por vários autores em diferentes contextos. A fertilidade e a drenagem do solo são apontadas como importantes preditores (Eiten, 1972, Ratter e Dargie, 1992; Oliveira-Filho e Ratter, 2002; Dantas e Batalha, 2011), assim como a sazonalidade da precipitação e o regime de fogo (Oliveira-Filho e Ratter, 2002). Ratter e Dargie (1992) também apontaram a heterogeneidade altitudinal como importante preditor nos padrões de distribuição da flora.

Autores destacam a importância de compreender padrões de variação de comunidades vegetais ao longo de gradientes ambientais para aprimorar a conservação (Margules et al., 2002; Tuomisto et al., 2003). Como reforça Costa et al. (2005), a homogeneidade na distribuição das espécies significa que qualquer parte da vegetação em questão terá o mesmo peso para conservação, porém não é o que se observa quando há presença de barreiras geográficas e habitas com alto nível de especificidade, como é o caso da Serra do Espinhaço.

A riqueza biológica no Serra do Espinhaço é ainda pouco conhecida, sendo de importância inestimável a se pensar nos serviços ecológicos que garantem a biodiversidade local, e também nos possíveis usos sustentáveis a disposição da sociedade humana. Portanto, neste estudo objetivou-se estudar o padrão de distribuição das espécies de Asteraceae, uma das famílias 
mais importantes nos Complexos Rupestres de Quartzito. A partir da descrição desses padrões espera-se responder questões de planejamento e manejo em Unidades de Conservação ligadas principalmente à conservação destas espécies. 


\section{ASTERACEAE BERCHT. \& J. PRESL.: COMPOSIÇÃO FLORÍSTICA, ABUNDÂNCIA E FORMAS DE VIDA NO PLANALTO DE DIAMANTINA, BRASIL}

\subsection{INTRODUÇÃO}

A família Asteraceae (ou Compositae) representa uma das mais ricas famílias botânicas dentre as plantas vasculares no mundo, estima-se entre 1.600 - 2.000 gêneros e 24.000 - 30.000 espécies (Funk et al., 2005, Benoît, 2011). Sua distribuição estende-se a todos os continentes com exceção da Antarctica, sendo observada em quase todos os ambientes, principalmente em formações abertas onde geralmente é encontrada elevada diversidade de espécies (Loeuille \& Pirani, 2011).

Asteraceae é monofilética e pode ser facilmente reconhecida por meio de algumas características marcantes, como as pequenas flores arranjadas em capítulo rodeadas por brácteas, também pelas anteras fundidas em um anel que funciona como um mecanismo secundário de polinização e ainda pela presença de pappus na cipsela na maioria das espécies (Funk et al., 2005; Moreira-Muñoz \& Muñoz-Schick, 2003; Benoît, 2011). As espécies de Asteraceae podem assumir várias formas de vida, tais como herbáceas, epífitas, arbustos e árvores (Funk et al., 2005; Teles \& Stehmann, 2011), podendo a mesma espécie assumir diferentes formas de vida em função das condições físicas do ambiente ou então periodicidade de alguns eventos, como o fogo.

Vários trabalhos em fitofisionomias no domínio do Cerrado apontam Asteraceae como uma das famílias mais importantes para o bioma (Nakajima \& Semir, 2001), representada por 106 gêneros e 557 espécies (Mendonça, 1998). Nas formações rupestres também aparece entre as mais ricas (Giulietti et al, 1987), esse ambiente apresenta também maior número de espécies endêmicas e ameaçadas, com grande atenção para os gêneros Lychnophora, Richterago e Vernonia (Franco et al., 2014). Porém falta informação à família. Franco et al. (2014) associam a lacuna de informações para a família com o elevado número de espécies, incluindo a diversidade morfológica entre elas, e ainda ao número reduzido de taxonomistas para a família. Tais implicações geram impacto negativo no manejo e uso da biodiversidade, tanto pela escassez de levantamentos florísticos como também em estudos sistemáticos (Andrino \& Costa, 2013).

Estudos na Serra da Canastra, ambiente similar à Cadeia do Espinhaço, demonstrou que Asteraceae é a família mais rica, sendo representada por 215 espécies (Nakajima \& Semir, 2001). Também foi a mais representativa em estudos no Pico das Almas com 132 espécies (Harley, 
1995) e na Serra do Cipó com 169 espécies (Giulietti, 1987). Os três citados acima destacam a relevância de estudos com a família, pela sua elevada riqueza de espécies e importância ecológica no Brasil e no Cerrado, com destaque para os "Complexos Rupestres de Quartzito".

Nesse estudo foi descrita a composição florística e a diversidade em espécies de Asteraceae em duas Áreas Protegidas no Planalto de Diamantina. Mais especificamente este capítulo pretende responder às seguintes perguntas: Qual a composição florística e diversidade de Asteraceae em duas áreas protegidas do Planalto de Diamantina; as espécies coletadas e que são consideradas ameaçadas estão contempladas nas duas Unidades de Conservação?

\subsection{MATERIAL E MÉTODOS}

\subsection{1. ÁREA DE ESTUDO}

O estudo foi conduzido no Parque Nacional das Sempre-Vivas (PNSV) e no Parque Estadual do Rio Preto (PERP), ambos localizados no Planalto de Diamantina, setor meridional da Cadeia do Espinhaço em Minas Gerais (Figura 1). De acordo com a classificação de Koppen, o clima na região é mesotérmico $(\mathrm{Cwb})$, com temperatura média anual de $18,7^{\circ} \mathrm{C}$, característico de invernos frios e secos e verões brandos e úmidos e a precipitação média anual é de $1.500 \mathrm{~mm}$ (Silva et al., 2005).

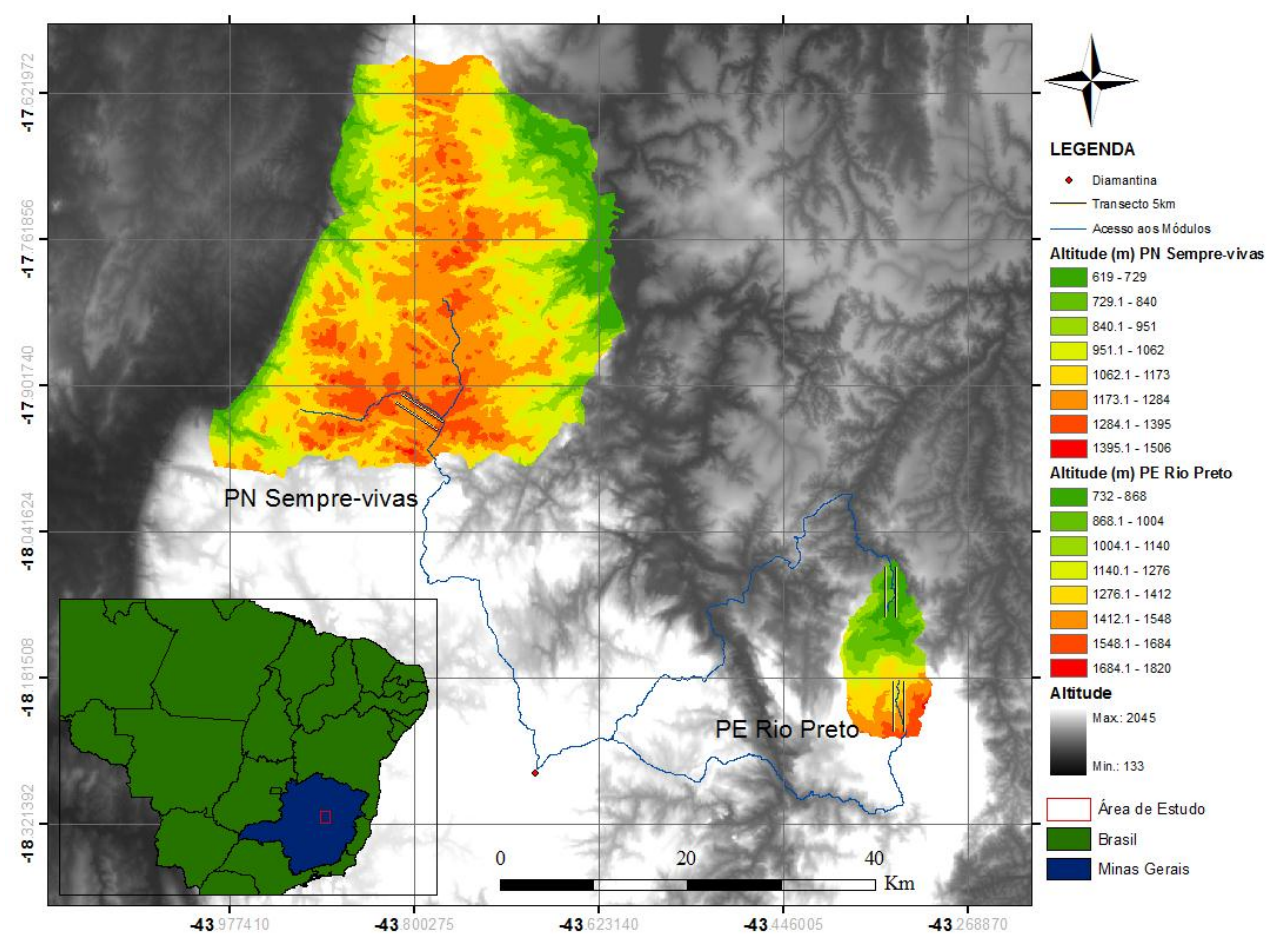

Figura 1: Localização dos Módulos RAPELD usados para estudo de comunidades vegetais da família Asteraceae no Parque Estadual do Rio Preto e Parque Nacional das Sempre-Vivas, localizados no Planalto de Diamantina em Minas Gerais, Brasil. 
O Parque Estadual do Rio Preto (PERP) está localizado no município de São Gonçalo do

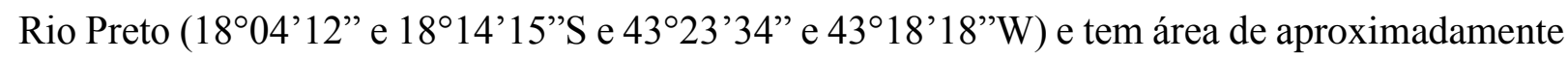
10.700 hectares. Nas partes menos elevadas do PERP, além de Matas Ciliares, é constituída por Cerrado stricto sensu, sendo comum constatar espécies características das formações rupestres de altitude, como pode ser notado nas ocorrências de Lychnophora passerina (Mart. ex DC.) Gardner e Wundelichia mirabilis Riedel ex (Baker). Estas formações de Cerrado stricto sensu podem ser encontradas de forma mais contínua entre 800 e $900 \mathrm{~m}$ de altitude e vão se tornando menos frequentes à medida que a altitude aumenta (entre 900 e 1.200), aparecendo em manchas menores e desconectadas. O solo geralmente é arenoso, profundo e penetrável, no entanto esse tipo de vegetação é encontrado também sobre solos rasos e pedregosos (quartzito). Apesar de muito arenoso, os solos desses ambientes apresentam considerável teor de argila (observações pessoais).

Nas partes mais elevadas do PERP (entre 900 e $1.600 \mathrm{~m}$ de altitude) predominam formações campestres com inserções das formações rupestres de quartzito, afloramentos enormes que desfragmentam rochas menores que criam diversidade de habitas muito específico, onde a diferenciação de habitas em curto espaço é muito brusca. Os solos são extremamente arenosos praticamente ausentes de argilas, havendo melhor estruturação quando estes se constituem de matéria orgânica. Também são comuns solos pedregosos formados quase que só por rochas quartzíticas e lajeados contínuos. Estão presentes formações florestais, como Matas Ciliares e Matas de Galeria e capões de mata, nas partes mais baixas, em meio às formações campestres e rupestres nas partes mais elevadas. As formações florestais comumente estão associadas à umidade local que se mantêm mais constante ao longo do ano em função dos cursos d'água e nascentes. Também são encontradas florestas estacionais nas encostas (entre 900 e 1.000 m de altitude), normalmente associadas a solos mesotróficos com considerável teor de argila vermelha em meio a muitos afloramentos (observações pessoais).

O Parque Nacional das Sempre-Vivas (PNSV) está localizado entre os municípios de

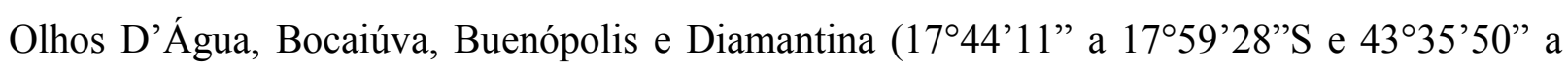
4359’33”W). O Parque foi criado em 2002 e apresenta aproximadamente 124 mil hectares dentro de uma faixa de altitude entre 650 a $1.350 \mathrm{~m}$, com fisionomias tipicamente florestais, savânicas e campestres, extremamente diversificado (Almeida et al. 2007). O ambiente onde se concentrou o estudo é típico dos Complexos Rupestres de Quartzito, formações campestres com várias inserções das formações rupestres de quartzito e afloramentos enormes que desfragmentam rochas menores. Os solos são extremamente arenosos praticamente ausentes de 
argilas, havendo melhor estruturação quando estes se constituem de matéria orgânica. Também são comuns solos pedregosos formados principalmente por rochas quartzíticas. Também estão presentes Matas Ciliares, Matas de Galeria e capões de mata nas partes mais baixas do relevo, em meio às formações campestres e rupestres nas partes mais altas. As formações florestais comumente estão associadas à umidade local que se mantêm mais constante ao longo do ano em função dos cursos d'água e nascentes (observações pessoais).

\subsubsection{COLETA DE DADOS}

Previamente ao inventário foram realizadas coletas botânicas por caminhamento (Filgueiras et al., 1994) nas duas áreas de estudo, para listar a composição de espécies de Asteraceae e facilitar a identificação em campo das espécies que possivelmente seriam amostradas nas unidades amostrais (UA’s). A identificação das espécies foi realizada com a ajuda de bibliografia especializada e por comparação com material de herbário. Os vouchers foram depositados no Herbário da Universidade de Brasília (UB) e da Universidade Federal de Jequitinhonha e Mucuri (UFVJM) de acordo com a metodologia usual (Mori et al., 1985). Todos os nomes científicos foram atualizados de acordo com a Lista de Espécies da Flora do Brasil (http:// floradobrasil.jbrj.gov.br/jabot/listaBrasil).

Para analisar os padrões florísticos foi utilizado o método RAPELD (Magnusson et al., 2005) (Figura 2) para padronizar a coleta dos dados nas duas áreas amostrais. Foram inventariados todos os hábitos das espécies de Asteraceae encontradas dentro das UA's. De acordo com o método proposto por Magnusson et al. (2005), as unidades amostrais seguem a curva de nível do terreno para minimizar a variação no solo.

Foram demarcados três locais no Planalto de Diamantina, cada local representado por um Módulo. Cada Módulo é representado por sete UA's, portanto 21 UA's no total foram amostradas. Quatorze UA's foram amostradas no PERP, nos Módulos identificados como PERP I e PERP II e sete UA’s no PNSV no Módulo identificado como PNSV I (Figura 1).

Mediante a coleta feita anteriormente para a florística da área de estudo e prevendo as dificuldades em constatar a presença das espécies, foi estabelecido qual faixa de amostragem as espécies pertenceriam (Figura 2). 


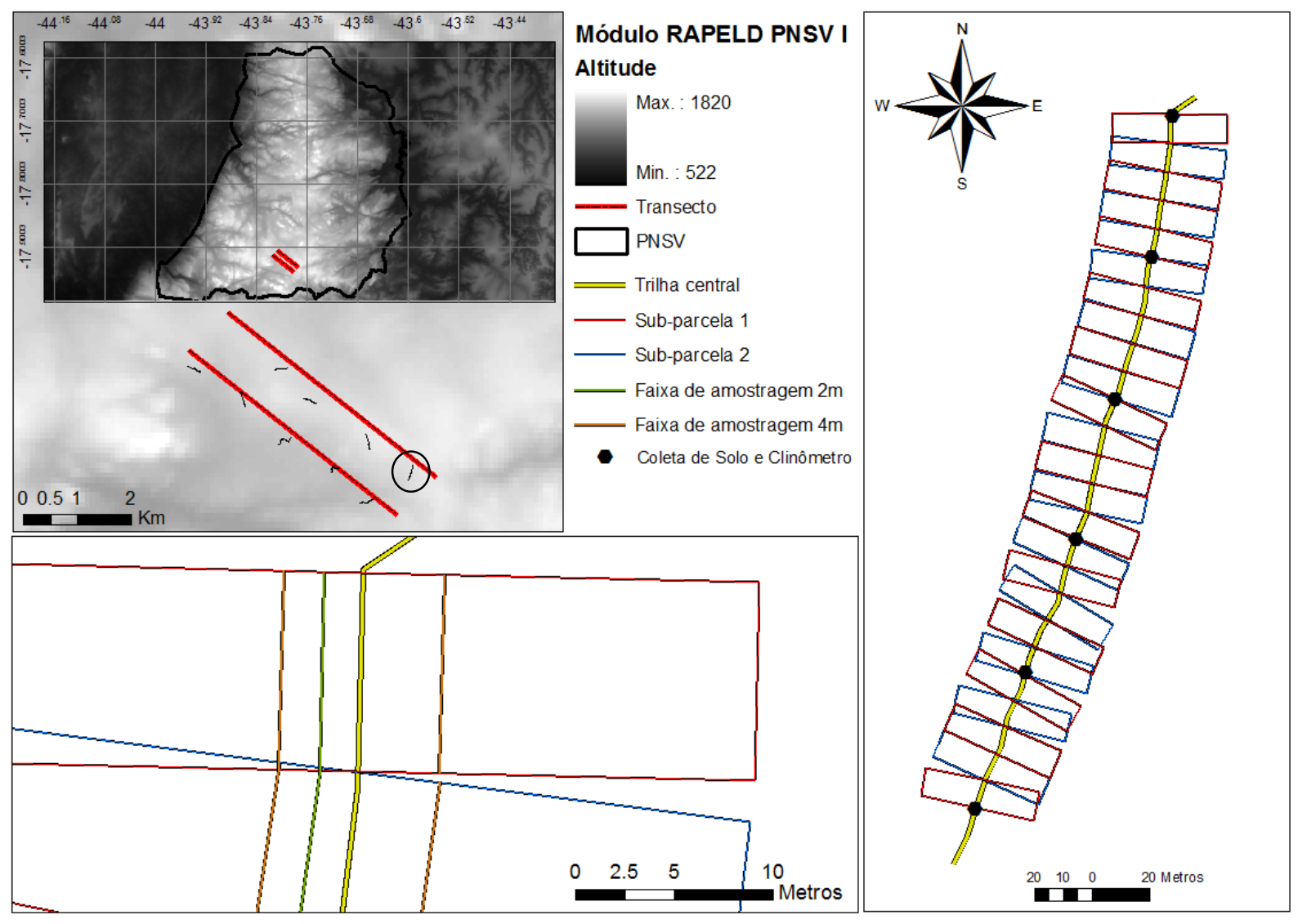

Figura 2. Desenho amostral do módulo RAPELD PNSV I localizado no Parque Nacional das Sempre-Vivas no Planalto de Diamantina. Na figura superior a esquerda mostra s posição do módulo dentro do Parque Nacional das Sempre-Vivas e a localização das unidades amostrais, destacada por um círculo. A figura da direita mostra a unidade amostral SV1P1 e como seus 25 seguimentos de 40 x 10 m foram alocadas. A figura inferior à esquerda mostra a faixa de amostragem para as áreas de 0,05 hectares (faixa de 2 metros), 0,2 hectares (faixa de 4 metros para os dois lados da trilha), e 1 hectare (toda extensão da subunidade).

\subsubsection{DESCRIÇÃO DAS UNIDADES AMOSTRAIS}

Apesar da cota dentro de cada unidade amostral ser a mesma, em muitas das unidades amostrais não se observou homogeneidade absoluta como preconiza o método com unidades amostrais estreitas (Costa et al., 2005). Ao contrário, houve variações visíveis no ambiente físico (solo e rocha) o qual foi caracterizado para cada unidade amostral.

A caracterização do ambiente foi baseada no trabalho de Zappi et al. (2014) para as plantas do setor noroeste da Serra do Cipó em Minas Gerais, onde os ambientes de ocorrência das espécies foram descritos detalhadamente. 


\subsubsection{FORMAS DE VIDA}

As espécies foram separadas de acordo com os hábitos em oito classes. As características usadas como base foram o tipo ou formato das raízes conforme observações em campo (Figura 3) e literatura (Appezzato-da-glória et al., 2008; Santos et al., 2013; Vilhalva \& Appezzato-daglória, 2006); o comportamento da estrutura aérea frente à sazonalidade climática e ao fogo (Appezzato-da-glória et al., 2008; Vilhalva \& Appezzato-da-glória, 2006); e também a persistência da planta quanto a ser anual ou perene.

\subsubsection{ANÁLISE DE DADOS}

A composição e abundância foram analisadas para a família por meio da distribuição de indivíduos, espécies e gêneros que ocorreram nos três locais de estudo (PERP I, PERP II e PNSV I).

Para comparar a diversidade entre os módulos, foram calculadas a riqueza de espécies e a diversidade de Shannon com rarefações baseadas no número de indivíduos e intervalos de confiança de 95\% (Gotelli e Colwell, 2001). Para comparar a diversidade entre os módulos foi calculado o perfil de diversidade pela série de Rényi, como recomendado por Peet (1974). O perfil de diversidade considera tanto as espécies raras como as comuns (Tóthmérész, 1995) evitando a falta de critérios na escolha do índice de diversidade que ocorre nos índices tradicionais (Melo, 2008).

Para todas as análises foi utilizado o programa RStudio (The R Foundation for Statistical Computing, 2014).

\subsection{RESULTADOS}

\subsubsection{COMPOSIÇÃO FLORÍSTICA}

Foram realizadas 609 coletas pertencentes a 195 espécies, 45 gêneros, um número total de 986 vouchers depositados nos Herbários UB (Brasília - DF) e HDJF (Diamantina - MG) (Tabela 1). O PERP teve o maior número de espécies exclusivas (71), no PNSV foram 22 e fora das áreas protegidas foram 28 (Figura 3). 


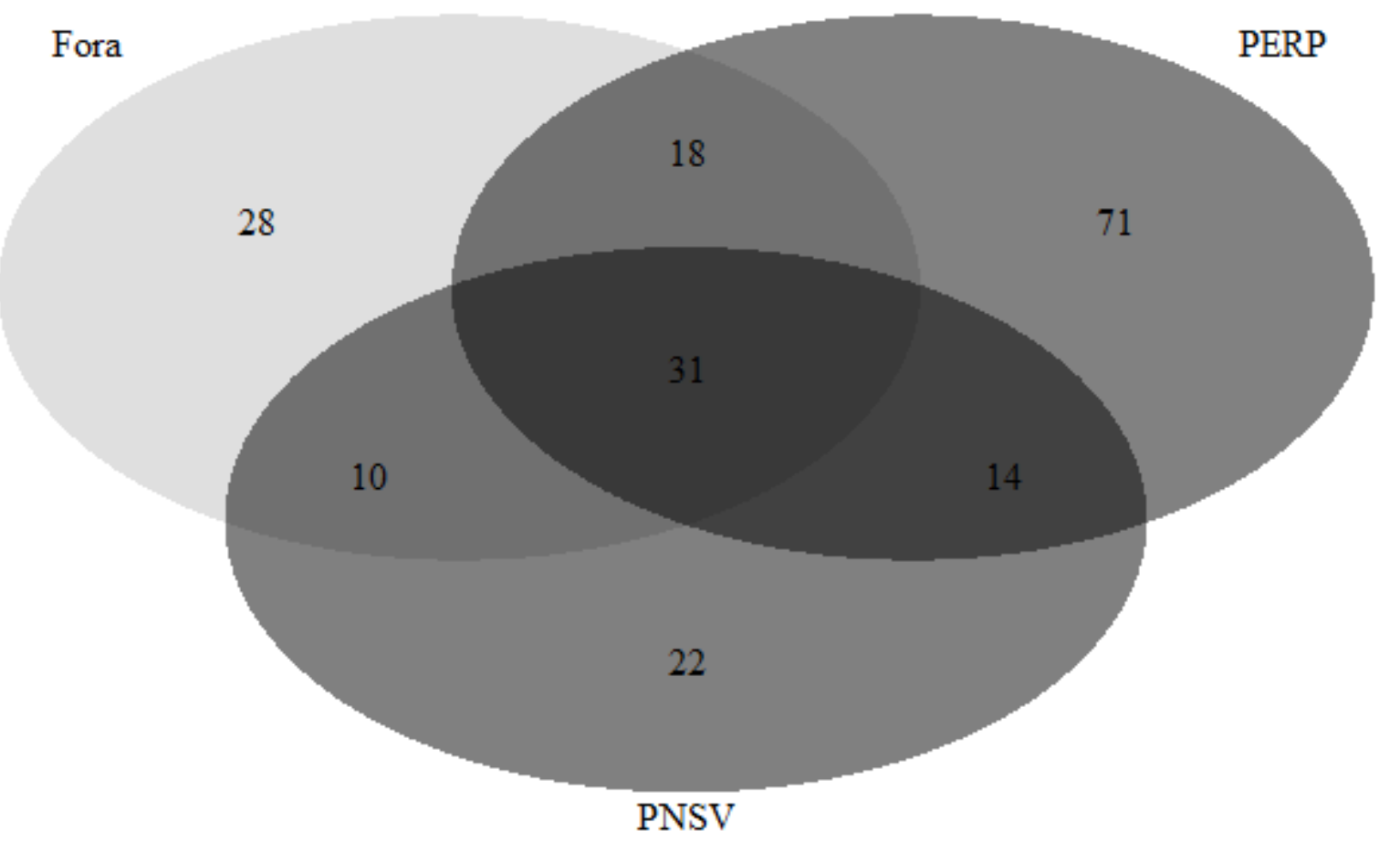

Figura 3. Diagrama de Venn mostra a distribuição do número de espécies entre as duas áreas protegidas e fora delas. PERP (Parque Estadual do Rio Preto) e PNSV (Parque Nacional das Sempre-vivas) situados no Planalto de Diamantina, Serra do Espinhaço, Minas Gerais. 
Tabela 1. Lista de espécies de ASTERACEAE BERCHT. \& J. PRESL. coletadas dentro do Parque Estadual do Rio Preto (PERP), Parque Nacional das Sempre-vivas (PNSV) e fora das áreas protegidas no Planalto de Diamantina, Minas Gerais. (+) indica que a espécie foi coletada, (-) indica que a espécie não foi encontrada dentro de áreas protegidas. " $\mathrm{N}^{\circ}$ de coletas" é referente ao número de vezes que determinada espécie foi coletada. "No de exsicatas" é o número de exsicatas que foram produzidas com as coletas. (UB) Herbário da Universidade de Brasília, no Distrito Federal; e (HDJF) Herbário Dendrológico Jeanine Felfili, na Universidade Federal dos Vales do Jequitinhonha e Mucuri em Diamantina, Minas Gerais.

\begin{tabular}{|c|c|c|c|c|c|c|c|}
\hline $\mathrm{N}^{\circ}$ & Espécies & Fora & PERP & PNSV & $\mathrm{N}^{\circ}$ de coletas & $\mathrm{N}^{\circ}$ de exsicatas & Herbário \\
\hline 1 & Acanthospermum australe (Loefl.) Kuntze & + & - & + & 2 & 2 & UB; HDJF \\
\hline 2 & Acanthospermum sp. 1 & + & - & + & 3 & 6 & UB; HDJF \\
\hline 3 & Acanthospermum sp. 2 & - & - & + & 2 & 5 & UB; HDJF \\
\hline 4 & Achyrocline satureoides (Lam.) DC. & + & + & + & 4 & 6 & UB; HDJF \\
\hline 5 & Acritopappus longifolius (Gardner) R.M.King \& H.Rob. & + & + & + & 7 & 12 & UB; HDJF \\
\hline 6 & Ageratum fastigiatum (Gardner) R.M.King \& H.Rob. & + & - & + & 7 & 11 & UB; HDJF \\
\hline 7 & Aldama bracteata (Gardner) E.E.Schill. \& Panero & + & + & + & 8 & 8 & UB; HDJF \\
\hline 8 & Aldama sp. 1 & - & + & - & 3 & 5 & UB; HDJF \\
\hline 9 & Aspilia cf fruticosa (Gardner) Baker & - & - & + & 1 & 3 & UB \\
\hline 10 & Aspilia cf laevissima (Less. ex Baker) Baker & - & + & - & 11 & 11 & UB; HDJF \\
\hline 11 & Aspilia foliacea (Spreng.) Baker & + & + & + & 3 & 3 & UB; HDJF \\
\hline 12 & Aspilia foliosa (Gardner) Baker & - & + & + & 6 & 11 & UB; HDJF \\
\hline 13 & Aspilia riedelii Baker & + & - & - & 1 & 1 & UB \\
\hline 14 & Aspilia sp. 1 & + & - & - & 1 & 2 & UB \\
\hline 15 & Aspilia sp. 2 & + & - & - & 1 & 2 & UB \\
\hline 16 & Aspilia sp. 3 & + & + & - & 2 & 3 & UB; HDJF \\
\hline 17 & Ayapana amygdalina (Lam.) R.M.King \& H.Rob. & + & + & - & 3 & 3 & UB; HDJF \\
\hline 18 & Baccharis aphylla (Vell.) DC. & - & + & - & 1 & 2 & UB \\
\hline 19 & Baccharis cf concinna G.M.Barroso & + & + & + & 8 & 17 & UB; HDJF \\
\hline 20 & Baccharis lychnophora Gardner & - & + & - & 1 & 3 & UB \\
\hline 21 & Baccharis cf retusa DC. & - & + & - & 2 & 4 & UB; HDJF \\
\hline 22 & Baccharis cf trimera (Less.) DC. & + & + & - & 3 & 3 & UB; HDJF \\
\hline 23 & Baccharis platypoda DC. & + & + & + & 6 & 11 & UB; HDJF \\
\hline 24 & Baccharis punctulata DC. & - & + & - & 2 & 3 & UB; HDJF \\
\hline 25 & Baccharis sp. 1 & + & - & - & 1 & 1 & UB \\
\hline 26 & Baccharis sp. 2 & + & + & + & 6 & 9 & UB; HDJF \\
\hline 27 & Baccharis sp. 3 & - & + & + & 5 & 13 & UB; HDJF \\
\hline 28 & Baccharis sp. 4 & + & - & - & 1 & 3 & UB \\
\hline 29 & Baccharis sp. 5 & - & + & - & 2 & 4 & UB; HDJF \\
\hline 30 & Baccharis sp. 6 & - & - & + & 1 & 2 & UB \\
\hline 31 & Baccharis sp. 7 & - & + & - & 1 & 1 & UB \\
\hline 32 & Baccharis sp. 8 & - & - & + & 1 & 1 & UB \\
\hline 33 & Baccharis sp. 9 & - & + & - & 2 & 6 & UB; HDJF \\
\hline 34 & Baccharis sp. 10 & - & + & - & 4 & 5 & UB; HDJF \\
\hline 35 & Baccharis sp. 11 & - & + & - & 1 & 3 & UB \\
\hline 36 & Baccharis sp. 12 & - & + & - & 2 & 4 & UB; HDJF \\
\hline 37 & Baccharis subdentata DC. & - & + & - & 1 & 1 & UB \\
\hline 38 & Bejaranoa cf semistriata (Baker) R.M.King \& H.Rob. & - & - & + & 2 & 3 & UB; HDJF \\
\hline 39 & Bidens flagellaris Baker & - & - & + & 7 & 7 & UB; HDJF \\
\hline 40 & Calea graminifolia Sch.Bip. ex Krasch. & - & + & + & 2 & 3 & UB; HDJF \\
\hline 41 & Calea sp. 1 & - & + & - & 2 & 2 & UB; HDJF \\
\hline 42 & Calea sp. 2 & - & + & - & 1 & 1 & UB \\
\hline 43 & Calea sp. 3 & - & + & - & 1 & 1 & UB \\
\hline 44 & Calea sp. 4 & - & + & - & 2 & 3 & UB; HDJF \\
\hline 45 & Campuloclinium campuloclinioides (Baker) R.M.King \& H.Rob. & - & - & + & 1 & 4 & UB \\
\hline 46 & Campuloclinium sp. 1 & + & - & - & 1 & 2 & UB \\
\hline 47 & Chresta cf exsucca DC. & + & - & - & 1 & 3 & UB \\
\hline 48 & Chresta sphaerocephala DC. & + & - & + & 2 & 5 & UB; HDJF \\
\hline 49 & Chromolaena barrosoae R.M.King \& H.Rob. & + & + & + & 6 & 8 & UB; HDJF \\
\hline
\end{tabular}

\section{Continua...}


Tabela 1. Lista de espécies de ASTERACEAE BERCHT. \& J. PRESL. coletadas dentro do Parque Estadual do Rio Preto (PERP), Parque Nacional das Sempre-vivas (PNSV) e fora das áreas protegidas no Planalto de Diamantina, Minas Gerais. (+) indica que a espécie foi coletada, (-) indica que a espécie não foi encontrada dentro de áreas protegidas. " $\mathrm{N}^{\circ}$ de coletas" é referente ao número de vezes que determinada espécie foi coletada. " $\mathrm{N}^{\circ}$ de exsicatas" é o número de exsicatas que foram produzidas com as coletas. (UB) Herbário da Universidade de Brasília, no Distrito Federal; e (HDJF) Herbário Dendrológico Jeanine Felfili, na Universidade Federal dos Vales do Jequitinhonha e Mucuri em Diamantina, Minas Gerais.

\begin{tabular}{|c|c|c|c|c|c|c|c|}
\hline $\mathrm{N}^{\circ}$ & Especies & Fora & PERP & PNSV & $\mathrm{N}^{\circ}$ de coletas & $\mathrm{N}^{\circ}$ de exsicatas & Herbário \\
\hline 50 & Chromolaena cf leucocephala Gardner & + & + & + & 10 & 12 & UB; HDJF \\
\hline 51 & Chromolaena cinereoviridis (Sch.Bip. ex Baker) R.M.King \& H.Rob. & + & - & - & 3 & 5 & UB; HDJF \\
\hline 52 & Chromolaena decubens Gardner Gardner & + & + & - & 4 & 4 & UB; HDJF \\
\hline 53 & Chromolaena horminoides DC. & + & + & + & 12 & 17 & UB; HDJF \\
\hline 54 & Chromolaena sp. 1 & - & + & - & 4 & 4 & UB; HDJF \\
\hline 55 & Chromolaena sp. 2 & + & - & - & 1 & 1 & UB \\
\hline 56 & Chromolaena sp. 3 & + & - & - & 1 & 1 & UB \\
\hline 57 & Chromolaena sp. 4 & - & + & - & 1 & 2 & UB \\
\hline 58 & Chromolaena sp. 5 & - & + & - & 1 & 1 & UB \\
\hline 59 & Chromolaena sp. 6 & - & + & + & 3 & 3 & UB; HDJF \\
\hline 60 & Chrysolaena desertorum (Mart. ex DC.) Dematt. & - & - & + & 3 & 3 & UB; HDJF \\
\hline 61 & Chrysolaena obovata (Mart. ex DC.) Dematt. & - & + & + & 4 & 5 & UB; HDJF \\
\hline 62 & Chrysolaena simplex (Less.) Dematt. & - & + & - & 2 & 2 & UB; HDJF \\
\hline 63 & Dasyphyllum sprengelianum (Gardner) Cabrera & - & + & + & 4 & 9 & UB; HDJF \\
\hline 64 & Dimerostemma brasilianum Cass. & - & - & + & 1 & 2 & UB \\
\hline 65 & Dimerostemma sp. 1 & - & + & - & 2 & 2 & UB; HDJF \\
\hline 66 & Disynaphia praefcta (B.L.Rob.) R.M.King \& H.Rob. & + & + & + & 5 & 7 & UB; HDJF \\
\hline 67 & Echinocoryne schwenkiaefolia (Mart. ex DC.) H.Rob. & + & + & + & 7 & 9 & UB; HDJF \\
\hline 68 & Echinocoryne sp. 1 & - & + & - & 1 & 1 & UB \\
\hline 69 & Erechtites hieraciifolius (L.) Raf. ex DC. & + & + & + & 4 & 7 & UB; HDJF \\
\hline 70 & Erechtites valerianifolia (Wolf) DC. & + & - & - & 1 & 1 & UB \\
\hline 71 & Eremanthus cf capitatus (Spreng.) MacLeish & + & + & - & 5 & 13 & UB; HDJF \\
\hline 72 & Eremanthus cf erythropappus (DC.) MacLeish & + & - & + & 3 & 5 & UB; HDJF \\
\hline 73 & Eremanthus crotonoides (DC.) Sch.Bip. & - & - & + & 1 & 4 & UB \\
\hline 74 & Eremanthus elaeagnus (Mart. ex DC.) Sch.Bip. & + & + & + & 4 & 9 & UB; HDJF \\
\hline 75 & Eremanthus glomerulatus Less. & + & + & - & 4 & 6 & UB; HDJF \\
\hline 76 & Eremanthus incanus (Less.) Less. & + & + & - & 4 & 7 & UB; HDJF \\
\hline 77 & Eremanthus sp. 1 & - & - & + & 1 & 3 & UB \\
\hline 78 & Eremanthus sp. 2 & - & + & - & 1 & 3 & UB \\
\hline 79 & Gochnatia blanchetiana (DC.) Cabrera & - & + & + & 5 & 11 & UB; HDJF \\
\hline 80 & Gochnatia sp. 1 & - & + & - & 2 & 4 & UB; HDJF \\
\hline 81 & Gochnatia sp. 2 & - & + & - & 1 & 2 & UB \\
\hline 82 & Gochnatia sp. 3 & - & + & - & 1 & 1 & UB \\
\hline 83 & Heterocoma sp. 1 & - & + & - & 1 & 2 & UB \\
\hline 84 & Ichthyothere sp. 1 & - & + & - & 3 & 4 & UB; HDJF \\
\hline 85 & Lepidaploa aurea (Mart. ex DC.) H.Rob. & + & + & + & 8 & 14 & UB; HDJF \\
\hline 86 & Lepidaploa cf helophila (Mart. ex DC.) H.Rob. & - & + & - & 2 & 2 & UB; HDJF \\
\hline 87 & Lepidaploa pseudarea (D.J.N.Hind) H.Rob. & - & + & - & 2 & 4 & UB; HDJF \\
\hline 88 & Lepidaploa rufogrisea (A.St.-Hil.) H.Rob. & + & + & + & 10 & 17 & UB; HDJF \\
\hline 89 & lepidaploa sp. 1 & + & + & - & 7 & 7 & UB; HDJF \\
\hline 90 & Lepidaploa sp. 2 & - & + & - & 1 & 1 & UB \\
\hline 91 & Lessingianthus ammophillus (Gardner) H.Rob. & - & + & - & 1 & 2 & UB \\
\hline 92 & Lessingianthus cf bardanioides (Less.) H.Rob. & - & + & - & 1 & 3 & UB \\
\hline 93 & Lessingianthus cf stoechas (Mart. ex Baker) H.Rob. & - & - & + & 2 & 4 & UB; HDJF \\
\hline 94 & Lessingianthus cordiger (Mart. ex DC.) H.Rob. & - & + & - & 2 & 4 & UB; HDJF \\
\hline 95 & Lessingianthus coriaceus (Less.) H.Rob. & - & + & + & 5 & 9 & UB; HDJF \\
\hline 96 & Lessingianthus laevigatus (Mart. ex DC.) H.Rob. & - & + & - & 3 & 6 & UB; HDJF \\
\hline 97 & Lessingianthus myrsinites H.Rob. & + & + & + & 7 & 8 & UB; HDJF \\
\hline 98 & Lessingianthus psilophyllus (DC.) H.Rob. & + & + & + & 10 & 11 & UB; HDJF \\
\hline 99 & Lessingianthus santosii & - & - & + & 4 & 5 & UB; HDJF \\
\hline
\end{tabular}

\section{Continua...}


Tabela 1. Lista de espécies de ASTERACEAE BERCHT. \& J. PRESL. coletadas dentro do Parque Estadual do Rio Preto (PERP), Parque Nacional das Sempre-vivas (PNSV) e fora das áreas protegidas no Planalto de Diamantina, Minas Gerais. (+) indica que a espécie foi coletada, (-) indica que a espécie não foi encontrada dentro de áreas protegidas. " $\mathrm{N}^{0}$ de coletas" é referente ao número de vezes que determinada espécie foi coletada. " $\mathrm{N}^{\circ}$ de exsicatas" é o número de exsicatas que foram produzidas com as coletas. (UB) Herbário da Universidade de Brasília, no Distrito Federal; e (HDJF) Herbário Dendrológico Jeanine Felfili, na Universidade Federal dos Vales do Jequitinhonha e Mucuri em Diamantina, Minas Gerais.

\begin{tabular}{|c|c|c|c|c|c|c|}
\hline $\mathrm{N}^{\circ}$ Espécies & Fora & PERP & PNSV & $\mathrm{N}^{\circ}$ de coletas & $\mathrm{N}^{\circ}$ de exsicatas & Herbário \\
\hline 100 Lessingianthus sp. 1 & - & + & - & 2 & 4 & UB; HDJF \\
\hline 101 Lessingianthus sp. 2 & - & + & - & 2 & 2 & UB; HDJF \\
\hline 102 Lessingianthus sp. 3 & - & + & + & 3 & 4 & UB; HDJF \\
\hline 103 Lessingianthus sp. 4 & - & + & - & 2 & 2 & UB; HDJF \\
\hline 104 Lessingianthus vepretorum (Mart. ex DC.) H.Rob. & + & + & - & 4 & 8 & UB; HDJF \\
\hline 105 Lessingianthus warmingianus (Baker) H.Rob. & + & + & - & 3 & 6 & UB; HDJF \\
\hline 106 Lychnophora cf gardneri Sch.Bip. & + & - & - & 2 & 4 & UB \\
\hline 107 Lychnophora cf pinaster Mart. & - & - & + & 2 & 5 & UB; HDJF \\
\hline 108 Lychnophora cf pohlii Sch.Bip. & + & + & - & 7 & 13 & UB; HDJF \\
\hline 109 Lychnophora cf rupestris Semir & + & - & - & 1 & 2 & UB \\
\hline 110 Lychnophora cf triflora (Mattf.) H.Rob. & - & - & + & 3 & 7 & UB; HDJF \\
\hline 111 Lychnophora cf uniflora Sch.Bip. & + & - & - & 4 & 5 & UB; HDJF \\
\hline 112 Lychnophora diamantinana Coile \& Jones & + & - & - & 1 & 3 & UB \\
\hline 113 Lychnophora ericoides Mart. & + & - & - & 2 & 5 & UB; HDJF \\
\hline 114 Lychnophora martiana Gardner & - & + & - & 2 & 3 & UB; HDJF \\
\hline 115 Lychnophora passerina (Mart. ex DC.) Gardner & - & + & - & 4 & 8 & UB; HDJF \\
\hline 116 Lychnophora reticulata Gardner & + & - & - & 1 & 2 & UB \\
\hline 117 Lychnophora salicifolia Mart. & + & - & - & 2 & 5 & UB; HDJF \\
\hline 118 Lychnophora sellowi Sch.Bip. & + & - & - & 2 & 5 & UB; HDJF \\
\hline 119 Lychnophora sp. 1 & + & - & - & 1 & 1 & UB \\
\hline 120 Lychnophora sp. 2 & - & + & - & 1 & 1 & UB \\
\hline 121 Lychnophora sp. 3 & + & - & - & 1 & 2 & UB \\
\hline 122 Lychnophora staavioides Mart. & + & + & - & 3 & 5 & UB; HDJF \\
\hline 123 Lychnophora syncephala (Sch.Bip.) Sch.Bip. & + & - & + & 6 & 13 & UB; HDJF \\
\hline 124 Lychnophora tomentosa (Mart. ex DC.) Sch.Bip. & + & + & + & 5 & 6 & UB; HDJF \\
\hline 125 Lychnophora villosissima Mart. & + & - & + & 6 & 12 & UB; HDJF \\
\hline 126 Lychnophoriopsis candelabrum (Sch.Bip.) H.Rob. & + & - & - & 1 & 3 & UB \\
\hline 127 Mikania cf glabra D.J.N.Hind & - & + & - & 2 & 3 & UB; HDJF \\
\hline 128 Mikania cf leiolaena DC. & + & + & + & 8 & 12 & UB; HDJF \\
\hline 129 Mikania glauca Mart. ex Baker & - & + & - & 4 & 7 & UB; HDJF \\
\hline 130 Mikania officinalis Mart. & + & - & + & 2 & 5 & UB; HDJF \\
\hline 131 Mikania pohlii (Baker) R.M.King \& H.Rob. & - & + & + & 3 & 3 & UB; HDJF \\
\hline 132 Mikania reticulata Gardner & + & - & - & 10 & 15 & UB; HDJF \\
\hline 133 Mikania sp. 1 & - & + & - & 1 & 3 & UB \\
\hline 134 Mikania sp. 2 & - & - & + & 1 & 4 & UB \\
\hline 135 Mikania sp. 3 & - & + & - & 3 & 4 & UB; HDJF \\
\hline 136 Mikania sp. 4 & - & + & - & 2 & 6 & UB; HDJF \\
\hline 137 Mikania sp. 5 & - & + & - & 1 & 1 & UB \\
\hline 138 Minasia alpestris (Gardner) H.Rob. & - & + & + & 3 & 3 & UB; HDJF \\
\hline 139 Minasia scapigera H.Rob. & - & + & - & 3 & 3 & UB; HDJF \\
\hline 140 Minasia sp. 1 & - & - & + & 1 & 3 & UB \\
\hline 141 Moquinia racemosa (Spreng.) DC. & + & + & + & 5 & 7 & UB; HDJF \\
\hline 142 NI 1 & - & + & - & 1 & 2 & UB \\
\hline 143 NI 10 & - & + & - & 1 & 1 & UB \\
\hline 144 NI 11 & - & + & - & 1 & 1 & UB \\
\hline 145 NI 12 & - & + & - & 2 & 4 & UB; HDJF \\
\hline 146 NI 13 & - & + & - & 2 & 2 & UB; HDJF \\
\hline 147 NI 14 & - & + & - & 1 & 2 & UB \\
\hline 148 NI 2 & - & + & - & 1 & 1 & UB \\
\hline 149 NI 25 & - & + & - & 2 & 2 & UB; HDJF \\
\hline
\end{tabular}

\section{Continua...}


Tabela 1. Lista de espécies de ASTERACEAE BERCHT. \& J. PRESL. coletadas dentro do Parque Estadual do Rio Preto (PERP), Parque Nacional das Sempre-vivas (PNSV) e fora das áreas protegidas no Planalto de Diamantina, Minas Gerais. (+) indica que a espécie foi coletada, (-) indica que a espécie não foi encontrada dentro de áreas protegidas. " $\mathrm{N}^{0}$ de coletas" é referente ao número de vezes que determinada espécie foi coletada. " $\mathrm{N}^{\mathrm{o}}$ de exsicatas" é o número de exsicatas que foram produzidas com as coletas. (UB) Herbário da Universidade de Brasília, no Distrito Federal; e (HDJF) Herbário Dendrológico Jeanine Felfili, na Universidade Federal dos Vales do Jequitinhonha e Mucuri em Diamantina, Minas Gerais.

\begin{tabular}{|c|c|c|c|c|c|c|}
\hline $\mathrm{N}^{\circ}$ Espécies & Fora & PERP & PNSV & $\mathrm{N}^{\circ}$ de coletas & $\mathrm{N}^{\circ}$ de exsicatas & Herbário \\
\hline 150 NI 26 & - & + & - & 3 & 5 & UB; HDJF \\
\hline 151 NI 3 & + & - & - & 1 & 1 & UB \\
\hline 152 NI 33 & - & + & - & 1 & 1 & UB \\
\hline $153 \mathrm{NI} 4$ & + & - & - & 1 & 2 & UB \\
\hline 154 NI 6 & + & - & - & 1 & 1 & UB \\
\hline $155 \mathrm{NI} 7$ & - & + & - & 2 & 2 & UB; HDJF \\
\hline $156 \mathrm{NI} 8$ & - & + & - & 2 & 2 & UB; HDJF \\
\hline 157 NI 9 & - & + & - & 1 & 1 & UB \\
\hline 158 Paralychnophora bicolor (DC.) MacLeish & + & + & + & 5 & 11 & UB; HDJF \\
\hline 159 Piptolepis cf buxoides (Less.) Sch.Bip. & - & + & - & 1 & 2 & UB \\
\hline 160 Piptolepis cf ericoides Sch.Bip. & - & - & + & 1 & 4 & UB \\
\hline 161 Piptolepis cf leptospermoides (Mart. ex DC.) Sch.Bip. & + & - & + & 3 & 4 & UB; HDJF \\
\hline 162 Piptolepis sp. 1 & - & + & - & 2 & 3 & UB; HDJF \\
\hline 163 Piptolepis sp. 2 & + & - & - & 1 & 1 & UB \\
\hline 164 Porophyllum angustissimum Gardner & + & + & + & 10 & 13 & UB; HDJF \\
\hline 165 Praxelis sp. 1 & - & + & - & 1 & 1 & UB \\
\hline 166 Proteopsis argentea Mart. \& Zucc. ex Sch.Bip. & - & - & + & 2 & 6 & UB; HDJF \\
\hline 167 Pseudobrickellia angustissima (Spreng. ex Baker) R.M.King \& H.Rob. & + & + & + & 5 & 12 & UB; HDJF \\
\hline 168 Pseudobrickellia brasiliensis (Spreng.) R.M.King \& H.Rob. & + & + & + & 5 & 11 & UB; HDJF \\
\hline 169 Pterocaulon rugosum (Vahl) Malme & + & + & - & 2 & 2 & UB; HDJF \\
\hline 170 Richterago amplexifolia (Gardner) Kuntze & + & + & - & 8 & 9 & UB; HDJF \\
\hline 171 Richterago angustifolia (Gardner) Roque & - & - & + & 1 & 2 & UB \\
\hline 172 Richterago arenaria (Baker) Roque & + & + & - & 4 & 5 & UB; HDJF \\
\hline 173 Richterago campestris Roque \& J.N.Nakaj. & - & - & + & 2 & 3 & UB; HDJF \\
\hline 174 Richterago elegans Roque & + & + & + & 6 & 6 & UB; HDJF \\
\hline 175 Richterago polyphylla (Baker) Ferreyra & + & + & - & 7 & 12 & UB; HDJF \\
\hline 176 Senecio cf brasiliensis (Spreng.) Less. & - & + & - & 1 & 2 & UB \\
\hline 177 Senecio cf macrotis Baker & + & - & - & 1 & 1 & UB \\
\hline 178 Senecio sp. 1 & + & - & - & 1 & 3 & UB \\
\hline 179 Senecio sp. 2 & - & + & - & 1 & 3 & UB \\
\hline 180 Stenocephalum megapotamicum (Spreng.) Sch.Bip. & + & + & + & 5 & 7 & UB; HDJF \\
\hline 181 Stenocephalum sp. 1 & - & + & - & 1 & 1 & UB \\
\hline 182 Symphyopappus brasiliensis (Gardner) R.M.King \& H.Rob. & + & + & + & 4 & 8 & UB; HDJF \\
\hline 183 Symphyopappus decussatus Turcz. & + & + & + & 9 & 22 & UB; HDJF \\
\hline 184 Trichogonia hirtiflora (DC.) Sch.Bip. ex Baker & + & + & + & 9 & 9 & UB; HDJF \\
\hline 185 Trichogonia sp. 1 & - & + & - & 2 & 3 & UB; HDJF \\
\hline 186 Trichogonia villosa (Spreng.) Sch.Bip. ex Baker & + & + & + & 16 & 23 & UB; HDJF \\
\hline 187 Trixis glutinosa D.Don & - & + & - & 1 & 1 & UB \\
\hline 188 Trixis nobilis (Vell.) Katinas & - & - & + & 3 & 4 & UB; HDJF \\
\hline 189 Trixis vauthieri DC. & + & + & + & 6 & 14 & UB; HDJF \\
\hline 190 Vernonanthura laxa (Gardner) H.Rob. & - & + & - & 2 & 2 & UB; HDJF \\
\hline 191 Vernonanthura sp. 1 & - & - & + & 1 & 3 & UB \\
\hline 192 Vernonanthura sp. 2 & - & + & + & 2 & 2 & UB; HDJF \\
\hline 193 Vernonanthura westiniana (Less.) H.Rob. & + & + & + & 11 & 14 & UB; HDJF \\
\hline 194 Wunderlichia mirabilis Riedel ex Baker & - & + & - & 1 & 2 & UB \\
\hline 195 Wunderlichia senae Glaz. ex Maguire \& G.M.Barroso & - & + & - & 1 & 4 & UB \\
\hline
\end{tabular}

\subsubsection{FORMAS DE VIDA}

- Classe 1: Ervas rosetiforme escapulares ou não, altura aproximada de $30 \mathrm{~cm}$, geralmente dotadas de xilopódio suculento e raízes adventícias (Lessingianthus cf santosii (H.Rob.)) (Figura 4.1), em algumas espécies as gemas são envolvidas por catafilos (Chrysolaena $\mathrm{cf}$ simplex (Less.) Dematt.) (Figura 4.4). São ervas persistentes em função da presença de xilopódio bem definido, apresentando sinais de rebrotas dos anos anteriores que provavelmente perdeu a parte aérea em função da passagem de fogo ou déficit hídrico na 
estação seca do ano Chromolaena barrosoae R.M.King \& H.Rob. (Figura 4.3) e Lessingianthus psilophyllus (DC.) H.Rob. (Figura 4.2) também configuram esta classe.

- Classe 2: Ervas anuais ou pouco persistentes, sem xilopódio propriamente dito, porém com estruturas de reserva. Chrysolaena obovata (Less.) Dematt. (Figura 4.5) configura esta classe.

- Classe 3: Subarbustos de tamanhos variados, pode chegar até 2,5 m, como Bidens flagellaris Baker (Figura 4.6), xilopódio lenhoso, dotado de raízes adventícias que terminam ou não em outras estruturas tuberosas. São subarbustos persistentes, apresentando sinais de rebrotas dos anos anteriores quando perdeu a parte aérea no final do outono para entrar em estado de dormência (Appezzato-da-glória et al. 2008). Baccharis aphylla (Vell.) DC. (Figura 4.7) e Viguiera bracteata Gardner (Figura 4.8) configuram esta classe.

- Classe 4: Subarbustos rosetiformes com escapo ou caule curto coberto por folhas secas (Minasia alpestris (Gardner) H.Rob.). São subarbustos persistentes, de raiz "pivotante" espessada e raízes adventícias também espessas. A morfologia de Proteopsis argentea Mart. \& Zucc. ex Sch.Bip. (Figura 4.9) e Minasia scapigera H.Rob. (Figura 4.10) configuram esta classe.

- Classe 5: Arbustos de tamanhos variados, podendo chegar a medir mais de $3 \mathrm{~m}$ de forma arvoretóide, porém não lenhosos (Acrtitopappus longifolius (Gardner) R.M.King \& H.Rob.) ou escandente (Dasyphyllum sprengelianum (Gardner) Cabrera). Geralmente a raiz é pouco espessa se comparado ao tamanho da planta. São persistentes (para as duas espécies citadas anteriormente) ou pouco persistentes (Trichogonia villosa (Spreng.) Sch.Bip. ex Baker (Figura 4.11) e Lepidaploa rufogrisea (A. St.-Hil.) H.Rob.)) (Figura 4.12).

- Classe 6: Arbusto tipo liana, com presença ou ausência de xilopódio (Figura 4.13). Mikania sp. caracteriza esta classe de hábito.

- Classe 7: Arvoretas lenhosas que dificilmente passam dos $3 \mathrm{~m}$ com raízes espessas e lenhosas. São plantas persistentes. Lychnophora tomentosa (Mart. ex DC.) Sch.Bip. (Figura 4.14) configura esta classe.

- Classe 8: Árvores que podem atingir altura próximas a $5 \mathrm{~m}$ com raiz pouco espessada comparado ao tamanho da planta. São plantas persistentes, alguns exemplos: Eremanthus incanus (Less.) Less. (Figura 4.15), Wundelichia mirabilis Riedel ex Baker, Moquinia racemosa (Spreng.) DC. 

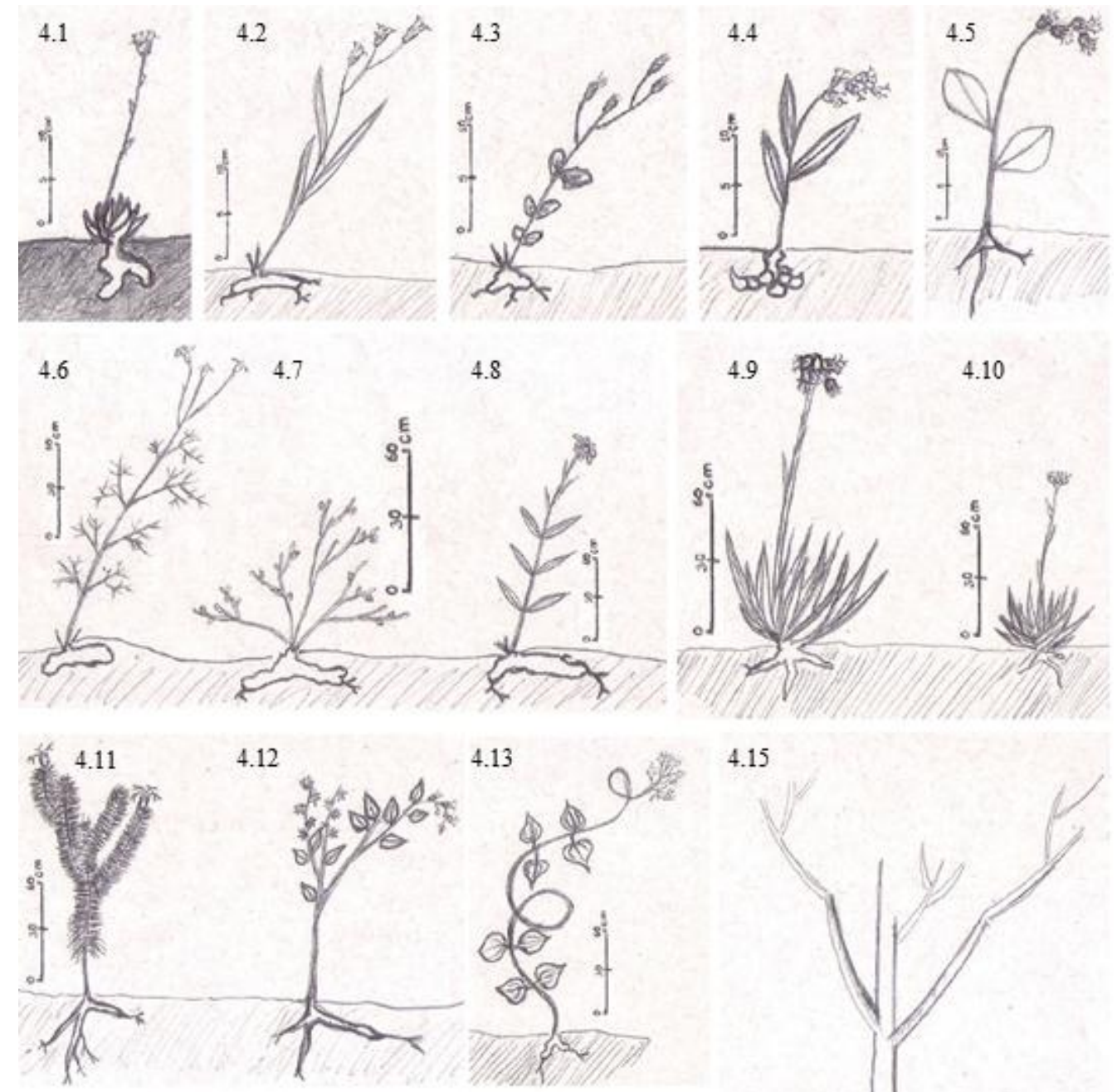

\subsection{5}
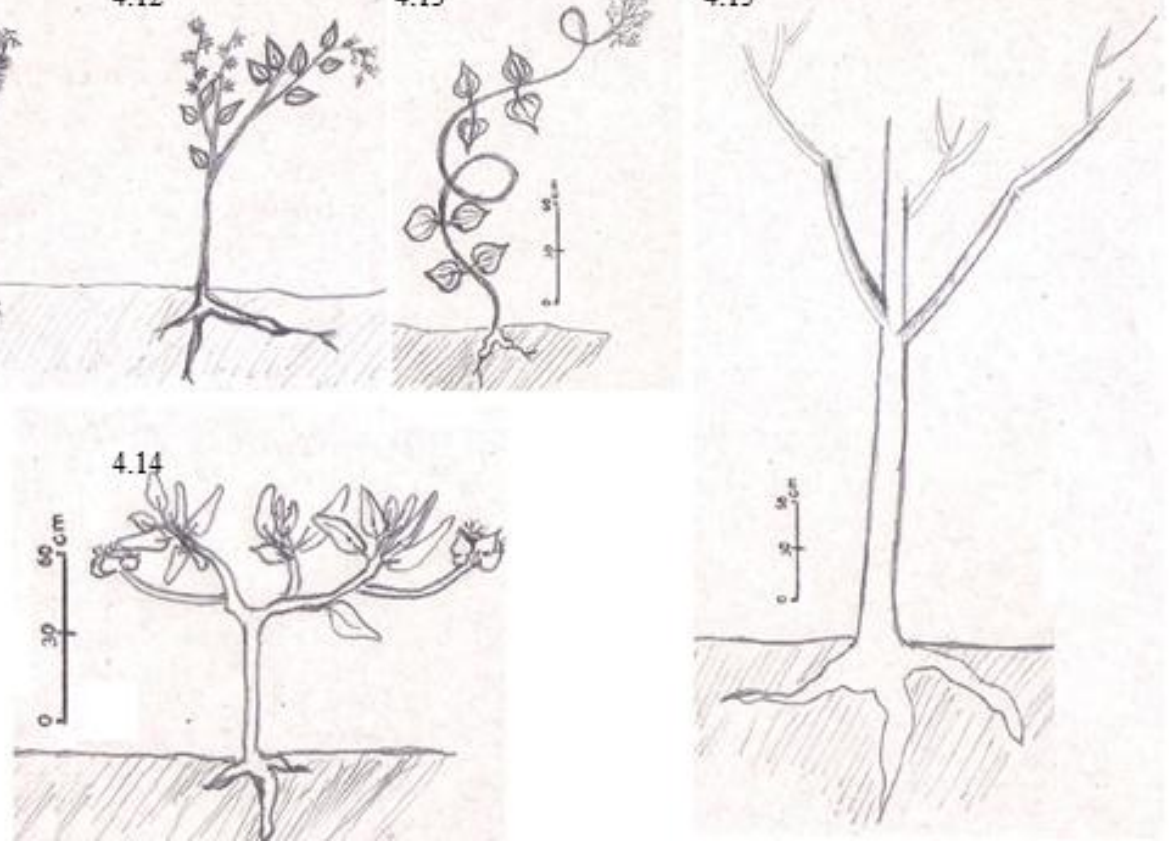

Figura 4. Desenho esquemático das formas de vida ou hábitos que foram observados entre as espécies coletadas no Parque Estadual do Rio Preto e Parque Nacional das Sempre-vivas, no Planalto de Diamantina, Minas Gerais. Hábito das espécies. (4.1) Lessingianthus cf. santosii (H.Rob.) H.Rob., (4.2) Lessingianthus psilophyllus (DC.) H.Rob., (4.3) Chromolaena barrosoae R.M.King \& H.Rob., (4.4) Chrysolaena cf simplex (Less.) Dematt., (4.5) Chrysolaena obovata (Less.) Dematt., (4.6) Bidens flagellaris Baker, (4.7) Baccharis aphylla (Vell.) DC., (4.8) Viguiera bracteata Gardner., (4.9) Proteopsis argentea Mart. \& Zucc. ex Sch.Bip., (4.10) Minasia scapigera H.Rob., (4.11) Trichogonia villosa (Spreng.) Sch.Bip. ex Baker, (4.12) Lepidaploa rufogrisea (A. St.-Hil.) H.Rob.), (4.13) Mikania sp., (4.14) Lychnophora tomentosa (Mart. ex DC.) Sch.Bip, e (4.15) Eremanthus incanus (Less.) Less. 


\subsubsection{COMPOSIÇÃO FLORÍSTICA}

Foram amostrados nos três módulos (PERP I, PERP II e PNSV I) 12.755 indivíduos de Asteraceae pertencentes a 130 espécies e 42 gêneros. O número de indivíduos para as unidades amostrais com área de 1 hectare $(40 \mathrm{~m}$ x $250 \mathrm{~m})$ variou entre 0 e 1.087; para área de 0,4 hectare ( 8 m x $250 \mathrm{~m})$ variou entre 12 e 379; e para área de 0,05 hectare $(2 \mathrm{~m}$ x $250 \mathrm{~m})$ variou entre 3 e 371. O número de espécies por unidade amostral variou entre 5 e 39 espécies.

O módulo PERP II apresentou maior número de espécies $(64,6 \%)$ como também o maior número de espécies exclusivas (42,3\%). Os módulos PERP I e PNSV I apresentaram valores muito próximos para o número de espécies, $37,7 \%$ e 38,5\% respectivamente, e número de espécies exclusivas, 14,6\% e 15,4\% respectivamente (Figura 5).

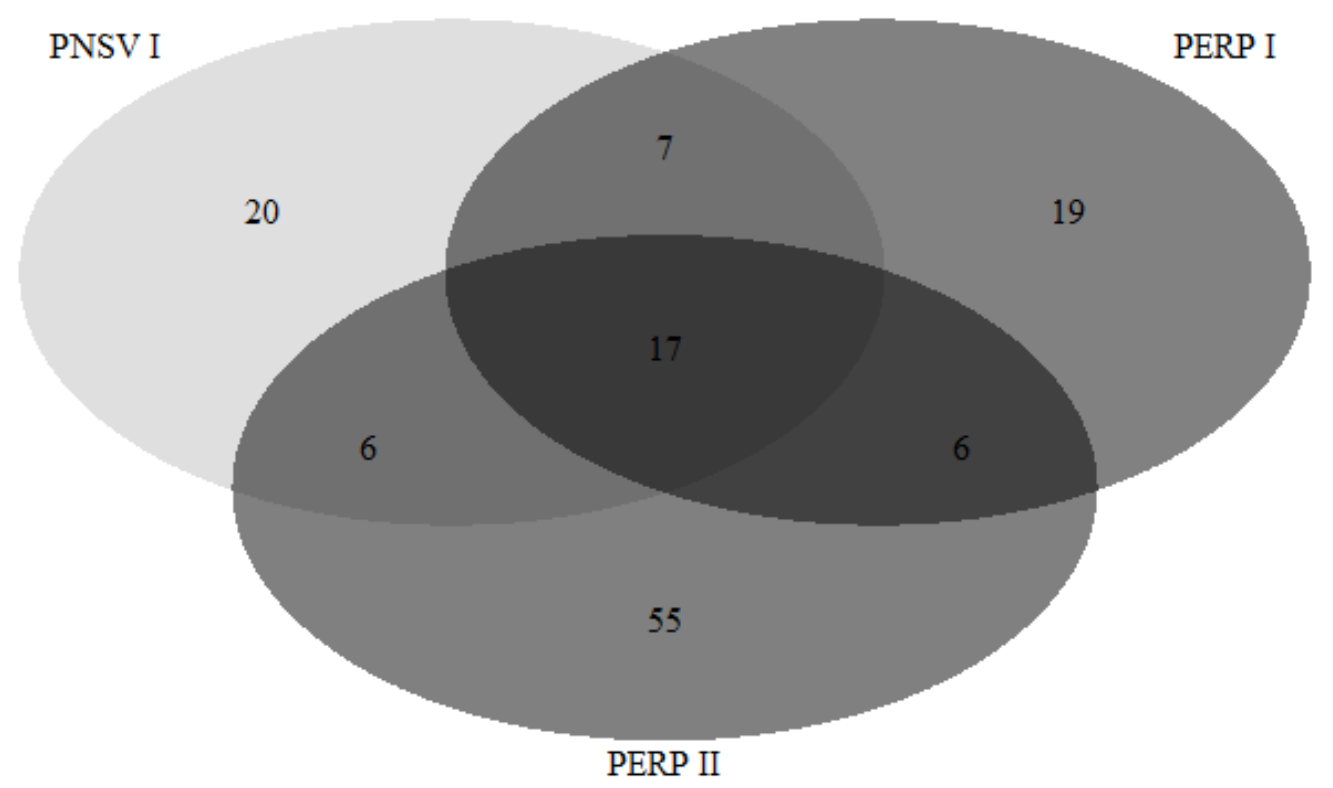

Figura 5. Diagrama de Venn mostrando a distribuição do número de espécies entre os três módulos. Os módulos PERP I e PERP II localizados no Parque Estadual do Rio Preto e o módulo PNSV I localizado no Parque Nacional das Sempre-vivas, ambos no Planalto de Diamantina, Serra do Espinhaço, Minas Gerais. 
Tabela 2. Lista de espécies de ASTERACEAE BERCHT. \& J. PRESL. amostradas nos Módulos RAPELD no Parque Estadual do Rio Preto (PERP) e Parque Nacional das Sempre-vivas (PNSV) no Planalto de Diamantina, Minas Gerais. (+) indica as espécies que foram amostradas, (-) indica as espécies que não foram amostradas dentro da área protegida. "Hábito 1" foi uma primeira separação das espécies quanto a forma de vida e "Hábito 2" é uma segunda separação, mais específica, das formas de vida (Figura 4). "Faixa de amostra" corresponde a área de amostragem estabelecida para a espécie dentro das unidades amostrais.

\begin{tabular}{|c|c|c|c|c|c|c|}
\hline \multirow{2}{*}{$\mathrm{N}^{\circ}$} & \multirow{2}{*}{ ASTERACEAE Bercht. \& J. Presl. } & \multicolumn{2}{|c|}{ Amostrada } & \multirow{2}{*}{ Hábito 1} & \multirow{2}{*}{ Hábito 2} & \multirow{2}{*}{ Faixa de amostra } \\
\hline & & PERP & PNSV & & & \\
\hline 1 & Acanthospermum sp.1 & - & + & Arbusto & 5 & $8 \mathrm{~m}$ \\
\hline 2 & Achyrocline satureoides (Lam.) DC. & + & - & Erva & 2 & $2 \mathrm{~m}$ \\
\hline 3 & Achyrocline sp.1 & + & - & Erva & 2 & $2 \mathrm{~m}$ \\
\hline 4 & Acritopappus longifolius (Gardner) R.M.King \& H.Rob. & + & + & Arbusto & 5 & $8 \mathrm{~m}$ \\
\hline 5 & Aldama sp.2 & + & - & Arbusto & 3 & $2 \mathrm{~m}$ \\
\hline 6 & Aldama bracteata Gardner & + & + & Arbusto & 3 & $8 m$ \\
\hline 7 & Argeratum fastigiatum (Gardner) R.M.King \& H.Rob. & + & - & Erva & 2 & $2 \mathrm{~m}$ \\
\hline 8 & Aspilia foliacea (Spreng.) Baker & + & + & Arbusto & 3 & $2 \mathrm{~m}$ \\
\hline 9 & Aspilia foliosa (Gardner) Baker & + & + & Arbusto & 5 & $8 \mathrm{~m}$ \\
\hline 10 & Aspilia laevissima (Less. ex Baker) Baker & + & - & Arbusto & 3 & $2 \mathrm{~m}$ \\
\hline 11 & Aspilia sp.1 & + & - & Arbusto & 3 & $2 \mathrm{~m}$ \\
\hline 12 & Ayapana amigdalina (Lam.) R.M.King \& H.Rob. & + & - & Arbusto & 3 & $2 \mathrm{~m}$ \\
\hline 13 & Baccharis aphylla (Vell.) DC. & + & - & Arbusto & 3 & $2 \mathrm{~m}$ \\
\hline 14 & Baccharis brevifolia DC. & + & - & Arbusto & 5 & $8 \mathrm{~m}$ \\
\hline 15 & Baccharis cf concinna G.M.Barroso & + & + & Arbusto & 5 & $8 m$ \\
\hline 16 & Baccharis cf trimera (Less.) DC. & + & - & Arbusto & 3 & $2 \mathrm{~m}$ \\
\hline 17 & Baccharis cf minutiflora Mart. ex Baker & + & - & Arbusto & 5 & $8 \mathrm{~m}$ \\
\hline 18 & Baccharis cf punctulata DC. & + & - & Arbusto & 5 & $8 m$ \\
\hline 19 & Baccharis cf retusa DC. & + & - & Arbusto & 5 & $8 \mathrm{~m}$ \\
\hline 20 & Baccharis platypoda $\mathrm{DC}$. & + & - & Arbusto & 5 & $8 \mathrm{~m}$ \\
\hline 21 & Baccharis sp. 1 & - & + & Arbusto & 5 & $8 \mathrm{~m}$ \\
\hline 22 & Baccharis sp. 2 & - & + & Arbusto & 5 & $8 \mathrm{~m}$ \\
\hline 23 & Baccharis sp. 3 & + & - & Arbusto & 5 & $8 \mathrm{~m}$ \\
\hline 24 & Baccharis sp.4 & + & - & Arbusto & 5 & $8 \mathrm{~m}$ \\
\hline 25 & Baccharis sp.5 & + & - & Arbusto & 5 & $8 \mathrm{~m}$ \\
\hline 26 & Baccharis sp.6 & + & - & Arbusto & 5 & $8 \mathrm{~m}$ \\
\hline 27 & Baccharis sp.7 & + & - & Arbusto & 5 & $8 \mathrm{~m}$ \\
\hline 28 & Baccharis sp. 8 & + & - & Arbusto & 5 & $8 \mathrm{~m}$ \\
\hline 29 & Baccharis sp. 9 & + & - & Arbusto & 5 & $8 \mathrm{~m}$ \\
\hline 30 & Baccharis sp. 10 & + & - & Arbusto & 5 & $8 \mathrm{~m}$ \\
\hline 31 & Baccharis sp.11 & + & - & Arbusto & 3 & $2 \mathrm{~m}$ \\
\hline 32 & Bidens flagellaris Baker & - & + & Arbusto & 3 & $8 \mathrm{~m}$ \\
\hline 33 & Calea cf graminifolia Sch.Bip. ex Krasch. & + & - & Erva & 1 & $2 \mathrm{~m}$ \\
\hline 34 & Calea sp. 1 & + & - & Arbusto & 3 & $8 \mathrm{~m}$ \\
\hline 35 & Calea sp.2 & + & - & Arbusto & 5 & $8 \mathrm{~m}$ \\
\hline 36 & Calea sp.3 & + & - & Arbusto & 5 & $8 \mathrm{~m}$ \\
\hline 37 & Chresta sphaerocephala DC. & + & + & Arbusto & 3 & $8 \mathrm{~m}$ \\
\hline & Chromolaena barrosoae R.M.King \& H.Rob. & + & - & Erva & 1 & $2 \mathrm{~m}$ \\
\hline 39 & Chromolaena cf leucocephala Gardner & + & + & Arbusto & 5 & $2 \mathrm{~m}$ \\
\hline 40 & Chromolaena horminoides DC. & + & + & Erva & 2 & $2 \mathrm{~m}$ \\
\hline & Chromolaena sp.1 & - & + & Arbusto & 5 & $2 \mathrm{~m}$ \\
\hline 42 & Chromolaena sp. 2 & + & - & Arbusto & 5 & $2 \mathrm{~m}$ \\
\hline & Chromolaena sp.3 & + & - & Arbusto & 5 & $2 \mathrm{~m}$ \\
\hline & Chromolaena sp. 4 & + & - & Arbusto & 5 & $2 m$ \\
\hline 45 & Chromolaena sp.5 & + & - & Arbusto & 5 & $2 \mathrm{~m}$ \\
\hline 46 & Chrysolaena desetorum (Mart. ex DC.) Dematt. & - & + & Erva & 1 & $2 \mathrm{~m}$ \\
\hline & Chrysolaena obovata (Less.) Dematt. & + & + & Erva & 2 & $2 \mathrm{~m}$ \\
\hline & Chrysolaena simplex (Less.) Dematt. & + & - & Erva & 1 & $2 \mathrm{~m}$ \\
\hline
\end{tabular}

\section{Continua...}


Tabela 2. Lista de espécies de ASTERACEAE BERCHT. \& J. PRESL. amostradas nos Módulos RAPELD no Parque Estadual do Rio Preto (PERP) e Parque Nacional das Sempre-vivas (PNSV) no Planalto de Diamantina, Minas Gerais. (+) indica as espécies que foram amostradas, (-) indica as espécies que não foram amostradas dentro da área protegida. "Hábito 1" foi uma primeira separação das espécies quanto a forma de vida e "Hábito 2" é uma segunda separação, mais específica, das formas de vida (Figura 4). "Faixa de amostra" corresponde a área de amostragem estabelecida para a espécie dentro das unidades amostrais.

\begin{tabular}{|c|c|c|c|c|c|c|}
\hline \multirow{2}{*}{$\mathrm{N}^{\circ}$} & \multirow{2}{*}{ ASTERACEAE Bercht. \& J. Presl. } & \multicolumn{2}{|c|}{ Amostrada } & \multirow{2}{*}{ - Hábito 1} & \multirow{2}{*}{ Hábito 2} & \multirow{2}{*}{ Faixa de amostra } \\
\hline & & PERP & PNSV & & & \\
\hline 49 & Dasyphyllum sprengelianum (Gardner) Cabrera & + & + & Arbusto & 5 & $8 \mathrm{~m}$ \\
\hline 50 & Dimerostemma brasilianum Cass. & - & + & Erva & 2 & $2 \mathrm{~m}$ \\
\hline 51 & Dimerostemma sp.1 & + & - & Erva & 2 & $2 \mathrm{~m}$ \\
\hline 52 & Disynaphia praeficta (B.L.Rob.) R.M.King \& H.Rob. & + & + & Arvoreta & 7 & $40 \mathrm{~m}$ \\
\hline 53 & Echinocoryne schwenkiifolia (Mart. ex DC.) H. Rob. & + & + & Erva & 2 & $2 \mathrm{~m}$ \\
\hline 54 & Erechtites hieracifolius (L.) Raf. ex DC. & + & + & Erva & 2 & $2 \mathrm{~m}$ \\
\hline 55 & Eremanthus cf capitatus (Spreng.) MacLeish & + & - & Árvore & 8 & $40 \mathrm{~m}$ \\
\hline 56 & Eremanthus elaeagnus (Spreng.) MacLeish & + & + & Árvore & 8 & $40 \mathrm{~m}$ \\
\hline 57 & Eremanthus erythropappus (DC.) MacLeish & + & + & Árvore & 8 & $40 \mathrm{~m}$ \\
\hline 58 & Eremanthus glomerulatus Less. & + & - & Árvore & 8 & $40 \mathrm{~m}$ \\
\hline 59 & Eremanthus incanus (Less.) Less. & + & + & Árvore & 8 & $40 \mathrm{~m}$ \\
\hline 60 & Eremanthus sp. 1 & - & + & Árvore & 8 & $40 \mathrm{~m}$ \\
\hline 61 & Gochnatia blanchetiana (DC.) Cabrera & + & + & Arbusto & 7 & $40 \mathrm{~m}$ \\
\hline 62 & Gochnatia sp.1 & + & - & Arbusto & 7 & $40 \mathrm{~m}$ \\
\hline 63 & Ichthyothere sp. 1 & + & - & Erva & 2 & $2 \mathrm{~m}$ \\
\hline 64 & Lepidaploa aurea (Mart. ex DC.) H.Rob. & + & + & Arbusto & 5 & $8 m$ \\
\hline 65 & Lepidaploa cf pseudarea (D.J.N.Hind) H.Rob. & + & - & Arbusto & 5 & $8 \mathrm{~m}$ \\
\hline 66 & Lepidaploa rufogrisea (A. St.-Hil.) H.Rob. & + & + & Arbusto & 5 & $8 m$ \\
\hline 67 & Lepidaploa $\mathrm{sp} .1$ & + & - & Arbusto & 5 & $8 m$ \\
\hline 68 & Lepidaploa sp. 2 & + & - & Arbusto & 5 & $8 \mathrm{~m}$ \\
\hline 69 & Lepidaploa $\mathrm{sp} .3$ & + & - & Arbusto & 5 & $8 \mathrm{~m}$ \\
\hline 70 & Lessingianthus ammophillus (Gardner) H.Rob. & + & - & Arbusto & 3 & $2 \mathrm{~m}$ \\
\hline 71 & Lessingianthus coriaceus (Less.) H.Rob. & - & + & Arbusto & 3 & $2 \mathrm{~m}$ \\
\hline 72 & Lessingianthus laevigatus (Mart. ex DC.) H.Rob. & + & - & Arbusto & 3 & $2 \mathrm{~m}$ \\
\hline 73 & Lessingianthus myrsinites H.Rob. & + & + & Arbusto & 5 & $8 m$ \\
\hline 74 & Lessingianthus psilophyllus (DC.) H.Rob. & + & - & Erva & 1 & $2 \mathrm{~m}$ \\
\hline 75 & Lessingianthus santosii (H.Rob.) H.Rob. & - & + & Erva & 1 & $2 m$ \\
\hline 76 & Lessingianthus $\mathrm{sp} .1$ & + & - & Erva & 1 & $2 \mathrm{~m}$ \\
\hline 77 & Lessingianthus sp. 2 & + & - & Erva & 1 & $2 \mathrm{~m}$ \\
\hline 78 & Lessingianthus warmingianus (Baker) H.Rob. & + & - & Arbusto & 3 & $2 \mathrm{~m}$ \\
\hline 79 & Lychnophora passerina (Mart. ex DC.) Gardner & + & - & Arvoreta & 7 & $40 \mathrm{~m}$ \\
\hline 80 & Lychnophora ericoides Mart. & - & + & Arvoreta & 7 & $40 \mathrm{~m}$ \\
\hline 81 & Lychnophora rsyncephala (Sch.Bip.) Sch.Bip. & - & + & Arvoreta & 7 & $40 \mathrm{~m}$ \\
\hline 82 & Lychnophora sp. 1 & + & - & Arbusto & 4 & $40 \mathrm{~m}$ \\
\hline 83 & Lychnophora tomentosa (Mart. ex DC.) Sch.Bip. & + & - & Arvoreta & 7 & $40 \mathrm{~m}$ \\
\hline 84 & Lychnophora villosissima Mart. & - & + & Arvoreta & 7 & $40 \mathrm{~m}$ \\
\hline 85 & Mikania glauca Mart. ex Mart. & + & - & Arbusto & 3 & $8 \mathrm{~m}$ \\
\hline 86 & Mikania leiolaena DC. & - & + & Arbusto & 3 & $8 \mathrm{~m}$ \\
\hline 87 & Mikania officinalis Mart. & - & + & Erva & 2 & $2 m$ \\
\hline 88 & Mikania cf pohlii (Baker) R.M.King \& H.Rob. & + & + & Arbusto & 3 & $8 m$ \\
\hline 89 & Mikania reticulata Gardner & + & - & Arbusto & 3 & $8 m$ \\
\hline & Mikania sp.1 & + & - & Arbusto & 3 & $8 \mathrm{~m}$ \\
\hline & Mikania sp.2 & + & - & Arbusto & 3 & $8 m$ \\
\hline & Mikania sp. 3 & + & - & Arbusto & 6 & $8 m$ \\
\hline & Mikania sp.4 & + & - & Arbusto & 6 & $8 \mathrm{~m}$ \\
\hline & Minasia scapigera H.Rob. & + & - & Arbusto & 4 & $8 \mathrm{~m}$ \\
\hline & Minasia sp.1 & - & + & Arbusto & 4 & $8 \mathrm{~m}$ \\
\hline & Moquinia racemosa (Spreng.) DC. & + & - & Árvore & 8 & $40 \mathrm{~m}$ \\
\hline
\end{tabular}

\section{Continua...}


Tabela 2. Lista de espécies de ASTERACEAE BERCHT. \& J. PRESL. amostradas nos Módulos RAPELD no Parque Estadual do Rio Preto (PERP) e Parque Nacional das Sempre-vivas (PNSV) no Planalto de Diamantina, Minas Gerais. (+) indica as espécies que foram amostradas, (-) indica as espécies que não foram amostradas dentro da área protegida. "Hábito 1" foi uma primeira separação das espécies quanto a forma de vida e "Hábito 2" é uma segunda separação, mais específica, das formas de vida (Figura 4). "Faixa de amostra" corresponde a área de amostragem estabelecida para a espécie dentro das unidades amostrais.

\begin{tabular}{|c|c|c|c|c|c|}
\hline \multirow{2}{*}{ ASTERACEAE Bercht. \& J. Presl. } & \multicolumn{2}{|c|}{ Amostrada } & \multirow{2}{*}{ - Hábito 1} & \multirow{2}{*}{ Hábito 2} & \multirow{2}{*}{ Faixa de amostra } \\
\hline & PERP & PNSV & & & \\
\hline 97 NI sp.1 & + & - & Arbusto & 3 & $8 \mathrm{~m}$ \\
\hline 98 NI sp.2 & + & - & Erva & 1 & $2 \mathrm{~m}$ \\
\hline 99 NI sp.3 & + & - & Arbusto & 3 & $8 \mathrm{~m}$ \\
\hline 100 NI sp.4 & + & - & Erva & 1 & $2 \mathrm{~m}$ \\
\hline 101 NI sp.5 & + & - & Arbusto & 3 & $8 \mathrm{~m}$ \\
\hline 102 NI sp.6 & + & - & Erva & 1 & $2 \mathrm{~m}$ \\
\hline 103 NI sp.7 & + & - & Arbusto & 3 & $8 \mathrm{~m}$ \\
\hline 104 NI sp. 8 & + & - & Arbusto & 5 & $8 \mathrm{~m}$ \\
\hline 105 NI sp.9 & + & - & Arbusto & 5 & $8 \mathrm{~m}$ \\
\hline 106 NI sp. 10 & + & - & Arbusto & 3 & $8 \mathrm{~m}$ \\
\hline 107 Paralychnophora cf bicolor (DC.) MacLeish & - & + & Arvoreta & 7 & $40 \mathrm{~m}$ \\
\hline 108 Piptolepis cf campestris Semir \& Loeuille & - & + & Arbusto & 5 & $8 \mathrm{~m}$ \\
\hline 109 Piptolepis sp. 1 & + & - & Arbusto & 5 & $8 \mathrm{~m}$ \\
\hline 110 Porophyllum angustissimum Gardner & + & + & Erva & 2 & $2 \mathrm{~m}$ \\
\hline 111 Proteopsis argentea Mart. \& Zucc. ex Sch.Bip. & + & - & Arbusto & 4 & $40 \mathrm{~m}$ \\
\hline 112 Pseudobrickellia angustissima (Spreng. ex Baker) R.M.King \& H.Rob. & + & + & Arbusto & 7 & $40 \mathrm{~m}$ \\
\hline 113 Pseudobrickellia brasiliensis (Spreng.) R.M.King \& H.Rob. & + & + & Arbusto & 5 & $8 \mathrm{~m}$ \\
\hline 114 Richterago amplexifolia (Gardner) Kuntze & + & - & Arbusto & 3 & $2 \mathrm{~m}$ \\
\hline 115 Richterago arenaria (Baker) Roque & + & - & Erva & 1 & $2 \mathrm{~m}$ \\
\hline 116 Richterago campestris Roque \& J.N.Nakaj. & - & + & Erva & 1 & $2 \mathrm{~m}$ \\
\hline 117 Richterago elegans Roque & + & + & Erva & 1 & $2 \mathrm{~m}$ \\
\hline 118 Richterago polyphylla (Baker ex Baker) Ferreyra & + & - & Arbusto & 3 & $2 \mathrm{~m}$ \\
\hline 119 Senecio sp. 1 & + & - & Arbusto & 5 & $8 \mathrm{~m}$ \\
\hline 120 Stenocephallum megapotamicum (Spreng.) Sch.Bip. & + & - & Erva & 1 & $2 \mathrm{~m}$ \\
\hline 121 Symphyopappus cf brasiliensis (Gardner) R.M.King \& H.Rob. & + & - & Arbusto & 5 & $8 \mathrm{~m}$ \\
\hline 122 Symphyopappus decussatus Turcz. & + & + & Arbusto & 5 & $8 \mathrm{~m}$ \\
\hline 123 Trichogonia hirtiflora (DC.) Sch.Bip. ex Baker & + & - & Arbusto & 5 & $8 \mathrm{~m}$ \\
\hline 124 Trichogonia villosa (Spreng.) Sch.Bip. ex Baker & + & + & Arbusto & 5 & $8 \mathrm{~m}$ \\
\hline 125 Trixis ef glutinosa D.Don & + & - & Erva & 2 & $2 \mathrm{~m}$ \\
\hline 126 Trixis nobilis (Vell.) Katinas & - & + & Arbusto & 3 & $8 \mathrm{~m}$ \\
\hline 127 Trixis vauthieri DC. & + & + & Arbusto & 5 & $8 \mathrm{~m}$ \\
\hline 128 Vernonanthura laxa (Gardner) H.Rob. & + & + & Arbusto & 3 & $8 \mathrm{~m}$ \\
\hline 129 Vernonanthura westiniana (Less.) H.Rob. & + & + & Arbusto & 5 & $8 \mathrm{~m}$ \\
\hline 130 Wundelichia mirabilis Riedel ex Baker & + & - & Árvore & 8 & $40 \mathrm{~m}$ \\
\hline
\end{tabular}

A abundância e composição dos gêneros entre os módulos foram bastante diferenciadas, principalmente PERP II dos demais módulos (Figura 6). Os gêneros com maior número de indivíduos no PERP I e PNSV I foram Eremanthus (46,3\% e 34,6\%, respectivamente) seguido por Lychnophora (16,4\% e 27,8\%, respectivamente), sendo que estes dois gêneros representam mais de 50\% dentre todos os indivíduos amostrados. No PERP II o gênero mais abundante foi Richterago (20,4\%) seguido de Trichogonia (11,5\%), Baccharis (10, 3\%) e Eremanthus $(9,6 \%)$ os quais somam mais de $50 \%$ da abundância de indivíduos entre os gêneros amostrados. 
PERP I

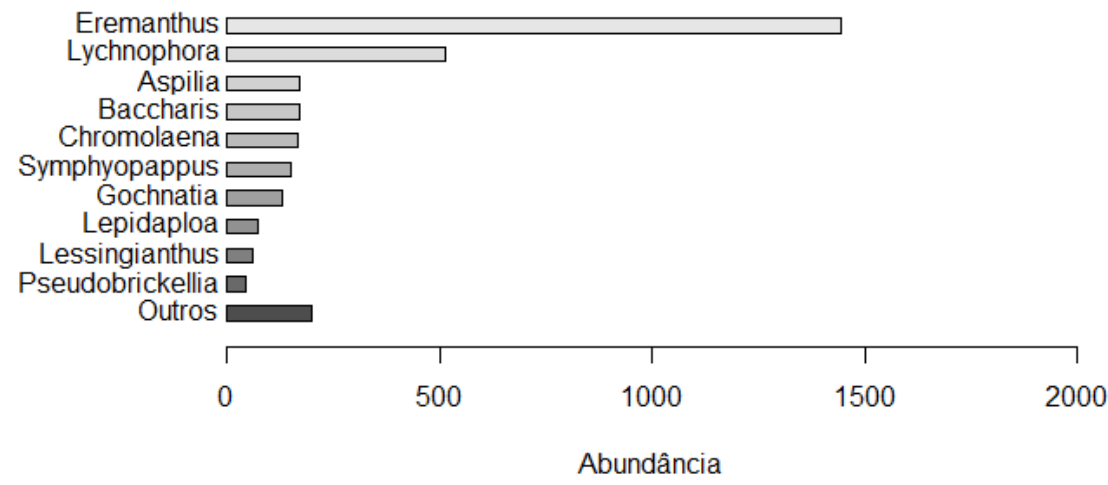

PERP II

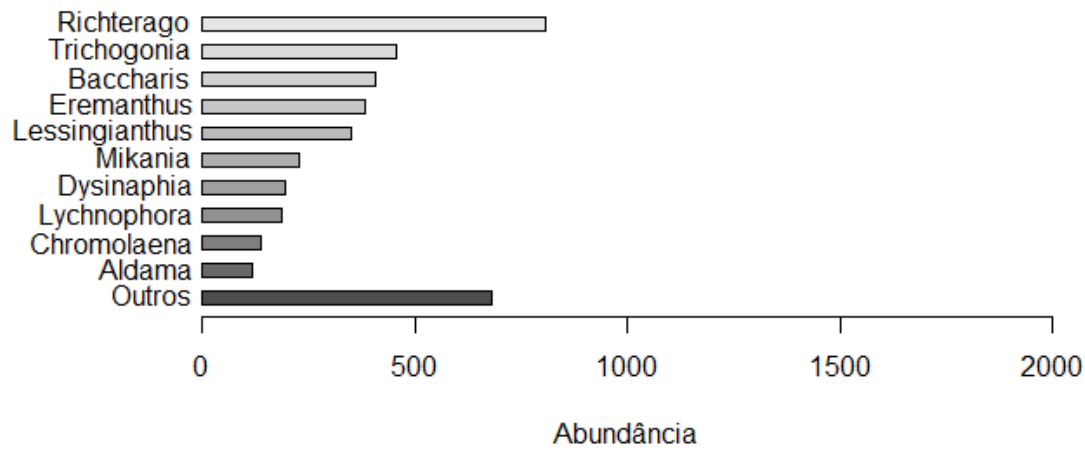

PNSV I

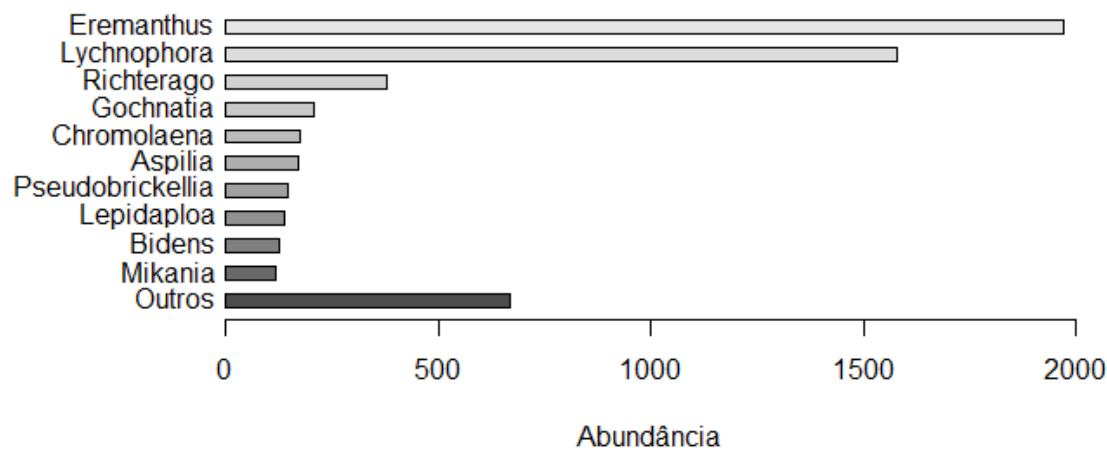

Figura 6. Representação dos dez gêneros mais abundantes dentro de cada módulo. PERP I e PERP II localizados no Parque Estadual do Rio Preto e PNSV I localizado no Parque Nacional das Sempre-vivas, ambos situados no Planalto de Diamantina, Serra do Espinhaço, Minas Gerais.

A nível de espécie também ocorreu variações da composição entre os módulos (Figura 7). Os módulos PERP I e PNSV I apesar de apresentarem os mesmos gêneros como os mais abundantes não prossegue para as espécies contidas dentro destes gêneros. No PERP I Eremanthus incanus $(35,4 \%)$ e Lychnophora passerina (16,5\%) representam os gêneros citados, como também são as espécies mais abundantes, representando mais de 50\% entre todos os indivíduos amostrados. Em contrapartida, no PNSV I as espécies contidas nos gêneros citados foram Eremanthus elaeagnus (31\%) e Lychnophora villosissima $(27,7 \%)$ que também somaram 
mais de 50\% da abundância dos indivíduos amostrados no módulo. Já no PERP II, este quadro muda muito, há número bem maior de espécies dentre os gêneros mais abundantes. As espécies que representaram mais que $50 \%$ dos indivíduos amostrados foram Trichogonia villosa $(11,1 \%)$, Richterago amplexifólia (9,2\%), Eremanthus elaeagnus (5,7\%), Disynaphia praefcta (5\%), Richterago polyphylla (4,8\%), Lychnophora tomentosa (4,7\%), Richterago elegans $(3,7 \%)$, Eremanthus incanus (3,4\%), Lessingianthus psilophyllus $(3,1 \%)$.

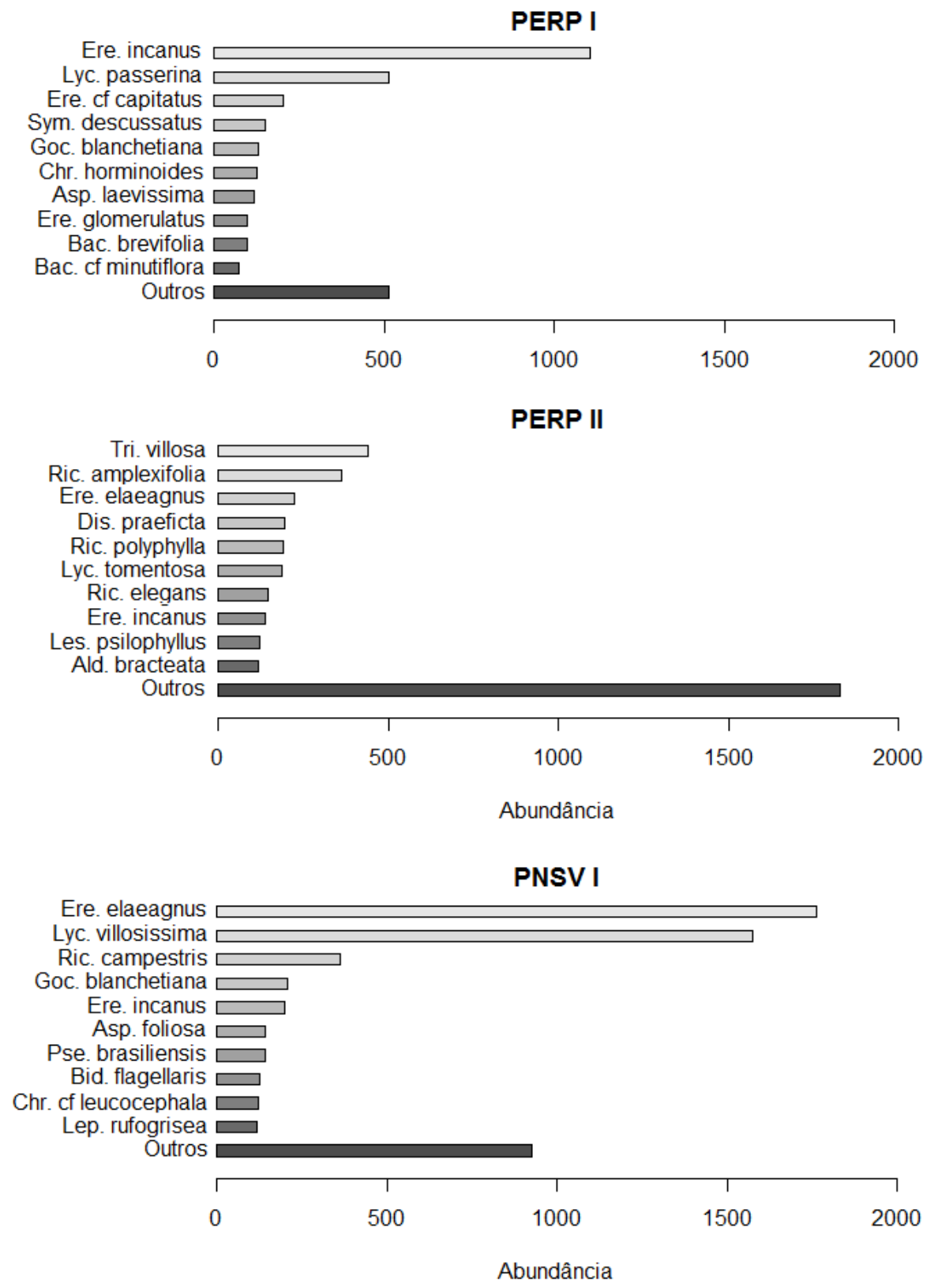

Figura 7. Representação das 10 espécies mais abundantes nos módulos PERP I e PERP II no Parque Estadual do Rio Preto e PNSV I no Parque Nacional das Sempre-vivas, situados no Planalto de Diamantina, Serra do Espinhaço, Minas Gerais. 


\subsubsection{FISIONOMIAS VEGETACIONAIS}

Nos módulos PERP I e PNSV I ocorrem tipos de Cerrado no sentido amplo, onde a profundidade do substrato geralmente é maior e com considerável teor de argila vermelha e/ou amarela, podendo as vezes haver substratos geralmente rasos e pedregosos também, porém com menor frequência, afloramentos rochosos quase não ocorrem.

Ambientes rupestres e campestres de altitude também estão presentes nos módulos PERP I, PERP II e PNSV I, com afloramentos rochosos frequentes, solos geralmente muito arenosos e pedregosos e pouca argila.

Ambientes hidromórficos, como os campos brejosos de solo geralmente rico em matéria orgânica foi amostrado apenas em uma unidade amostral (RP1P4) no módulo PERP I.

O módulo PERP II é em grande parte constituído por formações campestres e rupestres como descrito acima, sendo que as formações de Cerrado constituídas por elementos arbóreos são pouco frequentes, e quando presentes, se resumem a pequenas áreas descontínuas.

Outro tipo de ambiente que compôs algumas das unidades amostrais e que apresenta diferenciação abrupta do ambiente e da composição florística são os canais de escoamento pluvial. Estes cortam algumas das unidades amostrais transversalmente havendo contribuição no incremento da riqueza de espécies para as áreas com esta característica.

Como forma de retratar a heterogeneidade foi realizado um detalhamento dos ambientes e substratos que compuseram as unidades amostrais e que foram percebidos ao longo da trilha de 250 metros no centro de cada unidade (Tabela 3 ). 
Tabela 3. Caracterização ambiental das unidades amostrais (RAPELD) localizadas no Planalto de Diamantina, Minas Gerais: Parque Estadual do Rio Preto e Parque Nacional das Sempre-vivas. São descrições visuais da composição existente com base no trabalho de Zappi et al. (2014) para o setor noroeste da Serra do Cipó. (UA) unidades amostrais; e (N) riqueza de espécies.

\begin{tabular}{|c|c|c|c|c|c|c|c|c|c|c|c|}
\hline UA & $\mathrm{N}$ & Campo Brejoso & $\begin{array}{l}\text { Rego D'água } \\
\end{array}$ & $\begin{array}{l}\text { Canal Pluvial } \\
\end{array}$ & Cerrado Rupestre & Campo Arenoso & Campo Pedregoso & $\begin{array}{l}\text { Af. Rocha Cristalina } \\
\end{array}$ & $\begin{array}{ll}\text { Campo Sujo } \\
\end{array}$ & $\begin{array}{l}\text { Cerrado Típico } \\
\end{array}$ & Cerradão de Encosta \\
\hline RP1P2 & 14 & & & & & & $\begin{array}{l}\text { Cascalhos de quartzito } \\
\text { em solo arenoso }\end{array}$ & & & $\begin{array}{l}\text { Arenoso com pouco } \\
\text { cascalho e notável teor } \\
\text { de argila amarela }\end{array}$ & \\
\hline RPIP3 & 23 & & & & $\begin{array}{l}\text { Afloramentos e } \\
\text { cascallos de quartzito }\end{array}$ & & & & & $\begin{array}{l}\text { Arenoso com muito } \\
\text { cascalho notável teor } \\
\text { de argila amarela, } \\
\text { afloramentos isolados }\end{array}$ & \\
\hline RPIP4 & 5 & $\begin{array}{l}\text { Arenoso com alto teor } \\
\text { de matéria orgânica, } \\
\text { com lageados } \\
\text { aflorados }\end{array}$ & & & & & & & & & \\
\hline RPIP6 & 21 & & & & & & & & & $\begin{array}{l}\text { Arenoso com muito } \\
\text { cascalho notável teor } \\
\text { de argila vermellha, } \\
\text { afloramentos isolados }\end{array}$ & \\
\hline RPIP7 & 10 & & & & $\begin{array}{l}\text { Afloramentos e } \\
\text { cascallhos de quartzito }\end{array}$ & & & & & $\begin{array}{l}\text { Arenoso com notável } \\
\text { teor de argila amarela, } \\
\text { afloramentos isolados }\end{array}$ & \\
\hline RPIP9 & 21 & & & & $\begin{array}{c}\text { Afloramentos, com } \\
\text { muitos cascallhos de } \\
\text { quartzito em meio areia er } \\
\text { branca } \\
\end{array}$ & $\begin{array}{l}\text { Poucos afforamentos } \\
\text { em meio a areia branca }\end{array}$ & & $\begin{array}{l}\text { Aflorado em meio ao } \\
\text { campo arenoso }\end{array}$ & & & $\begin{array}{l}\text { Afloramentos, arenoso } \\
\text { e pedregoso, aparente } \\
\text { teor de argila amarela }\end{array}$ \\
\hline RPIP10 & 31 & & & $\begin{array}{l}\text { Canal sob solo } \\
\text { arenoso e pedregoso } \\
\text { com considervel teor } \\
\text { de argila vermelha }\end{array}$ & & & $\begin{array}{l}\text { Cascallhos de quartzito } \\
\text { em solo arenoso com } \\
\text { aparente teor dea argila } \\
\text { amarela }\end{array}$ & & & $\begin{array}{l}\text { Arenoso com notável } \\
\text { teor de argila amarela }\end{array}$ & $\begin{array}{l}\text { Afloramentos, arenoso } \\
\text { e pedregoso, aparente } \\
\text { teor de argila amarela }\end{array}$ \\
\hline RP2P1 & 25 & & & & $\begin{array}{l}\text { Afloramentos e } \\
\text { cascalhos de quartzito } \\
\text { em solo com aparente } \\
\text { teor de argila anarela }\end{array}$ & & $\begin{array}{l}\text { Cascalhos de quartzito } \\
\text { em solo arenoso com } \\
\text { aparente teor de argila } \\
\text { amarela }\end{array}$ & $\begin{array}{l}\text { Aflorado em meio ao } \\
\text { campo pedregoso }\end{array}$ & & & \\
\hline RP2P2 & 27 & & & & & $\begin{array}{l}\text { Afloramentos e } \\
\text { lageados em meio a } \\
\text { areia branca }\end{array}$ & $\begin{array}{l}\text { Cascallhos de quartzito } \\
\text { em solo arenoso }\end{array}$ & & $\begin{array}{l}\text { Arenoso com poucos } \\
\text { cascalhos e notável } \\
\text { teor de argika amareh }\end{array}$ & $\begin{array}{l}\text { Arenoso com notável } \\
\text { teor de argila amarela, } \\
\text { afloramentos isolados }\end{array}$ & \\
\hline RP2P3 & 29 & & & & & & & & $\begin{array}{c}\text { Mutito Cascallho em } \\
\text { solo arenoso com } \\
\text { notável teor de argiha } \\
\text { amarela }\end{array}$ & & \\
\hline RP2P4 & 39 & & & $\begin{array}{l}\text { Canal intermitente, sob } \\
\text { afloramento e cascalho } \\
\text { de quartzito }\end{array}$ & & & $\begin{array}{l}\text { Cascallhos de quartzito } \\
\text { em solo arenoso }\end{array}$ & $\begin{array}{l}\text { Aflorado em meio ao } \\
\text { campo pedregoso }\end{array}$ & $\begin{array}{l}\text { Arenoso com notável } \\
\text { teor de argikh amarela }\end{array}$ & & \\
\hline RP2P5 & 32 & & & & & & $\begin{array}{l}\text { Cascallhos de quartzito } \\
\text { em solo arenoso com } \\
\text { aparente teor de argila } \\
\text { amarela }\end{array}$ & & $\begin{array}{l}\text { Arenoso com notável } \\
\text { teor de argila amarela }\end{array}$ & & \\
\hline RP2P9 & 34 & & $\begin{array}{l}\text { Canal perene, ora sob } \\
\text { afloramento ora em } \\
\text { campo arenoso com } \\
\text { elevado teor de } \\
\text { matéria orgânica }\end{array}$ & & & $\begin{array}{l}\text { Areia branca de } \\
\text { quartzito }\end{array}$ & $\begin{array}{l}\text { Cascallhos de quartzito } \\
\text { em solo arenoso }\end{array}$ & $\begin{array}{l}\text { Aflorado em meio ao } \\
\text { campo pedregoso }\end{array}$ & & & \\
\hline RP2P10 & 27 & & & & & $\begin{array}{l}\text { Areia branca de } \\
\text { quartzito }\end{array}$ & $\begin{array}{l}\text { Cascallos de quartzito } \\
\text { em solo arenoso }\end{array}$ & $\begin{array}{l}\text { Afloramentos isolados } \\
\text { em meio ao campo } \\
\text { arenoso e pedregoso }\end{array}$ & & & \\
\hline SVIP1 & 14 & & & & & & & & $\begin{array}{l}\text { Arenoso com notável } \\
\text { teor de argila amarela }\end{array}$ & & \\
\hline SVIP2 & 21 & & & & $\begin{array}{c}\text { Afloramentos, com } \\
\text { muitos cascalhos de } \\
\text { quartzito em meio areia } \\
\text { branca } \\
\end{array}$ & & $\begin{array}{l}\text { Cascallhos de quartzito } \\
\text { em solo arenoso }\end{array}$ & $\begin{array}{l}\text { Aflorado em meio ao } \\
\text { campo pedregoso }\end{array}$ & $\begin{array}{l}\text { Arenoso com notável } \\
\text { teor de argila amarela }\end{array}$ & & \\
\hline SVIP3 & 22 & & & & & & $\begin{array}{c}\text { Solo contituído } \\
\text { basicamente por canga }\end{array}$ & & $\begin{array}{l}\text { Arenoso com notável } \\
\text { teor de argika amarela }\end{array}$ & & \\
\hline SVIP4 & 21 & & & & $\begin{array}{c}\text { Afloramentos, com } \\
\text { muitos cascalhos de } \\
\text { quartzito em meio areia } \\
\text { branca }\end{array}$ & & & & $\begin{array}{l}\text { Arenoso com notável } \\
\text { teor de argika amarela }\end{array}$ & & \\
\hline SVIP7 & 19 & & & $\begin{array}{l}\text { Canal intermitente, sob } \\
\text { afloramento }\end{array}$ & $\begin{array}{l}\text { Muitos affloramentos } \\
\text { com acúmulo de areia } \\
\text { e matéria orgânica nas } \\
\text { frestas das rochas }\end{array}$ & & & & & $\begin{array}{l}\text { Arenoso com notável } \\
\text { teor de argila amarela, } \\
\text { afloramentos isolados }\end{array}$ & \\
\hline SVIP8 & 21 & & & $\begin{array}{l}\text { Canal intermitente, } \\
\text { arenoso com pouco } \\
\text { cascalho e } \\
\text { considerável teor de } \\
\text { matéria orgânica }\end{array}$ & & $\begin{array}{l}\text { Afloramentos e areia } \\
\text { branca de quartzito }\end{array}$ & & & & $\begin{array}{l}\text { Arenoso com notável } \\
\text { teor de argila amarela }\end{array}$ & \\
\hline SVIP10 & 22 & & & $\begin{array}{l}\text { Canal intermitente, } \\
\text { arenoso com muito } \\
\text { cascalho e aparente } \\
\text { teor de argila amarela }\end{array}$ & & & $\begin{array}{l}\text { Cascallhos de quartzito } \\
\text { em solo arenoso com } \\
\text { aparente teor de argila } \\
\text { amarela }\end{array}$ & & $\begin{array}{l}\text { Afloramentos e } \\
\text { cascalho com notável } \\
\text { teor de argika amarela }\end{array}$ & & \\
\hline
\end{tabular}




\subsubsection{DIVERSIDADE}

A diversidade baseada no Índice de Shannon e na rarefação pelo número de indivíduos (Figura 8) foi mais elevada para o módulo PERP II $\left(\mathrm{H}^{\prime}=3,78\right)$, enquanto PERP I e PNSV I apresentam valores abaixo e próximo entre eles, 3,19 e 3,14, respectivamente.

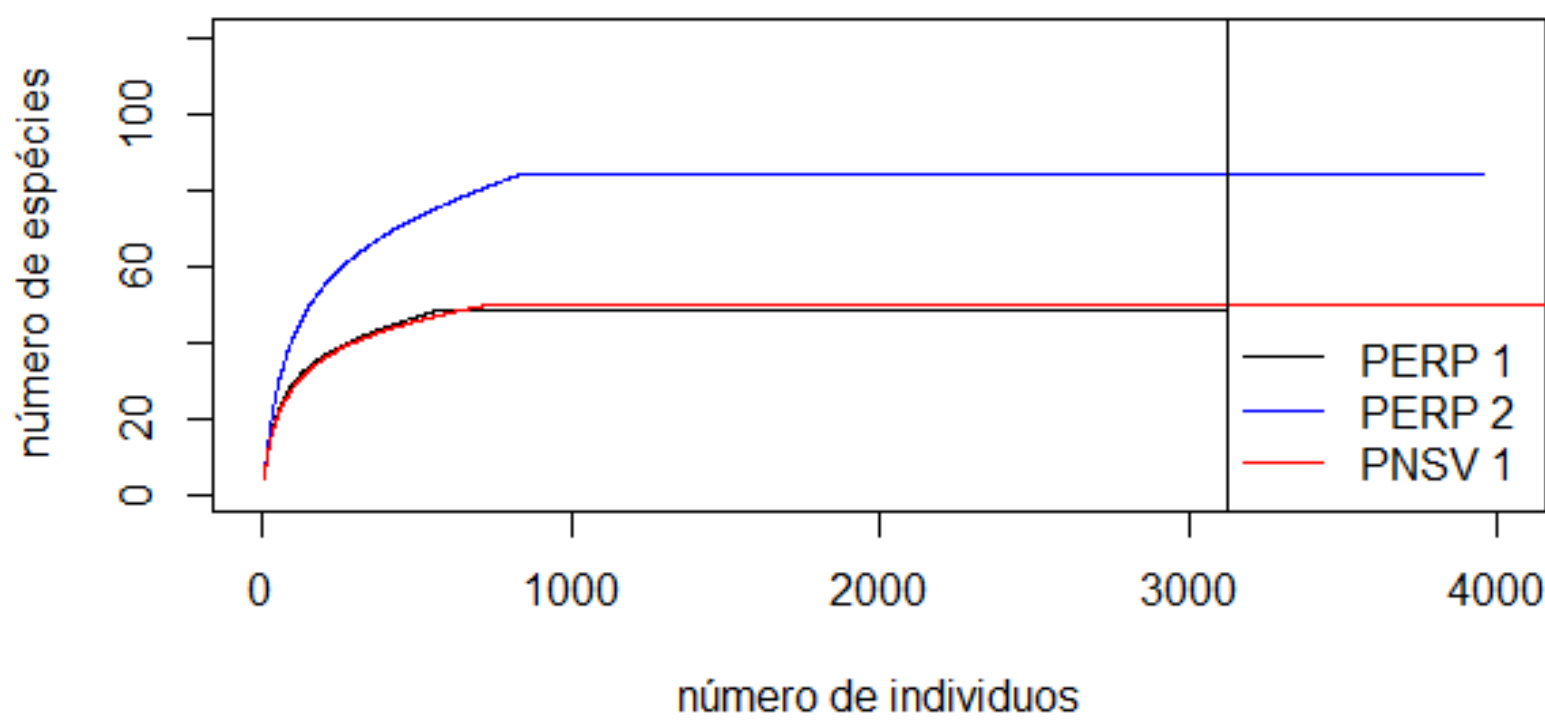

Figura 8: Curva de rarefação baseado no número de indivíduos. PERP I e PERP II localizados no Parque Estadual do Rio Preto e PNSV I localizado no Parque Nacional das Sempre-vivas, ambos situados no Planalto de Diamantina, Serra do Espinhaço, Minas Gerais.

As rarefações para as unidades amostrais no PERP II apresentaram uniformidade de suas unidades tanto na riqueza de espécies como na abundância dos indivíduos (Figura 9). O PERP I não apresenta uniformidade para a riqueza de espécies e nem abundância de indivíduos, se mostrando muito heterogêneo no número de espécies e número de indivíduos entre suas unidades, enquanto PNSV I apresentou uniformidade apenas para a riqueza de espécies. 


\section{Rarefação PERP I}

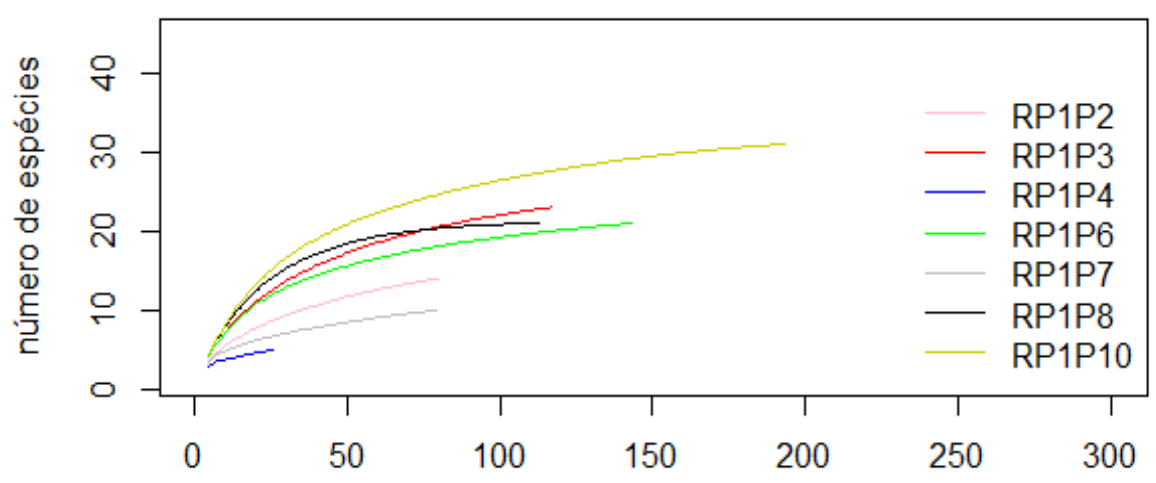

Frequência dos individuos

\section{Rarefação PERP II}

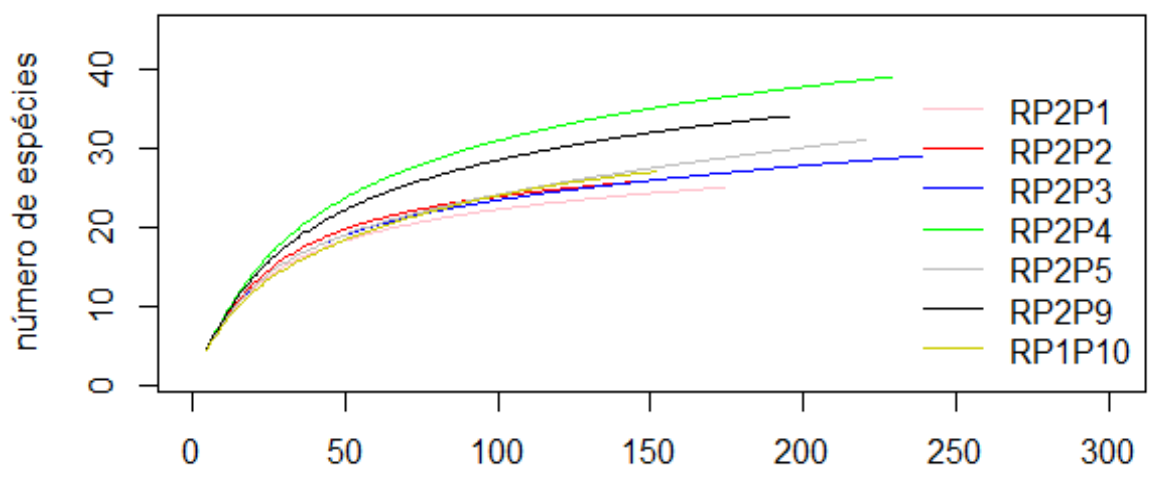

Frequência dos individuos

\section{Rarefação PNSV I}

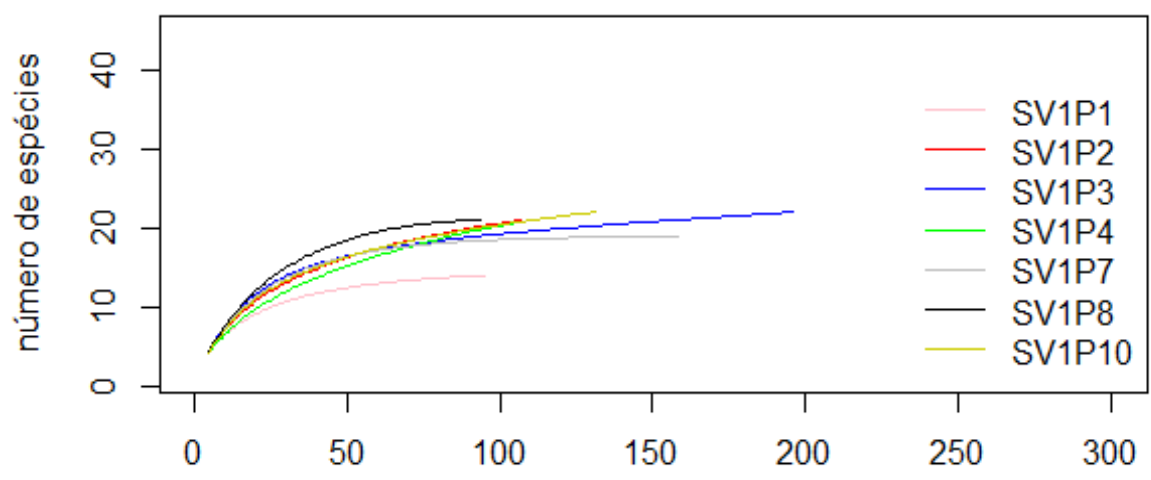

Frequência dos individuos

Figura 9. Comparação da riqueza entre as unidades amostrais dentro de cada módulo por meio da curva de rarefação baseado na frequência das espécies nos seguimentos em cada unidade amostral. PERP I e PERP II localizados no Parque Estadual do Rio Preto e PNSV I localizado no Parque Nacional das Sempre-Vivas, situados no Planalto de Diamantina, Serra do Espinhaço, Minas Gerais. A legenda para as unidades amostrais deve ser entendida como nos exemplos a seguir: RP1P2 - RP1: Módulo I do Parque Estadual do Rio Preto (PERP I); e P2: parcela 2. RP2P1 - RP2: Módulo II do Parque Estadual do Rio Preto (PERP II); e P1: parcela 1. SV1P1 - SV1: Módulo I do Parque Nacional das Sempre-Vivas; P1: parcela 1. 


\subsubsection{PERFIS DE DIVERSIDADE}

O perfil de diversidade para os módulos mostrou que o PERP II é mais diverso que os demais módulos, porém não é possível dizer entre PERP I e PNSV I qual é mais (Figura 10).

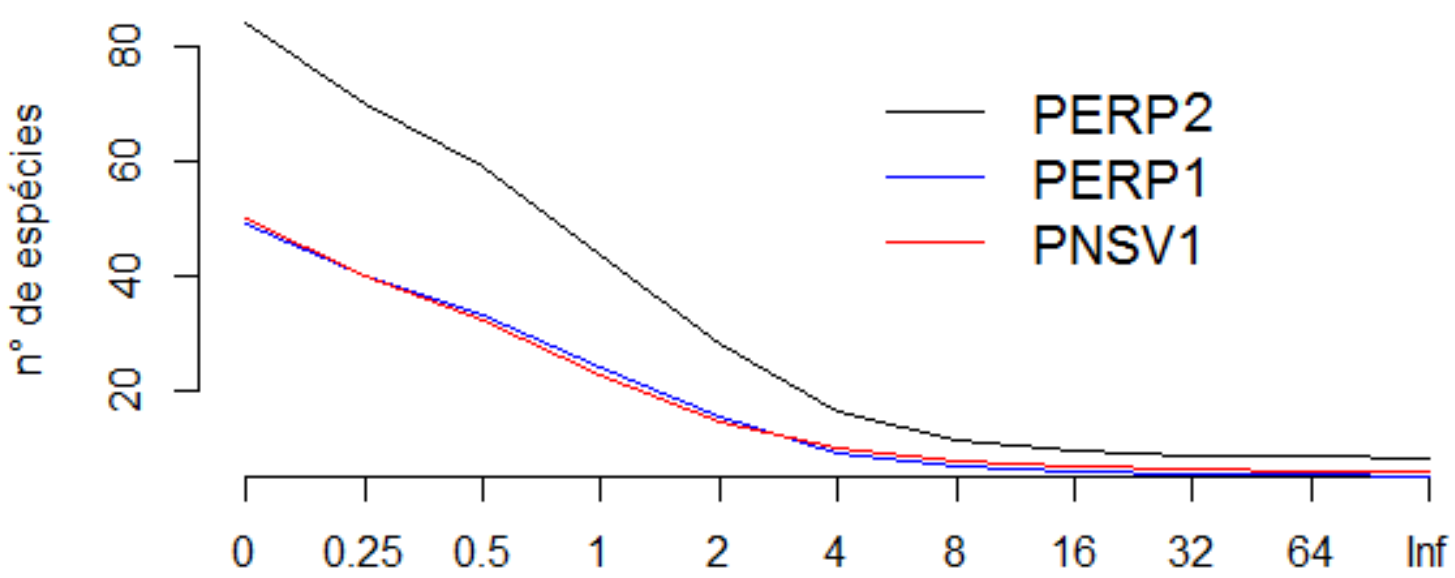

a

Figura 10. Perfis de diversidade para cada módulo. PERP 1 e PERP 2 localizados no Parque Estadual do Rio Preto e PNSV 1 localizado no Parque Nacional das Sempre-Vivas, ambos situados no Planalto de Diamantina, Serra do Espinhaço, Minas Gerais.

\subsubsection{COMPOSIÇÃO DAS FORMAS DE VIDA}

Os módulos PERP I e PNSV I, caracterizados por configurar variantes dos ambientes rupestres como também de Cerrado no sentido amplo, apresentaram estrutura constituída por maior abundância de elementos arbóreos, sendo que estes módulos estão compreendidos em altitudes menos elevadas em relação ao módulo PERP II. Por outro lado, o módulo PERP II apresentou estrutura mais abundante de elementos arbustivos, seguido pelos elementos herbáceos (Figura 11).

Os módulos PERP I e PNSV I apresentaram maior abundância de elementos arbóreos dentre as formas de vida (46,5\% e 34,7\%, respectivamente), sendo que no PERP II os elementos arbóreos foram os menos abundantes, apenas 9,7\%. Por outro lado, PERP II apresentou maior abundância nas formas de vida herbáceas e arbustivas, enquanto que as arbóreas, os indivíduos são pouco numerosos (Figura 11).

As espécies mais abundantes no PNSV I são atribuídas aos hábitos arborescentes, mas que também é bem representada pelas classes arbustivas e consideravelmente pelas herbáceas. $\mathrm{O}$ PERP II apresenta composição bastante distinta dos demais módulos, havendo uma predominância no número de indivíduos arbustivos e herbáceos, com exceção da unidade amostral RP2P1 que apresenta certa semelhança com os módulos PNSV I. 
As unidades amostrais do módulo PERP I, com exceção de RP1P4, apresenta estrutura dos estratos vegetativos semelhantes a um Cerrado no sentido amplo entremeado por formações rupestres. São formações constituídas em grande parte por elementos arbóreos e arbustivos, porém com equilibrada ocorrência de herbáceas. Dentro dos componentes arbóreos, o gênero Eremanthus foi muito representativo, com atenção para Eremanthus incanus que está presente em todas as unidades amostrais. Eremanthus capitatus também foi bem representado entre as arbóreas, não aparecendo apenas na unidade amostral RP1P7, ainda que 94\% dos indivíduos foram amostrados na unidade amostral RP1P6.

Nas unidades amostrais do PERP II houve maior abundância de espécies herbáceas e arbustivas, com exceção da RP2P1 que apresentou considerável abundância de indivíduos arbóreos, caracterizando ambientes rupestres até campos de altitude com afloramentos isolados. Os gêneros Richterago (809 indivíduos), Trichogonia (456) e Baccharis (409) foram os mais abundantes e representaram quase $50 \%$ de todos os indivíduos amostrados. O gênero Richterago exclusivamente representado por espécies herbáceas, o que demonstra quão importante são estes ambientes para estas formas de vida. Eremanthus erythropappus (382) foi a quarta espécie mais abundante, sendo que grande parte foi amostrada em uma unidade amostral (RP2P1), onde quase $50 \%$ das espécies amostradas pertencem ao hábito arbóreo. Dentre as espécies que representaram mais de $50 \%$ dos indivíduos amostrados estão Trichogonia villosa (438), Richterago amplexifolia (364), Eremanthus elaeagnus (225), Disynaphia praeficta (196), Richterago polyphylla (191), Lychnophora tomentosa (186), Richterago elegans (147), Eremanthus incanus (137) e Lessingianthus psilophyllus (122).

No Parque Nacional das Sempre-Vivas os elementos arbóreos e arvoretóides apresentavam elevada representatividade, porém há também grande número de espécies arbustivas e considerável número de herbáceas. Mais de $50 \%$ do número de indivíduos amostrados pertencem aos gêneros Eremanthus (1.972) e Lychnophora (1.579) pertencentes às formas de vida arbórea e arvoretóide, respectivamente. Entre os gêneros dominantes as espécies Eremanthus elaeagnus (1.763) e Lychnophora vilosissima (1.575) foram extremamente dominantes, caracterizando fisionomias com muitos elementos arbóreos. 


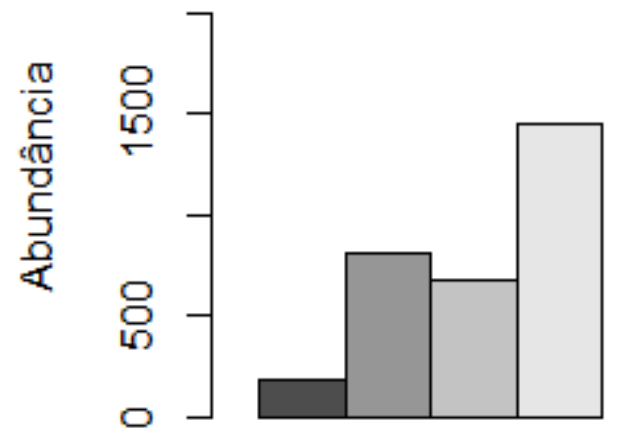

PERP I

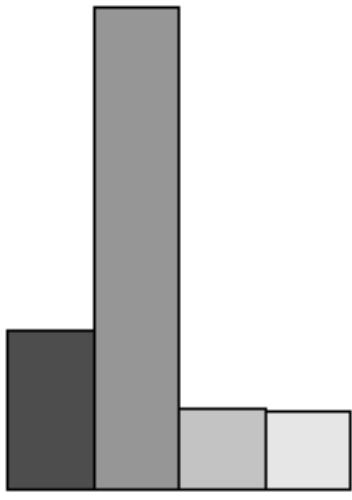

PERP ॥

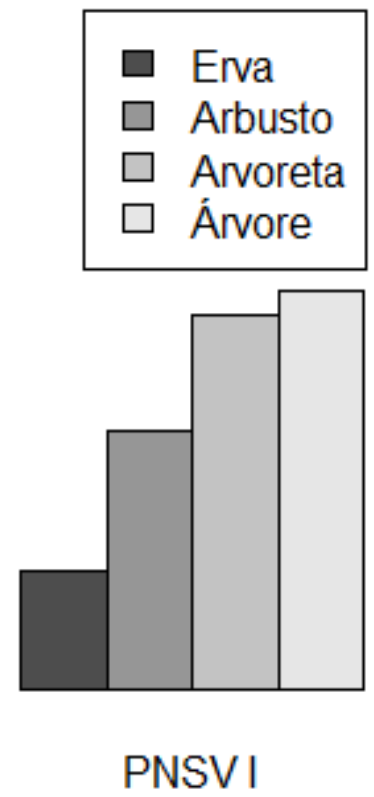

Figura 11. Gráfico de barras representando a abundância das formas de vida entre os módulos em áreas protegidas. PERP I e PERP II localizados no Parque Estadual do Rio Preto e PNSV I localizado no Parque Nacional das Sempre-Vivas, situados no Planalto de Diamantina, Serra do Espinhaço, Minas Gerais.

\subsection{DISCUSSÃO}

\subsubsection{COMPOSIÇÃO E DIVERSIDADE}

O número de espécies encontradas no levantamento florísticos na região do Planalto de Diamantina foi elevado (195) e que também foi elevado na Serra da Canastra, ambiente similar, com 215 espécies de Asteraceae (Nakajima e Semir, 2001). O elevado número de espécies aponta a importância da família Asteraceae nestes ambientes

Estudos florísticos em ambientes rupestres sobre quartzito no quadrilátero ferrífero em Minas Gerais, constataram que Asteraceae é a segunda família mais diversa em número de espécies (26 espécies) (Messias, 2011). Dentre as espécies mais importantes que aparecem sobre ambientes quartzíticos estão Eremanthus erythropappus e Eremanthus incanus (Messias, 2011), que no presente estudo também tiveram grande relevância pela abundância, exceto nos ambientes de maior altitude, onde a frequência de espécies arbóreas diminui muito. Messias (2011) registrou também elevado número de indivíduos da espécie Eremanthus crotonoides para região do quadrilátero ferrífero, porém no Planalto de Diamantina a espécie foi registrada apenas no PNSV e ainda com baixa frequência e em pequenas populações.

No presente estudo o gênero Baccharis foi o gênero mais rico em número de espécies (19). As espécies de Baccharis quando presentes, geralmente são muito abundantes nas mais diferentes formas de vida, desde arbustos rasteiros (Baccharis aphylla) até mesmo arbusto 
arborescentes (Baccharis retusa). Borges \& Forzza (2008) estudavam a tribo Asterae no Parque Estadual de Ibitipoca em Minas Gerais, e encontraram 20 espécies, sendo 17 delas pertencentes ao gênero Baccharis

Estudos em dois locais da Chapada Diamantina com delimitação de hábitats em ambientes rupestres, apontou a família Asteraceae como a segunda maior com 13 espécies (Conceição e Pirani, 2005). Sendo que em algumas das subunidades amostradas a família Asteraceae foi a mais abundante (Conceição e Pirani, 2005). Das 13 espécies apenas duas são comuns entre a Chapada Diamantina e as áreas protegidas no Planalto de Diamantina, são elas: Lychnophora triflora e Paralychnophora bicolor. Destas duas apenas P. bicolor foi contemplada pela amostragem em ambas as áreas protegidas do Planalto de Diamantina, porém são populações pequenas e extremamente restritas aos locais de afloramento, crescendo entre as frestas de rocha. Já L. triflora foi encontrada apenas no PNSV em uma população muito pequena e restrita ao ambiente de afloramentos em meio aos campos pedregosos, lembrando que a espécies não foi contemplada pela amostragem. Conceição e Pirani (2005) ao delimitar os habitas em ambientes rupestres na Chapada Diamantina, também perceberam que a diversidade da família não se limita apenas a alguns dos ambientes delimitados, a diversidade é consideravelmente contínua, entretanto com mudanças expressivas na composição das espécies.

No Parque Nacional das Sempre-Vivas foram amostradas 50 espécies de Asteraceae para este estudo. Mello (2012) em estudos com comunidades herbáceo-arbustivas no Parque Nacional das Sempre-vivas encontrou 26 espécies de Asteraceae, sendo que a família foi a quinta mais rica em número de espécies. Entre os estudos apareceram espécies incomuns, o que demonstra deficiências no registro de espécies que pode ser ainda mais elevado.

\subsubsection{ESPÉCIES ENDEMICAS E AMEAÇADAS}

Várias espécies para os gêneros Lychnophora, Richterago e Vernonia sensu lato foram encontradas neste trabalho, são apontados como fortemente ameaçados de extinção e por isso devem ser priorizados em estudos taxonômicos (Franco, et al. 2014) e ecológicos, pois estas informações são base para o desenvolvimento de ações de conservação e manejo em áreas protegidas. Lychnophora é endêmico de ambiente rupestre (Eiten, 1978) da Serra do Espinhaço nos estados de Minas Gerais e Bahia, como também em ambientes similares nas serras de Goiás (Coile e Jones, 1981). Richterago é endêmico das formações rupestres brasileiras (Sancho e Freire, 2009), sendo o seu centro de diversidade na região do Planalto de Diamantina. 
Neste estudo foi encontrado um número elevado de espécies contidas dentro do gênero Vernonia, que aqui foi tratado pela classificação que subdivide vários gêneros contidos dentro de Vernonia, como os gêneros Lessingianthus, Lepidaploa, Minasia e Vernonanthura. Estudos fitogeográficos tratam a região do Planalto de Diamantina como centro de diversidade e endemismo para o gênero Vernonia (Farias, 2000), corroborando com os resultados encontrados neste estudo.

Das espécies de Minasia identificadas neste estudo estão criticamente ameaçadas de extinção: Minasia alpestris e Minasia scapigera (Martinelli \& Moraes, 2013). O gênero Minasia é endêmico dos campos rupestres da Serra do Espinhaço (Loeuille, 2010) e até então foi registrado apenas no estado de Minas Gerais (Jesus et al., 2009), formado por um pequeno grupo de espécies descritas, seis, sendo que cinco destas foram descritas no Planalto de Diamantina, local considerado centro de diversidade para o gênero (Semir \& Jesus, 2013).

Minasia alpestris é endêmica da região do Planalto de Diamantina, uma espécie rara e dificilmente encontrada (Martinelli \& Moraes, 2013). Esta espécie não foi contemplada na amostragem, muito provavelmente pela especificidade do seu ambiente que não foi englobado dentro das unidades amostrais. $\mathrm{O}$ ambiente no qual se encontra é caracterizado por lajeados rochosos contínuos constituídos por muitas frestas onde acontece o acúmulo de quantidades consideráveis de matéria orgânica e areia proveniente da decomposição das rochas, onde os indivíduos de Minasia alpestris se estabelecem. No Parque Nacional das Sempre-vivas foram encontrados indivíduos que supostamente pertencem a espécie (identificação a confirmar) em três locais diferentes, porém são populações pequenas constituídas por indivíduos jovens notavelmente perturbados pelo fogo. No Parque Estadual do Rio Preto, houve apenas um local de coleta para a espécie, este local está aparentemente protegido, constituído por uma população grande com indivíduos em vários estágios de maturidade.

Vernonia scapigera, tratada aqui como Minasia scapigera é endêmica de Minas Gerais, mais especificamente é encontrada nos municípios de Diamantina, Joaquim Felício e Conselheiro Mata (Rivera, 2006). Foram observadas populações de $M$. scapigera que a apresentavam elevada abundância de indivíduos assim como outras com poucos indivíduos. A espécie foi amostrada apenas dentro do Parque Estadual do Rio Preto em ambientes denominados campos pedregosos (Zappi et al., 2014), colonizados quase que exclusivamente por ervas e arbustos. Tais ambientes com a presença da espécie são vistos com frequência e foram englobados dentro das unidades amostrais. 
Lessingianthus stoechas é uma espécie típica de regiões com elevada altitude e com dois centros de ocorrência bastante restrita na região nordeste do estado de Goiás e no Planalto de Diamantina (Rivera, 2006). Esta espécie foi encontrada apenas no Parque Nacional das Semprevivas em ambiente de campo arenoso (Zappi et al., 2014), porém não foi contemplada pela amostragem.

Grande número de espécies do Gênero Richterago foram registradas por este estudo, todas restritas à Cadeia do Espinhaço. Richterago arenaria registrada na Serra do Cipó e no Planalto de Diamantina, e Richterago polyphylla no Planalto de Diamantina e Serra do Cabral (Franco et al., 2014). Richterago angustifolia foi registrada no Planalto de Diamantina, Serra do Cipó e Serra do Cabral, e Richterago elegans registrada apenas no Planalto de Diamantina (Roque e Pirani, 2001). Todas as espécies citadas acima foram encontradas em algum dos dois parques estudados.

Lychnophora diamantinana se restringe ao Planalto de Diamantina e foi encontrada apenas fora das duas áreas protegidas estudadas (Coile e Jones, 1981). Encontrada em ambientes de campo pedregoso e geralmente divide espaço com outras espécies de Lychnophora, como L. sellowi e L. staavioides. As duas últimas citadas anteriormente também são endêmicas do Planalto de Diamantina (Coile e Jones, 1981), mas apenas L. staavioides foi coletada dentro de uma das áreas protegidas, no Parque Estadual do Rio Preto. Estas três espécies não são vistas com tanta frequência, apesar de suas populações serem bastante abundantes. Lychnophora uniflora mesmo registrada em Minas Gerais e Bahia, a espécie tem distribuição muito restrita dentro de cada estado (Semir, 1991). As populações desta espécie são muito pouco abundantes e não foram vistas dentro das áreas protegidas.

Segundo o Livro Vermelho da flora do Brasil (Martinelli \& Moraes, 2013), várias espécies coletadas para este trabalho estão ameaçadas e incluídas na lista por diversos motivos. As espécies aqui citadas são consideradas táxon "Em Perigo" ou "Vulnerável" por atender critérios dentro de categorias no qual as ameaçam.

Para espécie se enquadrar na categoria "Em Perigo", os critérios são relacionados à redução do tamanho da população, distribuição geográfica, tamanho das populações com menos de 2.500 e se as mesmas apresentam indivíduos maduros capazes de perpetuar, tamanho da população com menos de 250 indivíduos maduros, e por fim, uma análise quantitativa que indique a probabilidade de extinção na natureza em 20 anos ou cinco gerações (Martinelli e Moraes, 2013). Entre as espécies encontradas estão: Disynaphia praeficta, Lepdaploa pseudarea (não consta registros em Minas Gerais, apenas no estado da Bahia), Lychnophora gardinerii*, 
Lychnophora diamantinana*, Lychnophora martiana, Lychnophora pohlii*, Lychnophora reticulata, Lychnophora sellowii*, Lychnophora syncephala, Lychnophora vilosissima, Lychnophoreopsis candelabrum*, Mikania glabra, Mikania glauca, Minasia alpestris, Minasia scapigera, Paralychnophora bicolor, Richterago angustifolia, Richterago polyphylla e Wunderlichia sennaeii. As espécies assinaladas pelo asterisco foram coletadas apenas fora das áreas protegidas.

Para as espécies classificadas como "Vulneráveis" são considerados os critérios de redução da população com base nas áreas de ocupação das espécies assim como distúrbios diretos por perda de habitat e competição externas, a distribuição geográfica, populações estimadas em menos de 10.000 indivíduos reprodutivos, como também populações muito pequenas ou restritas com menos de 1.000 indivíduos maduros, assim como probabilidade de extinção na natureza em menos de 100 anos (Martinelli e Moraes, 2013). Entre as espécies encontradas estão: Baccharis concinna, Bacharis lychnophora, Lessingianthus stoechas, Lychnophora tomentosa, Proteopsis argentea, Richterago arenaria e richterago elegans.

\subsection{CONCLUSÃO}

Uma conclusão importante é a não equivalência entre os ambientes estudados, existe um número muito grande de espécies exclusivas para os ambientes, principalmente para as unidades amostrais localizadas nos ambientes de maior altitude. Portanto, concluímos que existe de fato uma grande heterogeneidade de ambientes e consequentemente variações expressivas na composição, onde a diversidade de Asteraceae foi considera elevada.

Muitas das espécies ameaçadas não estão devidamente incluídas dentro das Unidades de Conservação. Em alguns casos, mesmo que incluídas, são populações pouco representativas. Tal fato demonstra quão minucioso deve ser o planejamento de Unidades de Conservação para que sejam incluídas populações viáveis, principalmente as ameaçadas. 


\section{DISTRIBUIÇÃO DE ESPÉCIES DE ASTERACEAE AO LONGO DE UM GRADIENTE AMBIENTAL RUPESTRE EM DUAS ÁREAS PROTEGIDAS NO PLANALTO DE DIAMANTINA, MINAS GERAIS}

\subsection{INTRODUÇÃO}

Estudos ecológicos em comunidades tropicais foram os primeiros a fundamentar a importância de se entender como os padrões de distribuição das espécies variam em função do ambiente e do espaço geográfico, sendo essenciais no desenvolvimento de estratégias e aplicações no manejo e para conservação (Vormisto et al. 2004; Chave, 2013; Eisenlohr, 2013). $\mathrm{Na}$ Serra do Espinhaço, o elevado número de espécies restritas a determinados ambientes, torna estas áreas únicas e extremamente importantes para a conservação (Rapini et al., 2002; Conceição e Pirani, 2005), sendo necessário detectar os centros de diversidade e de endemismos na região (Ribeiro et al., 2012).

Os padrões florísticos encontrados na Serra do Espinhaço é resultado de uma grande fase de flutuações climáticas e pelo processo de barreiras geográficas que separavam as populações, funcionando como regulações no fluxo gênico (Giulietti \& Pirani, 1988). Tais populações foram se distanciando em nível de espécies, e se tornando muito específicas e dependentes dos seus ambientes de ocorrência, e consequentemente foram moldados padrões de espécies com ampla distribuição, como também aquelas com elevado grau de endemismo (Giulietti \& Pirani, 1988).

Giulietti e Pirani (1988) descreveram padrões de distribuição para algumas famílias importantes na Serra do Espinhaço e identificaram diversos padrões em que as espécies apresentavam ampla distribuição ou eram extremamente restritas a determinados habitat. Estes ambientes apresentam diversidade beta elevada (Rapini et al., 2008), onde os solos predominantemente quartzíticos associados a diversos fatores, principalmente a heterogeneidade da topografia, propiciam a formação de um mosaico de vegetação composto por vários habitats diferenciados prevalecido por muitas espécies endêmicas (Benites et al., 2003; Costa et al., 2008; Giulietti \& Pirani, 1988; Rapini et al., 2002; Rapini et al., 2008; Ribeiro \& Freitas, 2010; Silva, 2008).

Conforme a Teoria de Nicho proposta por Hutchinson (1957), os padrões de distribuição das espécies é resultado da adaptação ao meio e da exclusão competitiva, em que a disponibilidade de nichos é o grande determinante da composição e diversidade na comunidade onde os nichos são particionados em função das necessidades por recursos. Em contrapartida, a Teoria Neutra proposta por Hubbell, (2001) prevê estruturação das comunidades em função de 
fatores adjacentes, onde a riqueza e composição de espécies na comunidade são reflexos de processos estocásticos com a limitação da dispersão. Neste caso, a dispersão tem papel fundamental na Teoria Neutra, sendo que a imigração é uma das justificativas para a coexistência de espécies em uma comunidade e que por sua vez é afetada pelo espaço (Hubbell, 2005). No entanto as duas teorias podem ser vistas de forma complementar, sugerindo que a estrutura em comunidades reais é resultado do balanço decorrente entre a Teoria de Nicho e a Teoria Neutra (Gravel et al. 2006).

Estudos que descrevem padrões ecológicos em resposta ao ambiente envolvem grande número de variáveis físicas. Nesse estudo, foi descrito pela primeira vez os padrões de distribuição da comunidade de Asteraceae na região do Planalto de Diamantina e suas relações com fatores ambientais para responder as seguintes perguntas: Quais os determinantes dos padrões de composição florística e estrutural da comunidade de Asteraceae no Planalto de Diamantina? Considerando a importância da família na região, as duas áreas protegidas abrangem as variações florísticas de Asteraceae?

\subsection{MATERIAL E MÉTODOS}

\subsection{1. ÁREA DE ESTUDO}

Veja item 2.2.1

\subsubsection{COLETA DE DADOS DE ASTERACEAE}

Veja item 2.2.2

\subsubsection{COLETA DE DADOS DOS FATORES AMBIENTAIS}

Os descritores ambientais foram usados para compor as matrizes de dados a serem usadas nas análises multivariadas. Foram amostrados os seguintes descritores: rochosidade (Mello, 2012), declividade (Borges et al., 2011; Giulietti et al., 1996, 1997), altitude, solo (alumínio, soma de bases, fósforo e conteúdo de argila) (Giulietti et al., 1996, 1997; Rapini et al., 2008; Dantas \& Batalha, 2011).

O método Braun-Blanquet (1983) foi usado para estimar a cobertura de rocha em cada subparcelas nos 25 seguimentos de $10 \mathrm{~m}$ e ao final calculou-se a mediana. Para medir a declividade foi usado um clinômetro, seis medidas foram tomadas a cada $50 \mathrm{~m}$ ao longo da trilha e depois calculada a média para a unidade amostral (Figura 2). As altitudes foram obtidas in situ usando GPS. De acordo com manual de coleta e análise de solo proposto pela EMBRAPA (1997), 
foi coletado na camada de 0 a $20 \mathrm{~cm}$ de profundidade uma amostra composta (seis amostras simples foram coletadas a cada $50 \mathrm{~m}$ ao longo da trilha) para cada unidade amostral (Figura 2). As amostras foram analisadas quanto a quantidade de argila e químicas (soma de bases e teor de fósforo).

\subsubsection{ANÁLISE DOS DADOS}

As análises foram realizadas para composição e abundância das espécies juntas como também separadas nas formas de vida herbáceas, arbustivas, arvoretóides e arbóreas.

Foram preparados três tipos de matrizes para a análise de dados: uma contendo a composição e abundância das espécies (florística), outra contendo as variáveis ambientais (abiótica) e por fim, uma matriz espacial contendo as coordenadas geográficas (latitude/longitude) das 21 unidades amostrais. Na matriz ambiental foram consideradas as seguintes variáveis ambientais: altitude, teor de alumínio, quantidade de argila, declividade, teor de fósforo, rochosidade e soma das bases.

Para as análises de classificação foi utilizado o método de distância de Bray-Curtis para gerar um dendrograma hierárquico de similaridade em função dos dados de composição e abundância das espécies para identificar descontinuidades entre as unidades amostrais (Legendre \& Legendre, 1998; Borcard et al., 2011). Como proposto por Legendre \& Gallagher (2001), os dados de composição e abundância das espécies foram tratados a partir de transformações de Hellinger.

As ordenações foram realizadas por técnicas indiretas que permitem analisar os gradientes independentemente dos fatores ambientais (Felfili et al., 2011) por NMDS (Escalonamento Multidimensional Não Métrico; Kruskal, 1964) e DCA (Análise de Correspondência Distendida; Hill e Gauch, 1980), para investigar como as unidades amostrais se distribuíam em relação à composição e abundância das espécies. A distância adotada no NMS foi à de Bray-Curtis (Mccune e Grace, 2002). A escolha em usar NMDS ou DCA foi em função do efeito de arco que apareceu em algumas das funções na DCA.

Para confirmar as separações florístico-estruturais que emergiram dos eixos principais de ordenação (NMS e DCA), foram realizadas análises confirmatórias por meio de modelo linear (LM), usando os escores dos eixos como variável resposta (Eisenlohr, 2013).

Através do programa SAM gerou-se vários modelos que apresentam o modelo médio, o qual demonstra a importância dos condicionantes ambientais em todos os modelos gerados. Foi escolhido o modelo com menor valor de Akaike corrigido (AICc) (Burnham e Anderson, 2002). 
Foram utilizados os programas: SAM 4.0 (Rangel et al., 2010), para as análises de autocorrelação espacial e modelos de regressão múltipla por OLS; e RStudio (The R Foundation for Statistical Computing, 2014) para as análises multivariadas NMDS e DCA.

\subsection{RESULTADOS}

\subsubsection{ANÁLISES DE CLASSIFICAÇÃO}

O agrupamento das unidades amostrais pela composição e abundância das espécies separou três grandes grupos e a unidade amostral RP1P4 ficou isolada com elevado grau de dissimilaridade em relação às demais unidades amostrais (Figura 13a). O PERP II foi o único que agrupou todas as suas unidades amostrais, apresentando alto grau de dissimilaridade em relação aos demais módulos. O PERP I e PNSV I apresentam mais similaridade entre as suas unidades amostrais em relação ao PERP II. Além das unidades amostrais que pertencem ao PNSV I, este também agregou a unidade amostral RP1P9 que se mostrou mais similar às do módulo PNSV I. Apesar da segregação apresentada, a similaridade entre os grupos foi muito baixa $(<3,4)$, evidenciando grande heterogeneidade na composição e abundância entre as unidades amostrais e ainda mais forte entre os módulos.

Para as herbáceas, houve formação de um grande grupo representado pelas unidades amostrais do PERP I e PNSV I que compartilham características de composição e abundância muito próximas, contudo vale observar que a dissimilaridade ainda é alta entre os pequenos grupos formados (Figura 13b). Outro destaque é para as unidades SV1P2 e SV1P8 que demostraram ser muito similares.

A forma de vida arbustiva foi a mais rica e abundante dentre todos os hábitos, e apresentou formação de vários pequenos grupos (Figura 13c). As unidades amostrais pertencentes ao módulo PERP II se mantiveram numa relação mais próxima, enquanto os demais módulos apresentaram maiores semelhanças entre suas unidades.

Tanto para as arvoretas (Figura 13d) quanto para as arbóreas (Figura 13e) os agrupamentos formaram grupos pequenos, com as unidades amostrais dos três módulos embaralhadas, sem um claro padrão que as agregasse em função de menores distâncias, mas talvez por características ambientais. 
a)

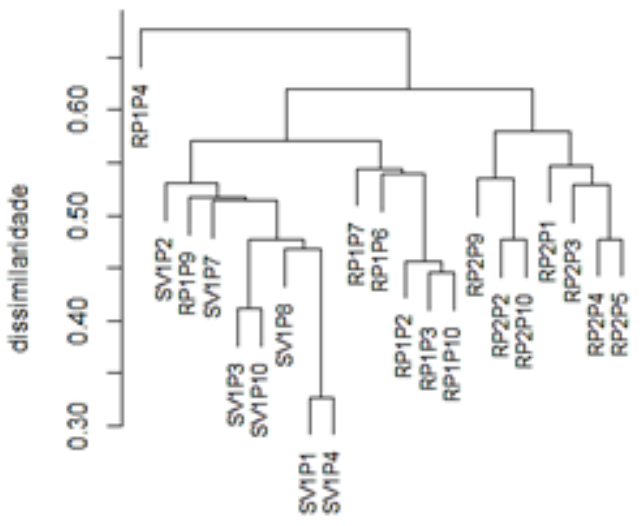

unidades amostrais

c)

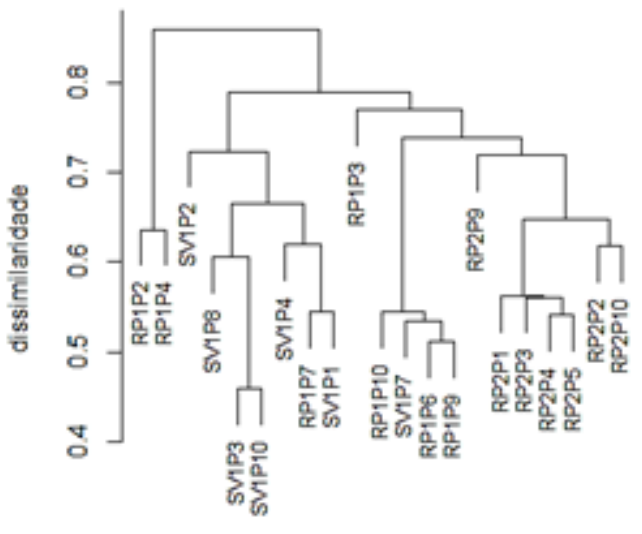

unidades amostrais b)

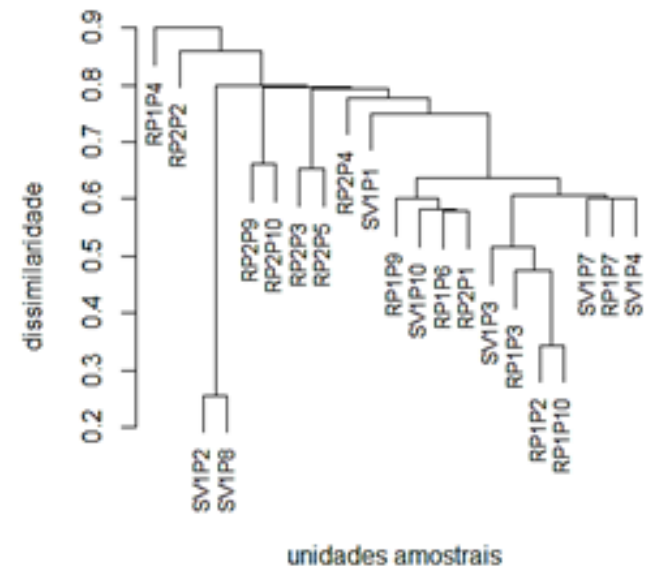

d)

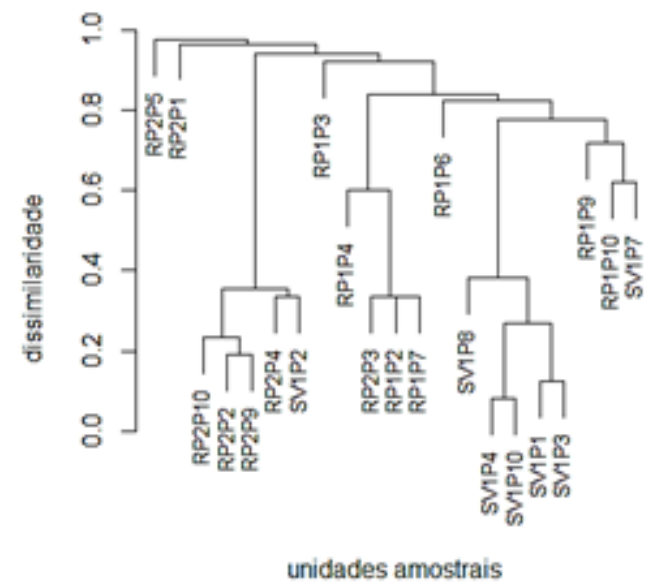

e)

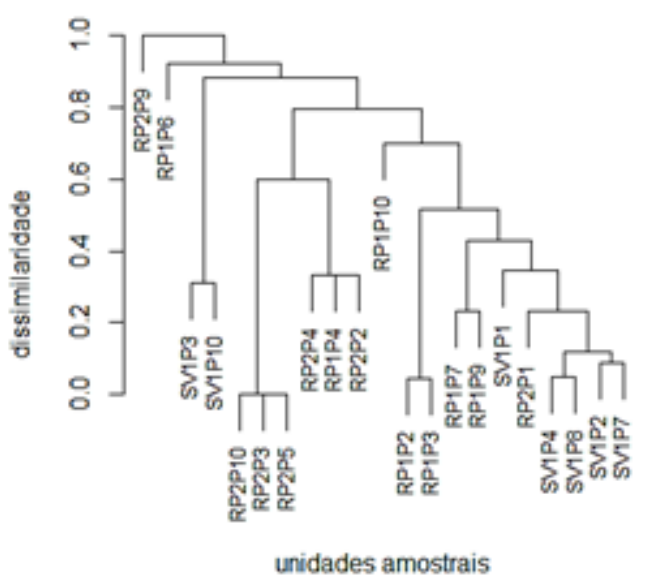

Figura 12. Classificação das unidades amostrais baseadas na composição e abundância das espécies em áreas protegidas do Planalto de Diamantina, Minas Gerais. a) Classificação de todas as espécies juntas; b) Classificação das espécies herbáceas; c) Classificação das espécies arbustivas; d) Classificação das espécies arvoretóides; e) Classificação das espécies arbóreas. RP1P2 - RP1: Módulo I do Parque Estadual do Rio Preto (PERP I); e P2: parcela 2. RP2P1 - RP2: Módulo II do Parque Estadual do Rio Preto (PERP II); e P1: parcela 1. SV1P1 - SV1: Módulo I do Parque Nacional das Sempre-Vivas; P1: parcela 1. 


\subsubsection{ANÁLISES DE ORDENAÇÃO}

Quando todas as espécies foram consideradas, houve separação nítidas no eixo 1 das unidades amostrais do PERP II com as demais unidades dos outros módulos (Figura 14a). O PERP I apresentou algumas de suas unidades amostrais muito semelhantes às do PNSV I, porém possuiu unidades muito distantes similarmente. O PNSV I teve suas unidades amostrais mais agrupadas, o que demostra menor heterogeneidade em composição e abundância das suas unidades amostrais em relação aos demais módulos. Do contrário, as unidades amostrais pertencentes aos módulos PERP I e PERP II foram mais heterogêneas em composição e abundância, apresentando suas unidades mais dispersas. A soma de base (Tabela 6) foi a variável ambiental mais forte na separação dos grupos, que demostra relação positiva das unidades amostrais do PERP II com este preditor. Também foi notado relação positiva com alumínio e negativa com fósforo (Tabela 6) que separou seleto grupo de espécies representado por algumas unidades amostrais do PERP I (Figura 14a). A rochosidade (Tabela 6) uma participação pequena na formação dos grupos, porém significativa, que segue no mesmo sentido do gradiente de fósforo.

Para as herbáceas, o módulo PERP II apresentou menor heterogeneidade de composições e abundâncias das espécies entre as suas unidades amostrais que estão mais agrupadas (Figura 14b), porém esta composição e abundância é extremamente diferenciada dos demais módulos, apresentando algumas semelhanças apenas com algumas unidades amostrais do PERP I. O PNSV I foi o módulo mais heterogêneo em composição e abundância, enquanto as unidades amostrais dos demais módulos foram mais agrupadas entre elas. No PNSV I foram percebidos dois grupos principais, um mediado pela baixa quantidade de argila no solo e outro mediado pela baixa quantidade de soma das bases (Tabela 6).

Para as arbustivas, o módulo PERP II apresentou composição e abundância das espécies extremamente diferenciada dos demais módulos (Figura 14c), onde os condicionantes ambientais mais expressivos são a altitude e a soma das bases que mediam positivamente a relação (Tabela $6)$.

Quando analisamos as arvoretas, as unidades amostrais se mostraram muito dispersas e não apresentaram padrão muito exclusivo para cada módulo (Figura 14d), sendo que tal característica implica em maior heterogeneidade de composição e abundância das espécies pertencentes a este hábito. A altitude foi a mais significativa, e separou dois grupos distintos. A declividade, o alumínio e o fósforo separam grupos menores e apresentaram menores significâncias dentro deste conjunto de espécies (Tabela 6). 
Quanto as espécies arbóreas, houve separação principal entre os módulos do PERP com o do PNSV (Figura 14e), tal característica elucida composições e abundâncias bastante heterogênea entre as duas áreas protegidas, onde a declividade e principalmente o alumínio apresentaram relação forte com a separação das áreas protegidas. A altitude também teve contribuição na separação das unidades amostrais, onde as unidades do PERP II apresentam relação negativa pela escassez de espécies pertencentes a este hábito, enquanto o PERP I apresenta relação negativa por haver muitas espécies pertencentes ao hábito arbóreo, porém restritas a faixa de altitude amostrada (Tabela 6).

Tabela 2. Valores mínimos e máximos para as variáveis ambientais coletadas nas áreas protegidas em ambiente rupestre no Planalto de Diamantina, Parque Estadual do Rio Preto (PERP) e Parque Nacional das Sempre-vivas (PNSV).

\begin{tabular}{|c|c|c|c|c|c|c|c|c|}
\hline Área & $\mathrm{N}^{\circ}$ de UA & Altitude (m) & Alumínio $\left(\mathrm{cmo} / \mathrm{dm}^{3}\right)$ & Argila (\%) & Declividade (graus) & Fósforo $\left(\mathrm{cmol} / \mathrm{dm}^{3}\right)$ & Rochosidade (\%) & Soma de Bases $\left(\mathrm{cmol} / \mathrm{dm}^{3}\right)$ \\
\hline \multicolumn{9}{|l|}{ PNSV } \\
\hline $\max$. & \multirow{2}{*}{7} & 1325 & 1.4 & 25 & 6.42 & 2.9 & 43.2 & 0.76 \\
\hline $\min$. & & 1237 & 0.7 & 15 & 3.42 & 1.1 & 0 & 0.4 \\
\hline \multicolumn{9}{|l|}{ PERP } \\
\hline $\max$ & 14 & 801 & 2.7 & 37.5 & 14.08 & 9.2 & 33.3 & 1.08 \\
\hline $\min$. & & 1613 & 1.1 & 15 & 2.58 & 0.8 & 0 & 0.37 \\
\hline
\end{tabular}


a) Todos os Hábitos

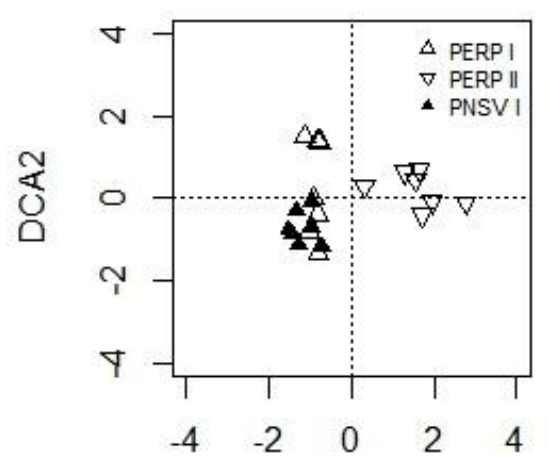

DCA1

c) Arbustos

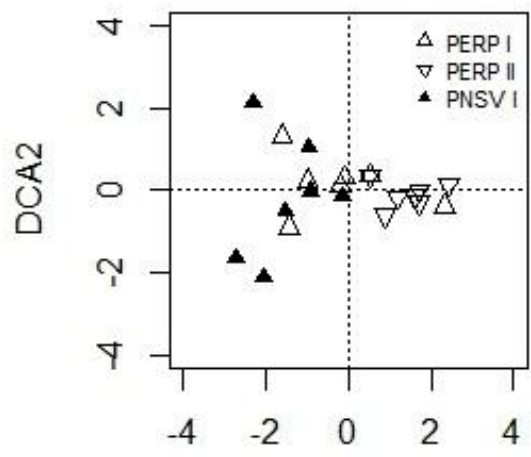

DCA1

e) Árvores

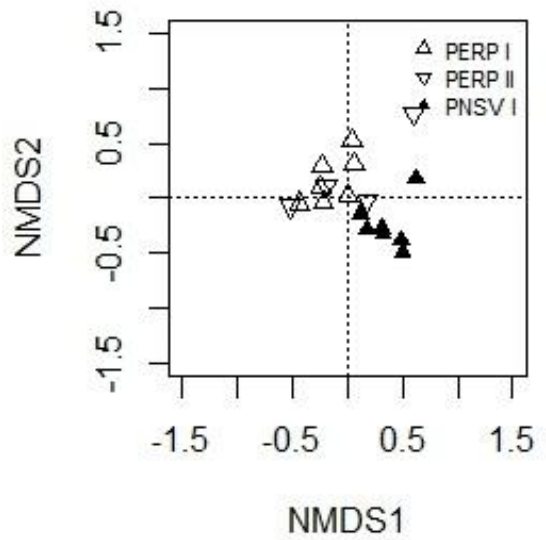

b) Ervas

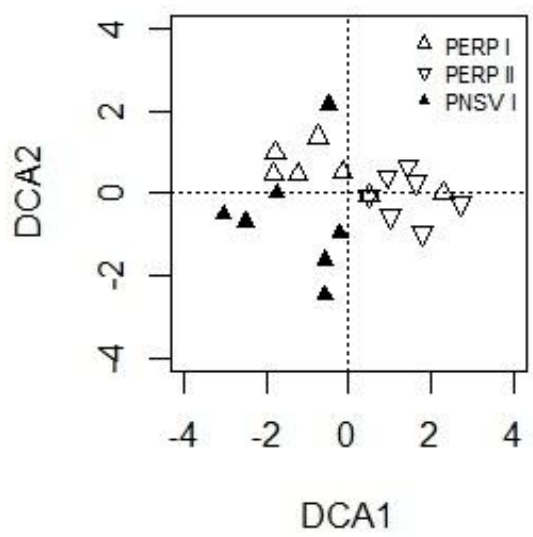

d) Arvoretas

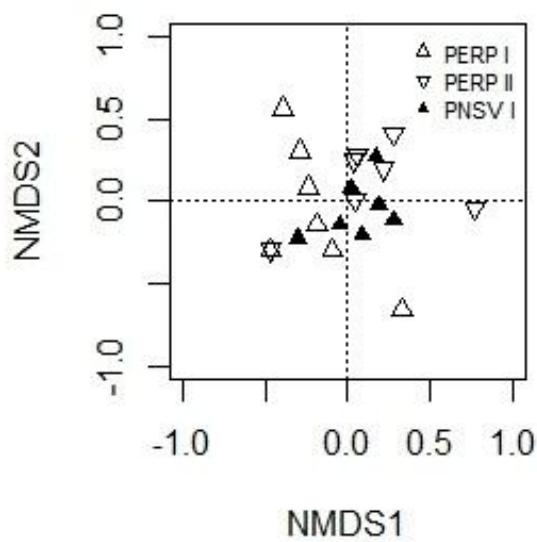

Figura 13. Ordenação das unidades amostrais baseadas na composição e abundância das espécies em áreas protegidas do Planalto de Diamantina, Minas Gerais. Classificação de: a) todas as espécies; b) espécies herbáceas; c) espécies arbustivas; d) espécies arvoretóides; e) espécies arbóreas. (alt) altitude; (alu) alumínio no solo; (arg) quantidade de argila no solo; (dec) declividade; (fos) fósforo; (roc) rochosidade; e (sba) soma das bases. 
Tabela 3. Resultados dos modelos de regressão linear múltipla da variação na composição e abundância das espécies de Asteraceae separado em hábitos herbáceos, arbustivos, arvoretóides, arbóreas e todos os hábitos juntos em ambientes rupestres localizados no Parque Estadual do Rio Preto (PERP) e Parque Nacional das Sempre-vivas (PNSV), situados no Planalto de Diamantina, Serra do Espinhaço, Minas Gerais. Beta: coeficiente padronizado; SE: erro-padrão; B: coeficiente não-padronizado. Significância $(\mathrm{p} \leq 0,05)$ indicada em negrito.

\begin{tabular}{|c|c|c|c|c|c|}
\hline \multicolumn{6}{|l|}{ Variáve is Ambientais } \\
\hline Todos os hábitos & & $\mathrm{B}$ & Beta & $\mathrm{SE}$ & p-valor \\
\hline Eixo 1 DCA - Modelo 1 & $\left(\mathrm{R}^{2}: 0.664 ; \mathrm{F}: 37.546 ; \mathrm{P}:<.001\right)$ & & & & \\
\hline Constante & & -226.876 .422 & 0 & 38.673 .382 & $<.001$ \\
\hline Soma de Bases & & 293.067 .406 & 0.815 & 47.828 .649 & $<.001$ \\
\hline \multicolumn{6}{|l|}{ Eixa 2 DCA - Modelo 2} \\
\hline Constante & $\left(\mathrm{R}^{2}: 0.192 ; \mathrm{F}: 4.514 ; \mathrm{P}: 0.047\right)$ & -50.563 .948 & 0 & 31.057 .392 & 0.123 \\
\hline Alumínio & & 95.047 .255 & 0.637 & 18.168 .733 & $<.001$ \\
\hline Fósforo & & -35.953 .114 & -0.773 & 5.780 .312 & $<.001$ \\
\hline Rochosidade & & -2.693 .664 & -0.363 & 887.739 & 0.008 \\
\hline Herbáceas & & $\mathrm{B}$ & Beta & SE & p-valor \\
\hline Eixo 1 DCA - Modelo 3 & $\left(\mathrm{R}^{2}: 0.522 ; \mathrm{F}: 9.829 ; \mathrm{P}: 0.001\right)$ & & & & \\
\hline Constante & & -269128.32 & 0 & 63.928 .304 & $<.001$ \\
\hline Fósforo & & 28.838 .917 & 0.331 & 14.184 .712 & 0.058 \\
\hline Soma de Bases & & 267.491 .161 & 0.632 & 69049.03 & 0.001 \\
\hline Eixo 2 DCA - Modelo 4 & $\left(\mathrm{R}^{2}: 0.238 ; \mathrm{F}: 5.922 ; \mathrm{P}: 0.025\right)$ & & & & \\
\hline Constante & & -172.068 .347 & 0 & 71.767 .422 & 0.028 \\
\hline Argila & & 778.945 & 0.487 & 320.097 & 0.026 \\
\hline Arbustivas & & B & Beta & SE & $p$-valor \\
\hline Eixo 1 DCA - Modelo 5 & $\left(\mathrm{R}^{2}: 0.743 ; \mathrm{F}: 16.35 ; \mathrm{P}:<.001\right)$ & & & & \\
\hline Constante & & -418.621 .935 & 0 & 108.671 .906 & 0.001 \\
\hline Altitude & & 231.944 & 0.376 & 108.908 & 0.049 \\
\hline Fosfato & & -23.042 .907 & -0.252 & 11.308 .979 & 0.058 \\
\hline Soma de Bases & & 227.813 .542 & 0.512 & 78.379 .456 & 0.01 \\
\hline Eixo 2 DCA - Modelo 6 & $\left(\mathrm{R}^{2}: 0.366 ; \mathrm{F}: 5.199 ; \mathrm{P}: 0.017\right)$ & & & & \\
\hline Constante & & 55647.96 & 0 & 25.253 .499 & 0.042 \\
\hline Fósforo & & -12.542 .715 & -0.325 & 7.394 .685 & 0.108 \\
\hline Rochosidade & & -3.576 .437 & -0.581 & 1.179 .887 & 0.008 \\
\hline Arvoretóides & & $\mathrm{B}$ & Beta & SE & p-valor \\
\hline Eixo 1 NMDS - Modelo 7 & $\left(\mathrm{R}^{2}: 0.584 ; \mathrm{F}: 12.62 ; \mathrm{P}:<.001\right)$ & & & & \\
\hline Constante & & 0 & 0 & -4.846 & $<.001$ \\
\hline Altitude & & 75525.91 & 0.691 & 16.645 .274 & $<.001$ \\
\hline Fósforo & & $>5 \times 10^{\wedge} 6$ & 0.363 & $>2 \times 10^{\wedge} 6$ & 0.029 \\
\hline Eixo 2 NMDS - Modelo 8 & $\left(\mathrm{R}^{2}: 0.23 ; \mathrm{F}: 5.667 ; \mathrm{P}: 0.028\right)$ & & & & \\
\hline Constante & & $>1 \times 10^{\wedge} 7$ & 0 & $>1 \times 10^{\wedge} 7$ & 0.414 \\
\hline Alumínio & & -29794007.41 & -0.612 & $>1 \times 10^{\wedge} 7$ & 0.02 \\
\hline Declividade & & $>4 \times 10^{\wedge} 6$ & 0.501 & $>2 \times 10^{\wedge} 6$ & 0.05 \\
\hline Arbóreas & & $\mathrm{B}$ & Beta & SE & p-valor \\
\hline Eixo 1 NMDS - Modelo 9 & $\left(\mathrm{R}^{2}: 0.54 ; \mathrm{F}: 10.569 ; \mathrm{P}:<.001\right)$ & & & & \\
\hline Constante & & 0 & 0 & -4.446 & $<.001$ \\
\hline Altitude & & 73.849 .348 & 0.669 & 17660.92 & $<.001$ \\
\hline Fósforo & & $>5 \times 10^{\wedge} 6$ & 0.339 & $>2 \times 10^{\wedge} 6$ & 0.049 \\
\hline Eixo 2 MNDS - Modelo 10 & $\left(\mathrm{R}^{2}: 0.287 ; \mathrm{F}: 3.621 ; \mathrm{P}: 0.048\right)$ & & & & \\
\hline Constante & & $>1 \times 10^{\wedge} 7$ & 0 & $>1 \times 10^{\wedge} 7$ & 0.437 \\
\hline Alumínio & & -29.966 .214 .592 & -0.606 & $>1 \times 10^{\wedge} 7$ & 0.021 \\
\hline Declividade & & $>5 \times 10^{\wedge} 6$ & 0.505 & $>2 \times 10^{\wedge} 6$ & 0.049 \\
\hline
\end{tabular}




\subsection{DISCUSSÃO}

A classificação pela composição e abundancia das espécies juntas ou separadas por hábitos evidenciou grande heterogeneidade entre as unidades amostrais. No caso do PNSV, a abundância dos indivíduos é mais expressiva que no PERP, e essa abundância em grande parte é atribuída a poucas espécies, que por processos fisiológicos podem sofrer segregação do órgão subterrâneo formando diversos clones vizinhos, como citou Appezzato-da-glória et al. (2008) quando descreveu sistemas subterrâneos de Asteraceae.

A classificação pela composição e abundância das espécies separadas por hábitos evidenciou grande heterogeneidade entre as unidades amostrais, que em muitas vezes, as maiores similaridades foram atribuídas às unidades amostrais vizinhas, denotando a provável influência do espaço com a facilitação da dispersão, e para o caso das unidades mais distantes a dificuldade em transpor barreiras físicas, muito comum no ambiente de estudo.

Quando analisamos as ordenações do conjunto total das espécies quanto às preferencias ambientais, notamos uma grande afinidade com a soma das bases, que separa as unidades amostrais do PERP II, apresentando uma relação positiva com a variável, das demais. Por outro lado, algumas unidades amostrais do PERP I e PNSV I segregam por uma relação com o alumínio e o fósforo. Dantas \& Batalha (2011) em estudos de mesma natureza em ambientes de cerrado também constataram a influência de algumas variáveis do solo, como o incremento da riqueza influenciado positivamente pela soma das bases, e também a variação da composição florística pela influência de alumínio no solo. Apesar da influência encontrada por Dantas \& Batalha (2011), esta obteve um valor de significância muito baixo, onde os autores atribuíram as dificuldades em interpretar tais influencias por conta da regulação do ambiente por meio de ambientes em equilíbrio e da geração estocástica (Hubbell, 1984; Hubbell e Foster, 1986).

A composição de espécies herbáceas apresentou diferenciação em relação a quantidade de argila no solo. A rochosidade foi significativamente importante na composição das espécies que pertencem ao hábito arbustivo, principalmente nas unidades amostrais do PERP I e PNSV I. Mello (2012) em estudo similar no Parque Nacional das Sempre-Vivas também encontrou relação na mudança de composição por influência da rochosidade e quantidade de argila no solo. Messias (2011) também investigou a relação de alguns fatores ambientais na composição de formas de vida, e encontrou alguns valores significativos para os tipos de substrato contendo rochosidade.

A altitude teve importância significativa apenas para os hábitos arbustivos, arvoretóides e arbóreos. Borges et al. (2011) quando estudou a variação da composição de espécies herbáceas 
no gradiente altitudinal em ambientes rupestres a sudeste da Serra do Espinhaço, também não constatou diferenças significativas para a mudança na composição de espécies para esta forma de vida, inclusive espécies da família Asteraceae, que aqui tiveram uma atribuição significativa das variáveis alumínio, fósforo e soma das bases. Em contrapartida, Mello (2012) em estudos de comunidades herbáceo-arbustivas em campos úmidos no Parque Nacional das Sempre-vivas encontrou mudanças significativas na composição mediante o gradiente de altitude.

A declividade obteve significância para os indivíduos arvoretóides, com efeito positivo sob a composição e abundância na maioria das unidades amostrais do PNSV I e negativas sob unidades amostrais do PERP I. Também foi constatado efeito sob a comunidade de espécies arbóreas, que demonstrou positiva para as unidades amostrais do PERP I e negativa às unidades do PNSV I. Borges et al. (2011) relatou que a elevada riqueza de algumas famílias está relacionada às características do relevo, como por exemplo a declividade. Também foram encontrados resultados positivos para trabalhos no bioma Amazônico, no qual destaca a declividade como condicionantes para regulações na abundância de determinadas espécies (Zuquim et al., 2012; Pansonato et al., 2013; Moser et al., 2014).

\subsection{CONCLUSÃO}

Espécies endêmicas dos ambientes rupestres de distribuição muito restrita estão fortemente ameaçadas, e para garantir a sobrevivência destas é necessário proteger os ambientes em que estão inseridas (Alves e Kolbek, 1993), ou seja, todas as características ambientais condicionantes de determinadas populações são muito importantes e a defasagem destas características implicam no declínio e posterior extinção da população. Assim como, também é importante haver um manejo de condicionantes e mantenedores estocásticos, como a existência natural do fogo nestes ambientes, a exclusão total destes eventos pode não ser tão vantajosa do ponto de vista de conservação da diversidade.

A altitude é um preditor importante no incremento da riqueza e diversidade de espécies e também na mudança da composição das mesmas. Principalmente no PERP, estas características estão muito evidentes, porém as áreas onde se observa tais características, a diversidade florística pode não estar devidamente incluída em um tamanho adequado que de fato protegesse e conservasse as populações de Asteraceae. A soma das bases também demostrou ser importante, nas ordenações aparece associado às unidades amostrais de maior altitude, reforçando a necessidade de proteção desses ambientes de altitude. Outro preditor importante foi a quantidade de fosforo no solo, aparecendo em maiores quantidades nos locais de maior concentração de 
afloramentos, sendo outro ambiente importante na especificidade de fatores que condicionam a diversidade de Asteraceae

A heterogeneidade florística das áreas protegidas abrange grandes variações na composição de Asteraceae, onde cada módulo resguarda espécies exclusivas. Ainda neste sentido, foi detectada também heterogeneidade ambiental muito grande, que media e mantém várias comunidades de Asteraceae. 


\section{CONSIDERAÇÕES FINAIS}

A heterogeneidade dos ambientes quanto mais diversos, mais complexo são do ponto de vista florístico e estrutural, o que contribui para a grande diversidade de espécies. Portanto é preciso conhecer bem o tamanho e a distribuição das populações para as espécies para que se possa de fato priorizar e manejar áreas em Unidades de Conservação com o cuidado em abranger ambientes colonizados pelas espécies.

A forma como as áreas protegidas são demarcadas podem estar comprometendo a proteção e sobrevivência de algumas espécies, uma vez que, muitas delas não foram encontradas dentro das áreas protegidas.

Dentro dos estudos comparados e que utilizaram alguma forma de amostragem, obtiveram números muito inferior de espécies para a família, mesmo em ambientes rupestres. Muito provavelmente causado pelo efeito do tamanho das unidades amostrais, sendo importante a utilização de unidades amostrais grandes e contínuas capazes de englobar uma gama de espécies suficientemente significativa para o ambiente em questão que é extremamente heterogêneo com alta especificidade das espécies de planta, como é o caso de muitas espécies endêmicas de Asteraceae. 


\section{REFERÊNCIAS BIBLIOGRÁFICAS}

Abreu, A. A., (1984). O Planalto de diamantina: um setor da Serra do Espinhaço em Minas Gerais. Orientação - Intituto de Geografia USP, 5: 75-79.

Alves, R. J. V., \& Kolbek, J. (1993). Penumbral Rock Communities in Campo Rupestre Sites in Brazil. Journal of Vegetation Science, 4(3), 357-366.

Almeida, T. A., Souza, D. T., Salino, A. and Teles, A. M. (2007). Levantamento florístico e caracterização das formações vegetacionais, Parque Nacional das Sempre Vivas. Relatório Técnico não publicado.

Anderberg, a a, \& Balddwin, B. G. (2007). Compositae. Kadereit, J.W., Jeffrey, C. (vol Eds) Asterales, 8(1763), 61-621.

Andrino, C. O., \& Costa, F. N. (2013). Paepalanthus subgen. Xeractis (Eriocaulaceae) na porção central da Cadeia do Espinhaço em Minas Gerais, Brasil. Rodriguesia, 64(1), 75-89.

Antonelli, A. \& Sanmartín, I. In press. Mass extinction, gradual cool- ing, or rapid radiation? Reconstructing the spatiotemporal evolu- tion of the ancient angiosperm genus Hedyosmum (Chloranthaceae) using empirical and simulated approaches. Syst. Biol.

Appezzato-da-Glória, B., Cury, G., Soares, M. K. M., Rocha, R., \& Hayashi, a H. (2008). Underground systems of Asteraceae species from the Brazilian Cerrado. Journal of the Torrey Botanical Society, 135(1), 103-113.

Ashton, P., 1969, Speciation among tropical forest trees: Some deductions in the light of recent evidence, Bioi. J. Linn. Soc. 1:155-1.

Barroso, G.M.; Peixoto, A.L.; Costa, C.G.; Ichaso, C.L.F.; Guimarães, E.F.; Lima, H.C. de. (1991). Sistemática de Angiospermas do Brasil. Viçosa: Universidade Federal de Viçosa. v.3. pp. 237-315.

Bautista, H.P. (2000). Sistemática e filogenia de um gênero endêmico do Brasil: Acritopappus R.M.King \& H.Rob. (Asteraceae, Eupatorieae). Tese de Doutorado, Universidade de Santiago de Compostela, Espanha.

Benites, V. de M., Caiafa, A. N., Mendonça, E. de S., Schaefer, C. E., \& Ker, J. C. (2003). Solos e vegetação nos complexos rupestres de altitude da mantiqueira e do espinhaço. Floresta $E$ Ambiente, 10(1), 76-85.

Borcard, D., Gillet, F., \& Legendre, P. (2011). Numerical Ecology with R. Media.

Borges, R. A. X., \& Forzza, R. C. (2008). A tribo Astereae (Asteraceae) no Parque Estadual do Ibitipoca, Minas Gerais, Brasil. Boletim de Botânica Da Universidade de São Paulo, 26(2), 131-154. 
Brandon, K.; Fonseca, G.A.B.; Rylands, A.B. \& Silva, J.M.C. (2005). Conservação brasileira: desafios e oportunidades. Megadiversidade 1: 7-13.

Braun-Blanquet, J. (1983). Plant sociology. Koeltz scientific, pp. 35-72.

Burnham, K.P.; Anderson, D.R. (2002). Model Selection and Multimodel Inference: A Practical Information-Theoretic Approach. 2 ed. Springer-Verlag, New York.

Chave, J. (2013). The problem of pattern and scale in ecology: What have we learned in 20 years? Ecology Letters, 16(SUPPL.1), 4-16.

Coile, N. C., \& Jones, S. B. (1981). Lychnophora (Compositae: Vernonieae), a genus Endemic to the Brazilian Planalto. Brittonia, 33(4), 528.

Conceição, A. A., \& Pirani, J. R. (2005). Delimitação De Habitats Em Campos Rupestres Na Chapada Diamantina, Bahia: Substratos, Composição Florística E Aspectos Estruturais. Boletim de Botânica Da Universidade de São Paulo, 23(1), 85-111.

Costa, F. N., Trovó, M., \& Sano, P. T. (2008). Eriocaulaceae na Cadeia do Espinhaço : riqueza, endemismo e ameaças. Megadiversidade, 4(1-2), 89-97.

Costa, F. R. C., Magnusson, W. E., \& Luizao, R. C. (2005). Mesoscale distribution patterns of Amazonian understorey herbs in relation to topography, soil and watersheds. Journal of Ecology, 93(5), 863-878.

Cronquist, A. (1988). The Evolution and Classification of Flowering Plants. Second Edition. Bronx, NY: The New York Botanical Garden.

Dantas, V. L.; Batalha, M. A. (2011). Vegetation structure: Fine scale relationships with soil in a cerrado site. Flora, v. 206, n. 4, p. 341-346.

Diniz, E. S., Pavanelli, A. P., \& Júnior, F. J. S. (2010). A ANÁLISE DA ESTRUTURA DE UMA POPULAÇÃO DE Lychnophora pinaster MEIO DA ESTATÍSTICA MULTIVARIADA. Ecología Aplicada, 9(2).

Eisenlohr, P. V. (2013). Challenges in data analysis: pitfalls and suggestions for a statistical routine in Vegetation Ecology. Brazilian Journal of Botany, 36(1), 83-87.

Eiten, G. (1972). The cerrado vegetation of Brazil. Botanical Review, v.38, n. 2, p.201-341.

Eiten, G. (1978). Delimitation of the cerrado concept. Vegetatio, 36(3), 169-178.

EMBRAPA. (1997). Manual de Métodos de Análise de Solo.

Farias, R. (2000). Fitogeografia dos gêneros Jacaranda e Tabebuia (Bignoniaceae) no Bioma Cerrado. Dissertação de Mestrado. Universidade de Brasília. Brasília, DF

Felfili, J. M. et al. (2004). Diversity, floristic and structural patterns of cerrado vegetation in Central Brazil. Plant Ecology, v. 175, n. 1, p. 37-46. 
Felfili, J.M.; Carvalho, F.A.; Libano, A.M.; Venturoli, F.; Pereira, B.A.S.; Machado, E.L.M. (2011). Análise multivariada: princípios e métodos em estudos de vegetacão. In: Felfili J.M., Eisenlohr, P.V., de Melo M.M.R.F., Andrade L.A., Meira Neto J.A.A. (eds) Fitossociologia no Brasil: Métodos e Estudos de Casos, vol 1. Editora UFV, Viçosa, pp 122-155.

Felfili, J. M.; Silva Júnior, M. C. (1993). A comparative study of Cerrado (Sensu stricto) vegetation in Central Brazil. Journal of Tropical Ecology, v. 9, n. 3, p. 277-289.

Filgueiras, T.S.; Nogueira, P.E.; Brochado, A.L. \& Guala II, G.F. (1994). Caminhamento: um método expedito para levantamentos florísticos qualitativos. Cadernos de Geociências 12: $39-43$

Fine P.V.A., Daly D.C., Muñoz G.V., Mesones I, Cameron K. M. 2005. The contribution of edaphic heterogeneity to the evolution and diversity of Burseraceae trees in the western Amazon. Evolution 59: 1464-1478.

Funk, V. a., Bayer, R. J., Keeley, S., Chan, R., Watson, L., Gemeinholzer, B., ... Jansen, R. K. (2005). Everywhere but Antarctica: Using a supertree to understand the diversity and distribution of the Compositae. Proceedings of a Symposium on Plant Diversity and Complexity Patterns - Local, Regional and Global Dimensions.

Gentry, a H. (1981). Distributional Patterns and an Additional Species of the Passiflora-Vitifolia Complex - Amazonian Species-Diversity Due To Edaphically Differentiated Communities. Plant Systematics and Evolution, 137(2), 95-105.

Gentry, A. H. (1982). Patterns of Neeotropical Plant Species Diversity. Evolutionary Biology.

Gentry, A. H. (1988). Changes in Plant Community Diversity and Floristic Composition on Environmental and Geographical Gradients. Missouri Botanical Garden, 75(1), 1-34.

Giulietti, a. M., \& Forero, E. (1990). WorkShop diversidade taxonômica e padrões de distribuição das angiospermas brasileiras introdução. Acta Botanica Brasilica, 4(1), 3-10.

Giulietti, A. M., Menezes, N. L., Pirani, J. R., Meguro, M., \& Wandeley, M. das G. L. (1987). FLORA DA SERRA DO CIPÓ, MINAS GERAIS: CARACTERIZAÇÃO E LISTA DE ESPÉCIES. Bolm Botânica, Universidade de São Paulo, 9(1), 1-151.

Giulietti, A. M., \& Pirani, J. R. (1988). Patterns of geographic distribution of some plant species from the Espinhaço Range, Minas Gerais and Bahia, Brazil. In Vanzolini, P. E. \& Heyer, W. R. (eds.). Proceedings of a workshop on neotropical distribution patterns held 12-16. January 1987 (pp. 39-69). 
Giulietti, N., Giulietti, A. M., Pirani, J. R., \& Menezes, N. L. De. (1987). Estudos em semprevivas: importância econômica do extrativismo em Minas Gerais, Brasil. Acta Botanica Brasilica, 1(2), 179-193.

Giulietti, A.M., Queiroz, L.P. \& Harley, R.M. 1996. Vegetação e flora da Chapada Diamantina, Bahia. Anais $4^{\text {a }}$ reunião especial da SBPC, Feira de Santana, Bahia, p. 144-156.

Giulietti, A.M., J.R. Pirani \& R.M. Harley (1997). Espinhaço range region. Eastern Brazil. In: S.D. Davis, V.H. Heywood, O. Herrera-MacBryde, J. Villa-Lobos \& A.C. Hamilton (eds). Centres of plant diversity. A guide and strategies for the conservation, Vol. 3. The Americas. pp. 397-404. WWF/IUCN, Cambridge.

Gotelli, N.J. e R.K. Colwell. (2001). Quantifying biodiversity: procedures and pitfalls in the measurement and comparison of species richness. Ecology Letters 4: 379-391.

Gravel, D., Beaudet, M. \& Messier, C. (2008) Partitioning the factors of spatial variation in regeneration density of shade- tolerant tree species. Ecology, 89, 2879-2888.

Harley, R.M. (1995). Introduction In B.L. Stannard (ed.) Flora of the Pico das Almas, Chapada Diamantina, Brazil. Royal Botanic Gardens. Kew, p.1-42.

Hendry, G.A.F. 1996. Fructan and the ecology and evolution of the Compositae. In: Caligari, P.D.S., Hind, D.J.N. (eds) Compositae: biology \& utilization. Proceedings of the International Compositae Conference, Kew, (1994) (D.J.N. Hind, Editor-in-Chief), vol. 2. Royal Botanic Gardens, Kew, pp. 121-128.

Hill, M.O.; Gauch, H.G. (1980). Detrended correspondence analysis, an improved ordination technique. Vegetation, v. 42, p. 47-58.

Hubbell, S. P. (1984). Methodologies for the study of the origin and maintenance of tree diversity in tropical rain forest. Pp. 8-13 in G. Maury-Lechon, M. Hadley \& T. Younes (editors), The Significance of Species Diversity in Tropical Forest Ecosystems. Biology International (IUBS). Special Issue 6.

Hubbell, S. P. \& R. Foster (1986). Biology, chance and history and the structure of tropical rain forest tree communities. Pp. 314-329 in J. Diamond \& T. Case (editors), Community Ecology. Harper \& Row, New York.

Hubbell, S. P. (2001). The Unified Neutral Theory of Biodiver. The Unified Neutral Theory of Biodiversity and Biogeography.

Hubbell, S. P. (2005). Neutral theory in community ecology and the hypothesis of functional equivalence. Func, 19(17), 166-172. 
Hutchinson, G. E. (1957). Concluding remarks. Cold Spring Harbor Symp. Quant. Biol. 22: 415427. [3, 245, 253, 356, 463, 569, 707]

Jesus, F. F., Abreu, A. G., Semir, J., \& Solferini, V. N. (2009). Low genetic diversity but local genetic differentiation in endemic Minasia (Asteraceae) species from Brazil. Plant Systematics and Evolution, 277(3-4), 187-196.

Jones, E. W. (1956). Ecological studies on the rain forest of southern Nigeria IV (Part 2). The plateau forest of the Okomu Forest Reserve. J. -Ecol. 44:83-117.

Joppa, L. N. et al. (2013). Achieving the convention on biological diversity ${ }^{\text {ee }}$ goals for plant conservation. Science, v. 341, n. 6150, p. 1100-1103.

Keigwin, L. D., Jr. (1978). Pliocene closing of the Isthmus of Panama, based on biostratigraphic evidence from nearby Pacific Ocean and Caribbean Sea cores. Geology 6: 630-634)

Kruskal, J.B. (1964). Multidimensional scaling by optimizing goodness of fit to a nonmetric hypothesis. Psychometrika, v. 29, p. 1-27.

Legendre, P., \& Gallagher, E. (2001). Ecologically meaningful transformations for ordination of species data. Oecologia, 129(2), 271-280.

Legendre, P., \& Legendre, L. (1998). Numerical ecology. Numerical Ecology Second English Edition (Vol. 20).

Loeuille, B. F. P., \& Pirani, D. J. R. (2011). Towards a phylogenetic classification of Lychnophorinae (Asteraceae: Vernonieae). Institute of Biosciences, Ph. D., 432.

Magnusson, W. E., Lima, A. P., Luizão, R., Luizão, F., Costa, F. R. C. C., Castilho, C. V., \& Kinupp, V. F. (2005). RAPELD : A MODIFICATION OF THE GENTRY METHOD FOR BIODIVERSITY SURVEYS IN LONG-TERM ECOLOGICAL RESEARCH SITES. Biota Neotropica, 5(2).

Margules, C.R., Pressey, R.L. \& Williams, P.H. (2002) Rep- resenting biodiversity: data and procedures for identifying priority areas for conservation. Journal of Bioscience, 27, 309326.

Marshall, L. G., S. D. Webb, J. J. Sepkoski e D. M. Raup. 1982. Mammalian evolution and the grat American interchange. Science 215: 1351-1357.

Martinelli, G., \& Moraes, M. (2013). Livro vermelho da flora do Brasil. ... de Conservação Da Flora, Rio de Janeiro, 1100.

Mauro, C. A. de; Dantas, M. \& Rosso, F. A., (1982). Geomorfologia. In projeto RADAMBRASIL, 29 (Fo. Sd.), 23, Brasília, p. 205-296. 
Mendonça, R.C.; Felfili, J.M.; Walter, B.M.J.; Silva Júnior, M.C.; Rezende, A.V.; Filgueira, J.S.; Nogueira, P.E. Flora vascular do Cerrado. In: Sano, S.M. \& Almeida, S.P. (1998). Cerrado: ambiente e flora. Planaltina, EMBRAPA - CPAC, 556p.

McCune, B.; Grace, J.B. (2002). Analysis of ecological communities. MjM, Gleneden Beach.

McKenna, M. C. (1981). Early history and biogeography of South America's extinct land mammals. In R. Ciochon \& A. Chiarelli (editors). Evolutionary Biology of the New World Monkeys and Continental Drift. Plenum Press, New York.

Melo, A.S. (2008). O que ganhamos "confundindo" riqueza de espécies e equabilidade em um índice de diversidade? Biota Neotropica, v. 8, n. 3, p. 21 - 27.

Mello, T. D. R. B. De. (2012). Comunidades Herbáceo-Arbustivas E Suas Relações Com Solo E Altitude, Em Áreas Secas E Úmidas, No Parque Nacional Das Sempre Vivas, Mg, 58.

Messias, M. C. T. B. (2011). Fatores ambientais condicionantes da diversidade florística em campos rupestres quartzíticos e ferruginosos no quadrilátero ferrífero, minas gerais.

Moreira-Muñoz, A. \& Muñoz-Schick, M. (2003) Estado de con- servación de la flora mediterránea de Chile. Revista Chagual (Santiago), 1, 46-52.

Mori, S. A.; Mattos-Silva, L. A.; Lisboa, G. \& Coradin, L. (1985). Manual de Manejo do Herbário Fanerogâmico. 2a ed. CEPLAC, Ilhéus.

Moser, P., Oliveira, W. L., Medeiros, M. B., Pinto, J. R., Eisenlohr, P. V., Lima, I. L., .. Simon, M. F. (2014). Tree Species Distribution along Environmental Gradients in an Area Affected by a Hydroelectric Dam in Southern Amazonia. Biotropica, 46(3), 367-376.

Nakajima, J.N.; Loeuille, B.; Heiden, G.; Dematteis, M.; Hattori, E.K.O.; Magenta, M.; Ritter, M.R.; Mondin, C.A.; Roque, N.; Ferreira, S.C.; Teles, A.M.; Borges, R.A.X.; Monge, M.; Bringel Jr. J.B. A.; Oliveira, C.T.; Soares, P.N.; Almeida, G.; Schneider, A.; Sancho, G.; Saavedra, M.M.; Liro, R.M.; Souza- Buturi, F.O.; Pereira, A.C.M. \& Moraes, M.D. (2010). Asteraceae in Lista de espécies da flora do Brasil. Jardim Botânico do Rio de Janeiro.

Nakajima, J. N., Junqueira, T. V., Freitas, F. S., \& Teles, A. M. (2012). Comparative analysis of red lists of the Brazilian flora: Asteraceae. Rodriguésia, 63(1), 39-54.

Nakajima, J. N., \& Semir, J. (2001). Asteraceae do Parque Nacional da Canastra, Minas Gerais, Brasil. Revista Brasileira de Botânica, 24(4), 471-478.

Oliveira Filho, A. T.; Ratter, J. A. (2002). Vegetation Physiognomies and Woody Flora of the Cerrado Biome. In: OLIVEIRA, P. S.; MARQUIS, R. J. (Eds.). The Cerrados of Brazil: ecology and natural history of a neotropical savanna. New York: Columbia University Press, p. 91-120. 
Pansonato, M. P., Costa, F. R. C., de Castilho, C. V., Carvalho, F. a., \& Zuquim, G. (2013). Spatial scale or amplitude of predictors as determinants of the relative importance of environmental factors to plant community structure. Biotropica, 45(3), 299-307.

Peet, R.K. The measurement of species diversity. Annual Review of Ecology and Systematics, v. 5, p. 285-307, 1974.

Rangel, T.F.; Diniz-Filho, J.A.F.; Bini, L.M. San: A comprehensive application for Spatial Analysis in Macroecology. Ecography, v. 33, p. 1-5, 2010.

Rapini, A., Mello-silva, R., \& Kawasaki, M. L. (2002). Richness and endemism in Asclepiadoideae (Apocynaceae) from the Espinhaço Range of Minas Gerais , Brazil - a conservationist view. Biodiversity and Conservation, 11, 1733-1746.

Rapini, A., Ribeiro, P. L., Lambert, S., \& Pirani, J. R. (2008). A flora dos campos rupestres da Cadeia do Espinhaço. Megadiversidade, 4(12), 15-23.

Ratter, J. A.; Dargie, T. C. D. An analysis of the floristic composition of 26 cerrado areas in Brazil. Edinburgh Journal of Botany, v. 49, n. 02, p. 235-250, 1992.

Ribeiro, K. T., \& Freitas, L. (2010). Impactos potenciais das alterações no Código Florestal sobre a vegetação de campos rupestres e campos de altitude. Biota Neotropica, 10(4), 239-246.

Ribeiro, P. L., Rapini, A., Silva, U. C. S., Konno, T. U. P., Damacena, L. S., \& van den Berg, C. (2012). Spatial analyses of the phylogenetic diversity of Minaria (Apocynaceae): assessing priority areas for conservation in the Espinhaço Range, Brazil. Systematics and Biodiversity, 10(3), 317-331.

Rivera, V.L. (2006). Estudos fitogeográficos em Vernonia Schreb. sensu lato (Asteraceae) no domínio Cerrado. Dissertação de Mestrado. Universidade de Brasília, Brasília. 106p.

Roque, N., \& Bautista, H. (2008). Asteraceae: caracterização e morfologia floral. Edufba, 79p.

Roque, N. \& Pirani, J.R. (1997). Flora da Serra do Cipó, Minas Gerais: Compositae Barnadesieae e Mutisieae. Boletim de Botânica da Universidade de São Paulo. 16: 151-185.

Roque, N. \& Pirani, J.R. 2001. Reinstatement of the name Richterago Kuntze and recircumscription of the genus to include species formerly treated as Actinoseris (Endl.) Cabrera (Compositae, Mutisieae). Taxon 50: 1155-1160.

Sancho, G. \& Freire, S.E. (2009). Gochnatieae (Gochnatioideae) and Hyalideae (Wunderlichioideae p.p.). In: Funk, V.A.; Susanna, A.; Stuessy, T.F. \& Bayer, R.J. (eds.). Systematics, evolution, and biogeography of Compositae. International Association for Plant Taxonomy, Vienna. Pp. 249-260. 
Santos, H. G. D., W. Carvalho, Junior, R. O., Dart, M. L. D., Áglio, J. S. Sousa, J. G., Pares, A., Fontana, A. L. S., Martins, And A. P. Oliveira. (2011). O novo mapa de solos do Brasil legenda atualizada. Emb- rapa Solos, Rio de Janeiro, Brazil.

Semir, J. (1991). Revisão Taxonomica de Lychnophora Mart. (Vernoniaeae: Compositae).

Semir, J. J., \& Jesus, F. F. (2013). A New Species of Minasia (Asteraceae, Vernonieae) from the Planalto de Diamantina, Minas Gerais Brazil. Missouri Botanical Garden, 14(2), 233-235.

Silva, J. D. A. (2008). BIODIVERSIDADE DA CADEIA DO ESPINHAÇO - IDENTIFICAÇÃO DE LACUNAS DE PROTEÇÃO E ESTRATÉGIAS PARA SUA CONSERVAÇÃO. Dissertação de Doutorado.

Teles, A. magalhães, \& Stehmann, J. R. (2011). Flora da Serra do Cipó, Minas Gerais: Asteraceae - Senecioneae. Bol. Bot. Univ. São Paulo, 29(1), 57-68.

Tilman, D. (1994). Competition and biodiversity in spatially structured habitats. Ecology 75: 216.

Tóthmérész, B. (1995). Comparison of different methods for diversity ordering. Journal of Vegetation Science, v. 6, p. 283-290.

Tuomisto, H., K. Ruokolainen, R. Kalliola, A. Linna,W. Dan- joy, and Z. Rodriguez. (1995). Dissecting Amazonian bio- diversity. Science 269:63-66.

Tuomisto, H., Ruokolainen, K., Aguilar, M. \& Sarmiento, A. (2003) Floristic patterns along a 43-km long transect in an Amazonian rain forest. Journal of Ecology, 91, 743-756.

Vilhalva, D. A. A., \& Appezzato-da-glória, B. (2006). Morfo-anatomia do sistema subterrâneo de Calea verticillata ( Klatt ) Pruski e Isostigma megapotamicum ( Spreng .) Sherff Asteraceae. Revista Brasileira de Botânica, 29(1), 39-47.

Vormisto, J.; Tuomisto, H.; Oksanen, J. (2004). Palm distribution patterns in Amazonian rainforests: What is the role of topographic variation? Journal of Vegetation Science 15: 485-494.

Wilson, E. O. (1986). Biodiversity. National Academy Press, Washington.

Zappi, D.C. et al. (2014) Plantas do Setor Noroeste da Serra do Cipó, Minas Gerais: guia ilustrado. Royal Botanic Gardens, Kew.

Zuquim, G., Tuomisto, H., Costa, F. R. C. C., Prado, J., Magnusson, W. E., Pimentel, T., ... Figueiredo, F. O. G. (2012). Broad Scale Distribution of Ferns and Lycophytes along Environmental Gradients in Central and Northern Amazonia, Brazil. Biotropica, 44(6), $752-762$. 